NBER WORKING PAPER SERIES

\title{
OWNERSHIP CONCENTRATION AND STRATEGIC SUPPLY REDUCTION
}

\author{
Ulrich Doraszelski \\ Katja Seim \\ Michael Sinkinson \\ Peichun Wang \\ Working Paper 23034 \\ http://www.nber.org/papers/w23034 \\ NATIONAL BUREAU OF ECONOMIC RESEARCH \\ 1050 Massachusetts Avenue \\ Cambridge, MA 02138 \\ January 2017, Revised May 2019
}

We thank Gabbie Nirenburg, Elizabeth Oppong, and Xuequan Peng for research assistance, Gavin Burris and Hugh MacMullan for technical assistance, and the Penn Wharton Public Policy Initiative and Dean's Research Funds for financial support. We have benefited from conversations with participants at the NBER Market Design meetings and Searle Center Conference on Antitrust Economics, as well as discussions with Eric Budish, Juan Escobar, Rob Gertner, Ali Hortaçsu, Evan Kwerel, Jonathan Levy, Greg Lewis, Rakesh Vohra, Glen Weyl, and others. Finally, we are grateful to a co-editor and three anonymous referees whose comments have greatly helped to improve the paper. The opinions expressed in the paper are accordingly those of the authors and do not represent the positions of the Federal Communications Commission, the U.S. Government, or the National Bureau of Economic Research.

NBER working papers are circulated for discussion and comment purposes. They have not been peer-reviewed or been subject to the review by the NBER Board of Directors that accompanies official NBER publications.

(C) 2017 by Ulrich Doraszelski, Katja Seim, Michael Sinkinson, and Peichun Wang. All rights reserved. Short sections of text, not to exceed two paragraphs, may be quoted without explicit permission provided that full credit, including $(\odot$ notice, is given to the source. 
Ownership Concentration and Strategic Supply Reduction

Ulrich Doraszelski, Katja Seim, Michael Sinkinson, and Peichun Wang

NBER Working Paper No. 23034

January 2017, Revised May 2019

JEL No. L10

\section{ABSTRACT}

We explore the implications of ownership concentration for the recently-concluded incentive auction that re-purposed spectrum from broadcast TV to mobile broadband usage in the U.S. We document significant multi-license ownership of TV stations. We show that in the reverse auction, in which TV stations bid to relinquish their licenses, multi-license owners have an incentive to withhold some TV stations to drive up prices for their remaining TV stations. Using a large-scale valuation exercise, we find that this strategic supply reduction conservatively increases payouts to TV stations by between $7.0 \%$ and $20.7 \%$.

Ulrich Doraszelski

The Wharton School

University of Pennsylvania

3620 Locust Walk

Philadelphia, PA 19104

and NBER

doraszelski@wharton.upenn.edu

Katja Seim

The Wharton School

University of Pennsylvania

1458 Steinberg-Dietrich Hall

3620 Locust Walk

Philadelphia, PA 19104

and NBER

kseim@wharton.upenn.edu
Michael Sinkinson

Yale School of Management

165 Whitney Ave, Suite 3473

New Haven, CT 06511

and NBER

michael.sinkinson@yale.edu

Peichun Wang

Microsoft AI \& Research

Building 112

14865 NE 36th Street

Redmond, WA 98052

will.wang@microsoft.com 


\section{Introduction}

In 2010, the Federal Communications Commission (henceforth FCC) proposed to acquire spectrum from broadcast TV license holders and sell it to wireless carriers to be re-purposed for mobile broadband usage. The ensuing incentive auction is the most novel auction designed since the inception of spectrum auctions in the U.S. in the 1990s. It combines a reverse auction, in which TV stations bid to relinquish their licenses in exchange for payment, with a forward auction, in which wireless carriers bid for spectrum. The incentive auction closed on March 30, 2017 and re-purposed $84 \mathrm{MHz}$ of spectrum, with $\$ 19.6$ billion raised from wireless carriers in the forward auction and $\$ 10.1$ billion paid to TV stations in the reverse auction.

In this paper, we study the role of ownership concentration and strategic supply reduction in the reverse auction. We document that following the announcement of the incentive auction, a number of private equity firms acquired TV stations, often purchasing multiple TV stations in the same local media market. Newspaper articles and industry reports claimed that these purchases were undertaken with the goal of "flipping" the TV stations for profit in the reverse auction. ${ }^{1}$ Politicians also raised concerns about speculation. ${ }^{2}$ We further document that despite the attention the private equity firms received, they account for just a small fraction of the joint ownership of TV stations.

We argue that besides any possible speculative motives, ownership concentration gives rise to strategic bidding in the reverse auction. We show that owners of multiple TV stations have an incentive to withhold some of their TV stations from the reverse auction, thereby driving up the prices for the remaining TV stations they own. This strategy of reducing supply affects a large transfer of wealth from the government - and ultimately taxpayers - to TV stations. In addition, strategic supply reduction can potentially cause efficiency losses if it distorts the set of TV stations that relinquish their licenses in the reverse auction, and it can reduce the amount of spectrum that is re-purposed in the incentive auction.

Re-purposing spectrum from broadcast TV to mobile broadband usage is no doubt an extremely valuable and complex undertaking and the incentive auction was very carefully designed. The reverse auction takes the form of a deferred-acceptance clock auction. The theoretical development and analysis of the properties of this type of auction in Milgrom and Segal (2018) is underpinned by a so-called "single-mindedness" assumption. If, counterfactually, all TV stations were independently owned, then it would be a dominant strategy for each TV station to truthfully bid its value as a broadcast business in the reverse auction; we refer to this as naive bidding. ${ }^{3}$ The single-mindedness

\footnotetext{
${ }^{1}$ See "NRJ Wins Bidding For WSAH New York", TVNewsCheck, November 29, 2011; "Small TV Stations Get Hot", The Wall Street Journal, September 3, 2012; "Speculators Betting Big on FCC TV Spectrum Auction", Current.org, February 26, 2013; "TV Spectrum Speculation Nears \$345 Million", TVNewsCheck, March 1, 2013; "Broadcast Incentive Spectrum Auctions: Gauging Supply and Demand", SNL Kagan Broadcast Investor, November 20, 2013; and "TV Station Spectrum Deals Expand Into Major Network Affiliates as Players Stake Out Positions Pre-Auction", SNL Kagan Broadcast Investor, December 4, 2013.

${ }^{2}$ See "Rep. LoBiondo Seeks FCC Info On Possible Spectrum Speculation", Broadcasting \& Cable, February 12, 2014.

${ }^{3}$ Under the single-mindedness assumption, deferred-acceptance clock auctions have many other desirable properties. Milgrom and Segal (2018) show that they are not only strategy proof but also weakly group-strategy proof, meaning that no coalition of bidders has a joint deviation from truthful bidding that is strictly profitable for all
} 
assumption thus rules out owners internalizing the benefits of multi-license ownership.

Our paper points to unintended consequences of the multi-license ownership that is prevalent in the data. In particular, the rules of the reverse auction leave room for strategic supply reduction by multi-license owners. This behavior is purely rent-seeking, as these owners attempt to increase their share of existing wealth without creating any new wealth. Consistent with a supply reduction strategy, we document that the private equity firms sold $40 \%$ of the acquired TV stations in the reverse auction, off-loading another $42 \%$ of the acquired TV stations soon after. While the private equity firms made - typically substantial - profits on the TV stations they relinquished in the reverse auction, they incurred losses on the TV stations they sold soon after.

In a first step, we provide a model and a series of examples to illustrate how strategic supply reduction works in the context of the reverse auction and under what circumstances it is a profitable strategy for multi-license owners. Our model implies that certain types of TV stations are more suitable for a supply reduction strategy. We document that the private equity firms acquired TV stations that are broadly consistent with this implication.

In a second step, we quantify the payout increases caused by strategic supply reduction. To do so, we undertake a large-scale valuation exercise to estimate reservation values for all auction-eligible TV stations. We combine various data sources to estimate a TV station's cash flow and use it to infer the station's value as a going concern. With estimates in hand, we compare the outcome of the reverse auction under strategic bidding when we account for the ownership pattern in the data and allow multi-license owners to engage in strategic supply reduction with the outcome under naive bidding. We enumerate all equilibria of a simplified version of the reverse auction that limits the geographic scope of strategic bidding and accounts for the repacking process at the regional-but not at the full national-level.

We show that strategic supply reduction has a large impact on prices and payouts to TV stations. For a clearing target of re-purposing $126 \mathrm{MHz}$ of spectrum, the starting point of the incentive auction when it commenced on March 29, 2016, strategic bidding by multi-license owners increases nationwide payouts by $20.7 \%$. For the $84 \mathrm{MHz}$ clearing target that the incentive auction ultimately reached, strategic bidding increases nationwide payouts by $7.0 \%$. These increases partly go to single-license owners, who as a group witness payout increases that are almost as large as those seen by multi-license owners.

We do not find a sizable distortion in the set of TV stations that relinquish their licenses in the reverse auction. Hence, strategic supply reduction has limited efficiency implications in our setting. A particularly striking result of our simulation exercise is that the outcome of the reverse auction is sensitive to small changes in bidding behavior: withholding even a few TV stations suffices to give rise to equilibria that have significantly higher payouts than those under naive bidding. Reaching these equilibria may thus not require widespread coordination of expectations between multi-license owners.

members of the coalition. In addition, deferred-acceptance clock auctions are nearly optimal and, assuming complete information, equivalent to pay-as-bid auctions. Dütting, Gkatzelis and Roughgarden (2017) provide both positive and negative results on the fraction of total surplus that can be guaranteed by deferred-acceptance auctions. 
Our paper may be viewed as measuring the importance of the single-mindedness assumption in Milgrom and Segal (2018) in a setting that is of immediate public policy concern. More broadly, however, we provide a framework for evaluating the design of the reverse auction. Our paper differs from most of the empirical literature on auctions and market design by taking an ex ante perspective, similar to recent papers on online dating (Hitsch, Hortacsu and Ariely, 2010) and course allocation (Budish and Cantillon, 2012). The literature typically takes an ex post perspective and uses realized outcomes combined with assumed equilibrium behavior to recover primitives such as preferences. In contrast, we estimate reservation values from secondary, commercially available data and take them as an input into simulating the reverse auction. One reason for relying on secondary data is quite pragmatically that the FCC has not released - and is not planning to release - data on participation and bids in the reverse auction. ${ }^{4}$ Another reason for adopting an ex ante perspective is our hope that exercises similar to ours will prove useful in designing future auctions in the U.S. and other countries as they strive to alleviate the "spectrum crunch" resulting from the rapid growth in data usage by smartphones users in recent years.

We illustrate the potential usefulness of our framework in two ways. First, we propose a simple change in the auction rules and investigate how placing a restriction on the bids of multi-license owners affects their ability to exploit the joint ownership of TV stations. We show that this rule change mitigates the payout increase from strategic bidding by between $62 \%$ and $80 \%$, depending on the clearing target.

Second, we investigate the consequences of a particular auction design choice that the FCC made. A key aspect to the incentive auction is a repacking process that sits between the reverse and the forward auctions. With it, the FCC reassigns all TV stations that opt to remain on the air post auction to new channels in order to clear a contiguous, nationwide block of spectrum for mobile broadband usage. In the repacking process, TV stations are not homogeneous for geographic and technological reasons related to signal interference between nearby stations. The FCC's choice of allowable levels of interference between stations determines how easily TV stations can be substituted for one another. Our simulation exercise traces out the relationship between substitutability in the repacking process and payouts in the reverse auction. By exploring how substitutability affects the scope for strategic bidding, our paper adds a new dimension to previous studies of strategic supply reduction in multi-unit auctions with homogeneous products in wholesale electricity markets (e.g., Wolfram, 1998, Borenstein, Bushnell and Wolak, 2002, Hortacsu and Puller, 2008).

We highlight unintended consequences of ownership concentration for the reverse auction and thereby also contribute to the literature on distortions induced by incentive schemes and regulation in various settings such as employee compensation (Oyer, 1998), environmental regulation (Fowlie, 2009; Bushnell and Wolfram, 2012), health care (Duggan and Scott Morton, 2006), and tax

\footnotetext{
${ }^{4}$ Even if more detailed data were available, the identification challenges discussed in Cantillon and Pesendorfer (2007) may make it difficult to extend the standard first-order conditions approach to our setting. The momentinequalities approach in Fox and Bajari (2013) identifies relative valuations but not the levels that we require to quantify the effects of ownership concentration.
} 
avoidance (Goolsbee, 2000). Our paper builds on the theoretical literature on strategic bidding in multi-unit auctions (Wilson, 1979; Back and Zender, 1993, 2001; Engelbrecht-Wiggans and Kahn, 1998; Ausubel et al., 2014) that we come back to in Section 3 after illustrating how strategic supply reduction works in the reverse auction. It complements the experimental evidence for strategic demand reduction (List and Lucking-Reiley, 2000; Kagel and Levin, 2001; Engelmann and Grimm, 2009; Goeree, Offerman and Sloof, 2013) and case studies of past spectrum auctions (Weber, 1997; Cramton and Schwartz, 2002; Grimm, Riedel and Wolfstetter, 2003).

The remainder of this paper is organized as follows: Section 2 provides background on the FCC incentive auction. Section 3 provides a model of the reverse auction and strategic supply reduction. Sections 4 and 5 present data and descriptive evidence in support of ownership concentration and strategic supply reduction. Sections 6 and 7 describe the main analysis of the reverse auction and results. Section 8 presents extensions and argues that the assumptions underlying our analysis tend to be conservative. Section 9 concludes.

\section{The FCC incentive auction}

The rapid growth in data and video usage by smartphone users has significantly increased the demand for mobile broadband spectrum. ${ }^{5}$ At the same time, some previously allocated spectrum is no longer used intensively. Each of approximately 7,900 currently operating TV stations in the U.S. holds a license to a $6 \mathrm{MHz}$ block of spectrum in a particular geographical area dedicated to over-the-air transmission of programming. ${ }^{6}$ Yet, as of 2010 only about $10 \%$ of TV households use broadcast TV, with a rapidly declining trend. ${ }^{7}$

In its 2010 National Broadband Plan, the FCC under then-chairman Julius Genachowski proposed, and received authorization by Congress in 2012, to conduct an incentive auction to reallocate spectrum from TV stations to wireless carriers. The incentive auction consists of a reverse auction, in which TV stations bid to relinquish their licenses in exchange for payment, and a forward auction, in which wireless carriers bid for the cleared spectrum. The reverse and forward auctions progress in a series of stages that are linked through a clearing target until a final stage rule terminates the incentive auction. The format of the incentive auction was publicly announced in June $2014 .^{8}$

The FCC has used auctions to award licenses for the commercial use of spectrum since 1993, to exploit a market-based mechanism that relies on voluntary participation and is relatively robust

\footnotetext{
${ }^{5}$ According to FCC then-chairman Tom Wheeler, "America has gone mobile. Most Americans would have a hard time imagining life without their smartphones, and tens of millions are similarly in love with their tablets. The problem is that spectrum, the lifeblood of all wireless technologies, is finite. That wasn't a problem before the mobile web, when most consumers were mostly watching videos or surfing the web at home. If we don't free up more airwaves for mobile broadband, demand for spectrum will eventually exceed the supply. If you've ever been frustrated by websites that loaded slowly or videos that wouldn't download to your phone, you have a sense what that world could look like." See https://www.fcc.gov/news-events/blog/2014/02/11/channel-sharing-new-opportunity-broadcasters, accessed on November 15, 2015.

${ }^{6}$ As of March 31, 2016. See https://apps.fcc.gov/edocs_public/attachmatch/D0C-338754A1.pdf, accessed on March 28, 2018.

7 "Connecting America: The National Broadband Plan", FCC, 2010, Chapter 5, p. 89.

${ }^{8}$ See https://apps.fcc.gov/edocs_public/attachmatch/FCC-14-50A1.pdf, accessed on November 15, 2015.
} 
to legal challenges. ${ }^{9,10}$ In contrast to bilateral negotiations or take-it-or-leave-it offers, auctions are less time consuming and do not require the FCC to estimate participants' valuations of spectrum. The incentive auction was the first time the FCC combined an auction to sell spectrum with an auction to buy spectrum from existing licensees.

Forward auction. The forward auction uses an ascending-clock format similar to previous spectrum auctions. The FCC accepted 62 qualified bidders into the forward auction. These wireless carriers bid for one or more licenses to contiguous blocks of spectrum in geographic areas called Partial Economic Areas (PEAs). There are 416 PEAs in the U.S. ${ }^{11}$

Reverse auction. The reverse auction uses a descending-clock format that we describe in detail in Section 3. The FCC declared 2,197 TV stations as eligible for the reverse auction, but revoked the licenses to three stations prior to the auction, reducing the number of eligible stations to $2,194 .^{12}$ These TV stations are classified by type of service into UHF stations that broadcast between channel 14 and 36 or between channel 38 and 51 and VHF stations that broadcast between channel 2 and 13. They can be further classified by type of use into commercial and non-commercial stations and by power output into full-power stations (primary and satellite stations) and low-power class-A stations. ${ }^{13}$ Appendix A.1 summarizes the types of TV stations.

A TV station has several options to relinquish its license: going off the air, moving channels from a higher frequency band (UHF channels 14-36 and 38-51 or high VHF channels 7-13) to a lower frequency band (VHF channels 2-13 for UHF or low VHF channels 2-6 for high VHF) that is less desirable for wireless carriers, or sharing a channel with another TV station. ${ }^{14}$ The auction rules stipulate that the payout to a VHF station for going off the air and the payouts to a UHF or a VHF station for moving bands are fixed fractions of the payout to a UHF station for going off

\footnotetext{
${ }^{9}$ FCC then-chairman Tom Wheeler puts this as follows: "Let's start with the concept of an incentive auction. While it has never been tried before, its power lies in how it addresses the root of all issues: economics. If it is possible to marry the economics of demand with the economics of current spectrum holders, it should be possible to allow market forces to determine the highest and best use of spectrum. In mid-2015 we will run the first ever incentive auction. Television broadcasters will have the opportunity to bid in a reverse auction to relinquish some or all of their spectrum rights, and wireless providers will bid in a forward auction on nationwide, 'repacked' spectrum suitable for two-way wireless broadband services." See https://apps.fcc.gov/edocs_public/attachmatch/D0C-326215A1.pdf, accessed on November 15, 2015.

${ }^{10}$ Theoretically, the FCC could institute a mandatory hand-over of licenses, but TV stations would have a strong due process claim under the 5th Amendment's takings clause.

${ }^{11}$ See https://apps.fcc.gov/edocs_public/attachmatch/DA-14-759A3.pdf and https://apps.fcc.gov/ edocs_public/attachmatch/DA-14-759A4.pdf, accessed on August 3, 2017.

${ }^{12}$ See http://wireless.fcc.gov/auctions/incentive-auctions/Reverse_Auction_Opening_Prices_111215. xlsx, accessed on March 7, 2018. Prior to the reverse auction, the FCC revoked the licenses of UHF stations KLHU-CD (facility ID 30932) and DWKOG-LP (facility ID 34894) and VHF station WDHS (facility ID 15498). The FCC excludes approximately 5,500 low-power non-class-A and translator stations from the reverse auction.

${ }^{13} \mathrm{~A}$ satellite station is a relay that repeats the broadcast TV signal of its parent primary station.

${ }^{14}$ The FCC has piloted a channel-sharing arrangement in Los Angeles, CA, to show that it is technologically feasible for one high-definition video stream and one or more standard-definition video streams to share $6 \mathrm{MHz}$ of spectrum. However, $6 \mathrm{MHz}$ of spectrum may no longer suffice if a TV station eventually transitions from a highdefinition to a ultra-high-definition $(4 \mathrm{~K})$ video stream. Hence, it is unclear how attractive this relinquishment option is.
} 
the air; hence, the auction rules recognize the latter as the primary relinquishment option.

Its license entitles a TV station to broadcast a TV signal on a particular frequency from a particular location with a particular power output; the station cannot, on its own, choose to repurpose its license for a new use such as wireless service. The FCC assigns each TV station to a local media market called a designated market area (DMA). A DMA is defined by Nielsen Media Research based on the reach and viewing patterns of TV stations as a group of counties such that the home market TV stations hold a dominance of total hours viewed. There are 210 DMAs in the U.S. that vary in size from New York, NY, with over 7 million TV households, to Glendive, MT, with 4,230 TV households. Appendix A.2 lists the top ten DMAs based on their 2015 rank. The 210 DMAs do not map neatly into the 416 PEAs that are the relevant market area in the forward auction. For example, the New York, NY, DMA consists of 32 counties in 6 states (CT, NJ, NY, MA, PA, and RI) whereas the New York, NY, PEA consists of 42 counties in 4 states (CT, NJ, NY, and PA).

Because of this divergence in market areas and because the TV stations that opt to remain on the air may currently be located on any UHF or VHF channel, the FCC undertakes a repacking process in which it consolidates the remaining TV stations into the lower end of the UHF band and into the VHF band. This creates a contiguous block of spectrum for mobile broadband usage in the higher end of the UHF band in a process that is visually similar to defragmenting a hard drive on a personal computer. However, it is far more complex because many pairs of TV stations, even if located in different DMAs, cannot be assigned to the same or immediately adjacent channels without causing unacceptable levels of interference. Several factors influence interference, including geography and the height and power output of the broadcast tower. These interference constraints have two consequences. First, the repacking process ties together all DMAs and effectively takes place at the national level. Second, accommodating $K$ remaining TV stations in a DMA typically requires far more than $6 \mathrm{~K} \mathrm{MHz}$ of spectrum. Throughout the remainder of the paper, we discuss how the auction design accommodates the interference constraints and highlight the role they play in the outcome of the reverse auction.

Clearing target and final stage rule. The auction rules integrate the reverse and forward auctions in a series of stages. The FCC sets an initial target for the amount of spectrum to clear and make available to wireless carriers. It then first runs the reverse auction to determine the payouts required to induce a set of TV stations to relinquish their licenses so that the clearing target can be met after repacking any TV stations that opt to remain on the air. Given the interference constraints on the repacking process, there are many different sets of TV stations that can relinquish their licenses to meet a particular clearing target; as a consequence, the FCC's "demand" for any particular TV station remains elastic.

The FCC next runs the forward auction to determine the willingness-to-pay of wireless carriers for the cleared spectrum. If the payouts demanded by TV stations in the reverse auction exceed the willingness-to-pay in the forward auction, then the FCC reduces the clearing target, requiring 
fewer TV stations to relinquish their licenses in the next stage of the incentive auction. The FCC repeats this process until proceeds in the forward auction more than cover payouts in the reverse auction and a final stage rule is met. ${ }^{15}$

Timeline and outcome. Technological and legal challenges resulted in several delays to the incentive auction from original projections for early 2014 to the ultimate starting date of March 29, 2016. ${ }^{16}$ The first public version of this research paper appeared in April of 2016, before any results of the actual auction were available.

The FCC set the initial clearing target to $126 \mathrm{MHz}$ in stage 1 of the auction. TV stations demanded payouts of $\$ 86.4$ billion in the reverse auction for relinquishing the licenses required to meet this clearing target, whereas wireless carriers offered only $\$ 23.1$ billion for the cleared spectrum in the forward auction.

In stage 2, the FCC reduced the clearing target to $114 \mathrm{MHz}$, with bidding commencing on September 13, 2016. TV stations demanded $\$ 54.6$ billion whereas wireless carriers offered $\$ 21.5$ billion. In stage 3, the FCC reduced the clearing target to $108 \mathrm{MHz}$, with bidding commencing on November 1, 2016. TV stations demanded $\$ 40.3$ billion whereas wireless carriers offered $\$ 19.7$ billion.

In stage 4, the FCC reduced the clearing target to $84 \mathrm{MHz}$. Bidding in the reverse auction commenced on December 13, 2016 and bidding in the forward auction closed on March 30, 2017. The forward auction raised $\$ 19.6$ billion in proceeds, covering payouts of $\$ 10.1$ billion in the reverse auction and leaving proceeds of more than $\$ 7$ billion for the U.S. Treasury. The fact that the FCC had to reduce the clearing target from $126 \mathrm{MHz}$ to $84 \mathrm{MHz}$ to trigger the final stage rule is widely attributed to unexpectedly weak demand for spectrum by wireless carriers in the forward auction. ${ }^{17}$ At the time of this writing, the FCC has begun reassigning channels to the TV stations that opted to remain on the air; this process is expected to extend into the middle of 2020.

In the forward auction, 50 out of 62 qualified bidders acquired a total of 2,776 licenses to mobile broadband spectrum. In the reverse auction, 175 out of 2,194 TV stations relinquished their licenses in some form: 141 UHF stations and 4 VHF stations went off the air and a further 29 UHF stations and 1 VHF station moved bands. ${ }^{18}$ The FCC has released the identity of and payouts to these TV stations. ${ }^{19}$ To protect the confidentiality of individual broadcasters, the FCC has not released data

\footnotetext{
${ }^{15}$ Specifically, the final stage rule requires that proceeds in the forward auction are at least $\$ 1.25$ per $\mathrm{MHz}$ per population (henceforth, MHz-pop) for the largest 40 PEAs and not only cover payouts in the reverse auction, but also the reimbursements of channel relocation expenses incurred by TV stations in the repacking process, the FCC's administrative expenses for the incentive auction, and the funding of the First Responder Network Authority's public safety operations.

${ }^{16}$ See https://www.fcc.gov/news-events/blog/2013/12/06/path-successful-incentive-auction-0, accessed on November 15, 2015, and "F.C.C. Delays Auction of TV Airways for Mobile", Edward Wyatt, The New York Times, October 24, 2014. See also http://www.shure.com/americas/incentive-auction-resource-center, accessed on March 7, 2018.

${ }^{17}$ See "FCC Airwaves Auction Cools for Broadcasters", Thomas Gryta and Joe Flint, The Wall Street Journal, January 19, 2017.

${ }^{18}$ See https://auctiondata.fcc.gov/public/projects/1000, accessed on March 7, 2018.

${ }^{19}$ See https://auctiondata.fcc.gov/public/projects/1000/reports/reverse-winning_bids, accessed on
} 
on participation or bids in the reverse auction and has not made any public plans to do so in the future. $^{20}$ We further report on the available data in Sections 5 and 7.

\section{A model of the reverse auction}

We illustrate the potential for strategic supply reduction in a model of the reverse auction. The reverse auction is a deferred-acceptance clock auction. Our formalization of it draws on Appendix D of FCC Public Notice 14-191 and Milgrom and Segal (2018). ${ }^{21,22}$ We leverage that the auction design limits interactions between the reverse and forward auctions and take the clearing target as given in our analysis. We follow Milgrom and Segal (2018) and focus on going off the air as the primary relinquishment option; as shown in Kazumori (2016), modeling channel sharing or band switching is a nontrivial undertaking.

There are $N$ stations that participate in the reverse auction. Let $v_{j}>0$ denote the reservation value of TV station $j$ that captures its value as a going concern. The reverse auction progresses in rounds. Let $P_{\tau} \geq 0$ denote the base clock price in round $\tau$. The base clock price decreases over the course of the reverse auction and maps into a "personalized" price $\varphi_{j} P_{\tau}$ for TV station $j$ through its broadcast volume, defined as

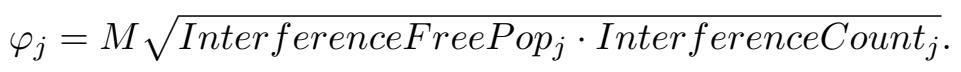

The FCC uses the broadcast volume to incentivize those TV stations to relinquish their licenses that are particularly valuable as broadcast businesses or particularly difficult to assign channels if they opt to remain on the air. The former is proxied for by the interference free population

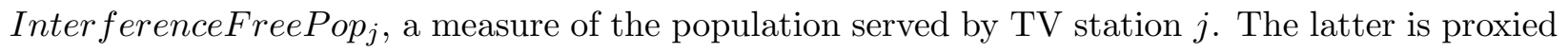
for by the interference count InterferenceCount ${ }_{j}$ that is derived from the number of interference constraints involving TV station $j$ that the repacking process has to respect. ${ }^{23}$ Finally, the FCC sets the scale factor $M=17.253$ so that $\max _{j \in\{1, \ldots, N\}} \varphi_{j}=1,000,000$.

Given its personalized price $\varphi_{j} P_{\tau}$ in round $\tau$, TV station $j$ may withdraw from the reverse auction and require a channel assignment to remain on the air. The FCC, by law, has to be able to assign a channel to any TV station that withdraws from the reverse auction at any point. The auction design integrates a piece of software, the feasibility checker $S A T F C$ (Frechette, Newman and Leyton-Brown, 2016), to ensure this is always the case. The feasibility checker $S A T F C$ defines an indicator function $S(X, R)$ that equals one if a set of TV stations $X \subseteq\{1, \ldots, N\}$ can be repacked into a set of available channels $R$ and zero otherwise. ${ }^{24}$ To simplify the notation, we

\footnotetext{
March 7, 2018.

${ }^{20}$ See https://docs.fcc.gov/public/attachments/FCC-15-78A1.pdf, accessed on March 7, 2018.

${ }^{21}$ See https://apps.fcc.gov/edocs_public/attachmatch/FCC-14-191A1.pdf, accessed on March 10, 2016.

${ }^{22}$ See Bikhchandani et al. (2011) for earlier work on deferred-acceptance auctions. Bikhchandani et al. (2011), in turn, build on the idea in Ausubel $(2004 ; 2006)$ of making partial, irrevocable allocations as the auction progresses.

${ }^{23}$ See Section 2.2 of Appendix D of FCC Public Notice 14-191 and footnote 2 of http://wireless.fcc.gov/ auctions/incentive-auctions/Reverse_Auction_Opening_Prices_111215.xlsx, accessed on March 7, 2018.

${ }^{24}$ The feasibility checker $S A T F C$ returns $S A T$ to indicate that the set of TV stations $X$ can be repacked into
} 
suppress that $S(X, R)$ depends on a set of interference constraints that codifies the pairs of TV stations that cannot be located on the same or immediately adjacent channels. We further suppress that $R$ depends on the given clearing target; intuitively, $R$ is smaller for a larger clearing target.

The reverse auction defines an extensive-form game. In round $\tau \geq 1$, the set of TV stations $\{1, \ldots, N\}$ is partitioned into a set of "active" TV stations $A_{\tau}$, a set of "inactive" TV stations $I_{\tau}$, and a set of "frozen" (or "conditionally winning") TV stations $F_{\tau}$. In round 1, the base clock price is initialized as $P_{1}=900$ and all TV stations as active, i.e., $A_{1}=\{1, \ldots, N\}, I_{1}=\emptyset$, and $F_{1}=\emptyset$.

In round $\tau \geq 1$, given its personalized price $\varphi_{j} P_{\tau}$, active TV station $j \in A_{\tau}$ may withdraw from the reverse auction and collect the payout $P O_{j}=0$. Let $Y_{\tau}$ be the set of active TV stations that withdraw from the reverse auction in round $\tau$. In round $\tau+1$, the set of inactive TV stations is thus $I_{\tau+1}=I_{\tau} \cup Y_{\tau}$; these are all TV stations that have previously withdrawn and require channel assignments. For ease of exposition, we assume that at most one active TV station withdraws in round $\tau>1$ but allow any number of stations to withdraw in round $1 .{ }^{25,26}$ The FCC then checks if it can guarantee a channel for each remaining active TV station $j^{\prime} \in A_{\tau} \backslash Y_{\tau}$ in round $\tau+1$. If, as a consequence of TV station $j$ withdrawing, the FCC cannot guarantee a channel for TV station $j^{\prime}$, then that TV station is frozen and collects the payout $P O_{j^{\prime}}=\varphi_{j^{\prime}} P_{\tau}$ in return for relinquishing its license. Let $Z_{\tau}=\left\{j^{\prime} \in A_{\tau} \backslash Y_{\tau} \mid S\left(I_{\tau+1} \cup\left\{j^{\prime}\right\}, R\right)=0\right\}$ be the set of active TV stations that are newly frozen in round $\tau$ because they cannot be repacked in addition to the TV stations that have previously withdrawn.

The next round $\tau+1$ sets a lower base clock price $P_{\tau+1}$ and updates the set of frozen stations to $F_{\tau+1}=F_{\tau} \cup Z_{\tau}$ and the set of active stations to $A_{\tau+1}=A_{\tau} \backslash\left(Y_{\tau} \cup Z_{\tau}\right)$. The reverse auction continues in this way as long as an active TV station remains and the base clock price is above its lower bound of zero. If $A_{\tau+1}=\emptyset$ or $P_{\tau+1}=0$, then the reverse auction concludes after round $\tau .{ }^{27}$

To complete the description of the extensive-form game, we specify the information sets of the TV stations. The FCC computes and publishes the broadcast volume of all TV stations before the start of the reverse auction. During the course of the reverse auction, the FCC releases minimal information to and forbids communication between TV stations. ${ }^{28}$ Because a TV station observes solely its personalized price but not the decisions of other TV stations, we assume that a strategy

the set of available channels $R, U N S A T$ to indicates that it cannot, and TIMEOUT to indicate that it has not succeeded in ascertaining feasibility in a pre-allotted amount of time. The FCC interprets TIMEOUT as UNSAT.

${ }^{25}$ In practice, the FCC uses a random tie-breaking rule that entails our assumption that at most one active TV station withdraws in round $\tau>1$ (FCC Public Notice 15-78, p. 63).

${ }^{26}$ If in round 1 the TV stations that withdraw from the reverse auction cannot be repacked, then the reverse auction fails at the outset and the payouts to all TV stations are zero.

${ }^{27} \mathrm{At}$ the conclusion of the reverse auction, we assume that any remaining active TV station $j \in A_{\tau+1}$ is frozen at the base clock price $P_{\tau+1}=0$.

${ }^{28}$ To be precise, in round $\tau$ of the reverse auction the FCC shows TV station $j$ its personalized price $\varphi_{j} P_{\tau}$ and which of the three intervals $[0.5,3),[3,6]$, or $(6,|R|]$ its vacancy index belongs to. The vacancy index of TV station $j$ in round $\tau$ is defined as

$$
V I_{j \tau}=\frac{\sum_{k \in G_{j \tau}} \varphi_{k} \max \left\{0.5, H_{k \tau}\right\} /|R|}{\sum_{k \in G_{j \tau}} \varphi_{k}}
$$

where $H_{k \tau}$ is the total number of feasible channels for TV station $k$ in round $\tau$ and $G_{j \tau}$ is the set of TV stations that have not been repacked in round $\tau$ but interfere with TV station $j$. 
for a TV station simply specifies a critical value for the base clock price above which the TV station continues in the reverse auction and at or below which the TV station opts to remain on the air. ${ }^{29}$ In the subsequent analysis we refer to this critical value as the "bid" $b_{j} \geq 0$ of TV station $j$.

Depending on whether a TV station knows the reservation values of other TV stations or not, the game is one of complete or incomplete information. We distinguish these cases in our subsequent analysis as needed, but do not assume that the FCC knows the reservation values of the TV stations in either case.

\subsection{Strategic supply reduction, overbidding, and underbidding}

In analyzing deferred-acceptance clock auctions, Milgrom and Segal (2018) assume that bidders are "single-minded." This, in particular, requires that a bidder has a single object for sale. Under this single-mindedness assumption, it is easy to see that truthful bidding is a dominant strategy in the sense of Li (2017) or "always optimal" in the sense of Milgrom (2004, p. 50), irrespective of whether the game is one of complete or incomplete information. In the context of the reverse auction, this means that an independently owned TV station withdraws from the reverse auction once its personalized price $\varphi_{j} P_{\tau}$ falls to its value as a going concern $v_{j}$, or $\varphi_{j} P_{\tau}=v_{j}$. We henceforth

refer to this strategy of bidding $b_{j}=\frac{v_{j}}{\varphi_{j}}$ as naive bidding and to $s_{j}=\frac{v_{j}}{\varphi_{j}}$ as the "score" of TV station $j$.

We use a series of examples to illustrate two points. First, we show that a firm owning multiple TV stations may have an incentive to deviate from naive bidding. Second, we illustrate the potential for multiple equilibria, not just in settings where bidders are single-minded, but also in settings with jointly owned TV stations. We begin with a first example that results in strategic supply reduction and overbidding $b_{j}>s_{j}$, before turning to a second example that illustrates underbidding $b_{j}<s_{j}$. For simplicity, we proceed in a game of complete information.

Table 1: Example 1: Strategic supply reduction and overbidding

\begin{tabular}{ccccc}
\hline $\begin{array}{c}\text { Station ID } \\
(j)\end{array}$ & Firm ID & $\begin{array}{c}\text { Reservation } \\
\text { value }\left(v_{j}\right)\end{array}$ & $\begin{array}{c}\text { Broadcast } \\
\text { volume }\left(\varphi_{j}\right)\end{array}$ & $\begin{array}{c}\text { Score } \\
\left(s_{j}=\frac{v_{j}}{\varphi_{j}}\right)\end{array}$ \\
\hline 2 & 2 & 500 & 1 & 500 \\
3 & 1 & 300 & 1 & 300 \\
1 & 1 & 100 & 1 & 100 \\
\hline
\end{tabular}

Example 1: Strategic supply reduction and overbidding. There are $N=3$ TV stations with the reservation values and broadcast volumes given in Table 1. TV stations 1 and 3 are owned by firm 1 and TV station 2 is owned by firm 2 . The set of available channels $R$ and the interference constraints are such that the FCC can repack just one of the three TV stations, i.e.,

\footnotetext{
${ }^{29}$ In doing so, we follow a long tradition in the auction literature of omitting the possibility that the participants learn something during the course of an auction that may cause them to revise their critical values (Milgrom, 2004, p. 187).
} 


$$
S(X, R)=\left\{\begin{array}{ccc}
1 & \text { if } & X=\emptyset,\{1\},\{2\},\{3\} \\
0 & \text { if } & X=\{1,2\},\{1,3\},\{2,3\},\{1,2,3\} .
\end{array}\right.
$$

Under naive bidding, $b_{j}=s_{j}$ for all $j \in\{1,2,3\}$ and TV station 2 is first to withdraw from the reverse auction at a base clock price of $P_{\tau}=500$. As a consequence of TV station 2 requiring a channel assignment to remain on the air, TV stations 1 and 3 can no longer be repacked and are frozen, collecting payouts $P O_{1}=P O_{3}=500$. The reverse auction concludes and firm 1's profit from the reverse auction is $500-100+500-300=600$. Firm 2's profit is 0 as TV station 2 remains a going concern.

However, naive bidding is not an equilibrium as firm 1 has an incentive to deviate. In particular, if instead $b_{1}=s_{1}$ and $b_{3}=900$, then firm 1 effectively withholds TV station 3 from the reverse auction at the initial base clock price of $P_{1}=900$. As a consequence, TV stations 1 and 2 can no longer be repacked and are frozen, collecting payouts $P O_{1}=P O_{2}=900$. The reverse auction concludes and firm 1's profit from the reverse auction is $900-100=800$. By strategically reducing supply, firm 1's profit increases from 600 to 800 . Firm 2's profit also increases from 0 to $900-500=400$. Indeed, it is easy to see that $b_{1}=s_{1}, b_{2}=s_{2}$, and $b_{3}=900$ is an equilibrium. Note that in this equilibrium two TV stations relinquish their licenses, just as under naive bidding. Yet, strategic supply reduction increases payouts to TV stations from 1,000 to 1,800. Further note that truthful bidding remains a dominant strategy for firm 2 even though firm 1 engages in strategic supply reduction by withholding one of its TV stations from the reverse auction. ${ }^{30}$

The literature has widely recognized the potential for strategic supply reduction in buying instead of selling auctions involving multiple objects, starting with Wilson (1979). Back and Zender (1993; 2001) and Engelbrecht-Wiggans and Kahn (1998) subsequently establish strategic demand reduction in static auctions. In dynamic auctions, strategic demand reduction is shown in Menezes (1996), Brusco and Lopomo (2002), Engelbrecht-Wiggans and Kahn (2005), and Riedel and Wolfstetter (2006). This literature culminates in Ausubel et al. (2014), who under fairly general conditions show strategic demand reduction in static auctions, and whose arguments largely extend to dynamic auctions. Our setting differs from this earlier literature that focused on homogeneous products in that the interference constraints on the repacking process effectively render TV stations differentiated products. We revisit this point in Section 7.4.

A generalization of this example illustrates when strategic supply reduction is profitable for a firm owning multiple TV stations. Consider arbitrary reservation values and broadcast volumes such that $\max \left\{s_{1}, s_{3}\right\}<s_{2}<900$, where $s_{j}=\frac{v_{j}}{\varphi_{j}}$ is the score of TV station $j$. Note that TV

\footnotetext{
${ }^{30}$ To show that the profit $\pi_{j}\left(b_{j}, b_{-j}\right)$ of an independently owned TV station $j$ under the truthful bid $b_{j}=s_{j}$ is at least as large as that under any alternative bid $\tilde{b}_{j} \neq s_{j}$ irrespective of the vector $b_{-j}$ of bids of the other TV stations, we proceed case by case. Suppose first that bids $\left(s_{j}, b_{-j}\right)$ leave TV station $j$ on the air so that $\pi_{j}\left(s_{j}, b_{-j}\right)=0$. Then any $\tilde{b}_{j}<s_{j}$ either continues to yield $\pi_{j}\left(\tilde{b}_{j}, b_{-j}\right)=0$ or freezes TV station $j$ at a base clock price below $s_{j}$, yielding $\pi_{j}\left(\tilde{b}_{j}, b_{-j}\right)<0$. Moreover, any $\tilde{b}_{j}>s_{j}$ continues to yield $\pi_{j}\left(\tilde{b}_{j}, b_{-j}\right)=0$. Next suppose that bids $\left(s_{j}, b_{-j}\right)$ freeze TV station $j$ so that $\pi_{j}\left(s_{j}, b_{-j}\right)>0$. Then any $\tilde{b}_{j}<s_{j}$ freezes TV station $j$ at the same base clock price as $s_{j}$ and thus continues to yield $\pi_{j}\left(\tilde{b}_{j}, b_{-j}\right)=\pi_{j}\left(s_{j}, b_{-j}\right)$. Moreover, any $\tilde{b}_{j}>s_{j}$ either freezes TV station $j$ at the same base clock price as $s_{j}$ and thus continues to yield $\pi_{j}\left(\tilde{b}_{j}, b_{-j}\right)=\pi_{j}\left(s_{j}, b_{-j}\right)$ or leaves TV station $j$ on the air, yielding $\pi_{j}\left(\tilde{b}_{j}, b_{-j}\right)=0$.
} 
stations 1 and 3 continue to be frozen at a base clock price of $s_{2}$ under naive bidding. Firm 1's profit under naive bidding is $s_{2}\left(\varphi_{1}+\varphi_{3}\right)-\left(v_{1}+v_{3}\right)$ whereas its profit from withholding TV station 3 from the reverse auction now is $900 \varphi_{1}-v_{1}$. Strategic supply reduction is more profitable than naive bidding if

$$
\left(900-s_{2}\right) \varphi_{1}>s_{2} \varphi_{3}-v_{3}
$$

On the right-hand side is the forgone profit from withholding TV station 3. On the left-hand side is the additional profit consisting of the increase in the base clock price from $s_{2}$ to 900 , "magnified" by the broadcast volume of TV station 1 . Withholding TV station 3 is thus more likely to be profitable if it has a low broadcast volume and a high reservation value and TV station 1 has a high broadcast volume. Furthermore, it is more profitable for firm 1 to withhold TV station 3 rather than TV station 1 from the reverse auction if

$$
900\left(\varphi_{1}-\varphi_{3}\right)>v_{1}-v_{3}
$$

This again is more likely to be satisfied if TV station 3 has a low broadcast volume and a high reservation value and TV station 1 has a high broadcast volume and a low reservation value. In short, strategic supply reduction is more likely to be profitable if the "leverage" from increasing the base clock price is large and the opportunity cost of continuing to operate the withheld TV station is small.

Table 2: Example 2: Underbidding

\begin{tabular}{ccccc}
\hline $\begin{array}{c}\text { Station ID } \\
(j)\end{array}$ & Firm ID & $\begin{array}{c}\text { Reservation } \\
\text { value }\left(v_{j}\right)\end{array}$ & $\begin{array}{c}\text { Broadcast } \\
\text { volume }\left(\varphi_{j}\right)\end{array}$ & $\begin{array}{c}\text { Score } \\
\left(s_{j}=\frac{v_{j}}{\varphi_{j}}\right)\end{array}$ \\
\hline 3 & 1 & 100 & $\frac{1}{3}$ & 300 \\
2 & 2 & 1000 & 5 & 200 \\
1 & 1 & 100 & 1 & 100 \\
\hline
\end{tabular}

Example 2: Underbidding. Our next example shows that a firm owning multiple TV stations may also engage in underbidding. There are $N=3 \mathrm{TV}$ stations with reservation values and broadcast volumes given in Table 2. We now allow the broadcast volume to vary across stations; consequently, the payout to a TV station is the base clock price at the time of its freeze scaled by its broadcast volume. As in Example 1, TV stations 1 and 3 are owned by firm 1 and TV station 2 is owned by firm 2 . The set $R$ of available channels and the interference constraints are now such that the FCC can repack either just one of the TV stations or TV stations 1 and 3 together, i.e.,

$$
S(X, R)= \begin{cases}1 & \text { if } \quad X=\emptyset,\{1\},\{2\},\{3\},\{1,3\} \\ 0 & \text { if } \quad X=\{1,2\},\{2,3\},\{1,2,3\}\end{cases}
$$

Under naive bidding, $b_{j}=s_{j}$ for all $j \in\{1,2,3\}$. TV station 3 is first to withdraw from the reverse auction at a base clock price of $P_{\tau}=300$. As a consequence, TV station 2 can no longer be 
repacked and is frozen, collecting payout $P_{2}=5 \cdot 300=1500$. TV station 1 is next to withdraw at a base clock price of $P_{\tau^{\prime}}=100$. The reverse auction concludes and firm 1's profit is 0 as TV stations 1 and 3 remain going concerns. Firm 2's profit is $1500-1000=500$.

However, naive bidding is no longer an equilibrium as firm 1 has an incentive to deviate. In particular, if instead $b_{1}=s_{1}$ and $b_{3}=0$, then TV station 2 is first to withdraw from the reverse auction at a base clock price of $P_{\tau}=200$. As a consequence, TV stations 1 and 3 can no longer be repacked and are frozen, collecting payouts $P O_{1}=200$ and $P O_{3}=\frac{200}{3}$. The reverse auction concludes and firm 1's profit is $200-100+\frac{200}{3}-100=\frac{200}{3}$. It is easy to see that $b_{1}=s_{1}, b_{2}=s_{2}$, and $b_{3}=0$ is an equilibrium. By underbidding, firm 1's profit increases from 0 to $\frac{200}{3}$. In contrast, firm 2's profit decreases from 500 to 0 .

Multiple equilibria. In illustrating the potential for multiple equilibria, we contrast the singlemindedness assumption of Milgrom and Segal (2018) that rules out jointly owned TV stations, with the case of jointly owned TV stations as we observe in the data. For brevity, we focus on Example 1. In Online Appendix A.5, we show that there also are multiple equilibria in Example 2.

If we impose the single-mindedness assumption on Example 1 as though all TV stations were independently owned, then the set of equilibria is

$$
\begin{gathered}
\left\{\left(b_{1}, b_{2}, b_{3}\right) \in[0, \infty)^{3} \mid b_{1} \geq 500, b_{2} \leq 100, b_{3} \leq 100\right\} \\
\cup\left\{\left(b_{1}, b_{2}, b_{3}\right) \in[0, \infty)^{3} \mid b_{1} \leq 300, b_{2} \leq 300, b_{3} \geq 500\right\} \\
\cup\left\{\left(b_{1}, b_{2}, b_{3}\right) \in[0, \infty)^{3} \mid \max \left\{b_{1}, b_{3}\right\}<b_{2}, 300 \leq b_{2} \leq 500\right\} \\
\cup\left\{\left(b_{1}, b_{2}, b_{3}\right) \in[0, \infty)^{3} \mid \max \left\{b_{1}, b_{3}\right\} \leq 500, b_{2}>500\right\} \\
\cup\left\{\left(b_{1}, b_{2}, b_{3}\right) \in[0, \infty)^{3} \mid b_{1} \geq 900, b_{2} \geq 900, b_{3} \geq 900\right\} .
\end{gathered}
$$

The auction rules thus admit a wide range of behaviors and outcomes, although a range of behaviors may result in identical outcomes in terms of payouts to each license. ${ }^{31}$ Focusing on truthful bidding as a dominant strategy amounts to singling out a particular equilibrium.

Recognizing that TV stations 1 and 3 are jointly owned, the set of equilibria in Example 1 is

$$
\begin{gathered}
\left\{\left(b_{1}, b_{2}, b_{3}\right) \in[0, \infty)^{3} \mid b_{1}<900, b_{2} \leq 600, b_{3} \geq 900\right\} \\
\cup\left\{\left(b_{1}, b_{2}, b_{3}\right) \in[0, \infty)^{3} \mid b_{1} \leq 500, b_{2} \geq 600, b_{3} \leq 500\right\} .
\end{gathered}
$$

The fact that truthful bidding is no longer an equilibrium complicates analyzing the reverse auction.

\footnotetext{
${ }^{31}$ The equilibria in the first four lines of equation (4), as well as those in the second line of equation (5), have the property that the TV station with the high bid is indifferent across a range of bids although its bid determines the payouts to the other TV stations. In this regard, these equilibria are reminiscent of the analysis of the combinatorial clock auction in Levin and Skrzypacz (2016). The combinatorial clock auction has been used to award spectrum in other countries. It combines an initial ascending clock phase during which participants state their demands in response to the current price with a final sealed package bidding phase and links the two phases by activity rules. In our model there is no analog to the predatory equilibria in Levin and Skrzypacz (2016) as these rely on the two-stage nature of the combinatorial clock auction.
} 
While focusing on truthful bidding as a dominant strategy for the independently owned TV station 2 shrinks the set of equilibria, it does not lead to a unique equilibrium. At the same time, the auction rules admit a rich set of behaviors by firms owning multiple TV stations, most notably including strategic supply reduction. Strategic supply reduction is an extreme form of overbidding in that a firm owning multiple TV stations withholds one or more of them from the reverse auction. There are other equilibria that entail milder forms of overbidding.

Given the large number of participating TV stations and the complex ownership patterns and interference constraints in the actual reverse auction, our subsequent analysis proceeds with a game of complete information and restricts the strategy space of firms owning multiple TV stations. Section 3.2 motivates this restriction and Section 3.3 develops the game of incomplete information as a robustness check.

\subsection{Further analysis: Complete information}

We follow Milgrom and Segal (2018) by focusing on truthful bidding as a dominant strategy for an independently owned TV station. We restrict the strategy space for a jointly owned TV station to extreme overbidding, extreme underbidding, and truthful bidding. The strategy space of TV station $j$ is thus $b_{j}=s_{j}$ if it is independently owned and $b_{j} \in\left\{0, s_{j}, 900\right\}$ if it is jointly owned. We argue below that this restriction on jointly owned TV stations is not overly arduous.

We partition the vector $b=\left(b_{1}, \ldots, b_{N}\right)$ as $\left(b_{j}, b_{-j}\right)$, where $b_{j}$ is the bid for TV station $j$ and $b_{-j}$ is the vector of bids of the other TV stations. In the interest of simplicity, we assume that different TV stations have different bids, i.e., $b_{j} \neq b_{k}$ for all $j \neq k$, except that we allow multiple TV stations to bid 0 or 900 . Let $\pi_{i}(b)$ be firm $i$ 's profit from the reverse auction. Denoting as $J_{i} \subseteq\{1, \ldots, N\}$ the set of TV stations owned by firm $i$ and as $F^{*} \subseteq\{1, \ldots, N\}$ the set of frozen TV stations at the conclusion of the reverse auction, we have

$$
\pi_{i}(b)=\sum_{j \in J_{i} \cap F^{*}(b)} P O_{j}(b)-v_{j}
$$

where our notation emphasizes that the payout $P O_{j}$ to TV station $j$ as well as the set of frozen TV stations $F^{*}$ depend on the vector of bids $b$.

We motivate the restriction to $b_{j} \in\left\{0, s_{j}, 900\right\}$ for a jointly owned TV station $j$ with two propositions. Proposition 1 tackles the case of overbidding:

Proposition 1. Suppose firm $i$ owns multiple TV stations including TV station $j$, i.e., $\left|J_{i}\right|>1$ and $j \in J_{i}$. Consider a vector of bids $b$ with $s_{j}<b_{j}<900$. If $S\left(Y_{1}(b) \cup\{j\}, R\right)=1$ and $\pi_{i}\left(b_{j}, b_{-j}\right)>\pi_{i}\left(s_{j}, b_{-j}\right)$, then $\pi_{i}\left(900, b_{-j}\right) \geq \pi_{i}\left(b_{j}, b_{-j}\right)$.

Proposition 1 assumes that it is feasible to repack TV station $j$ in addition to any TV stations that withdraw in round 1 of the reverse auction. It states that if a firm owning multiple TV stations finds it more profitable to overbid $b_{j}>s_{j}$ than to truthfully bid $b_{j}=s_{j}$, then the firm may as well bid $b_{j}=900$ and withhold TV station $j$ from the reverse auction. In this sense, restricting the 
strategy space of the jointly owned TV station $j$ from $b_{j} \in\left[s_{j}, 900\right]$ to $b_{j} \in\left\{s_{j}, 900\right\}$ does not make the firm worse off. Moreover, it is easy to construct specific situations where extreme overbidding $b_{j}=900$ ensures a strictly higher profit.

Proposition 1 is best thought of as characterizing the best reply of firm $i$ and differs from the standard notion of weak dominance. While eliminating strictly (but not weakly) dominated strategies is innocuous and does not affect the set of equilibria, the restriction to $b_{j} \in\left\{0, s_{j}, 900\right\}$ for a jointly owned TV station $j$ may well do so (see the examples in Section 3.1). Alas, a stronger result than Proposition 1 has eluded us. We note that the notion of dominance in Milgrom and Segal (2018) is also weaker than strict dominance.

Proposition 2 tackles the case of underbidding and parallels Proposition 1:

Proposition 2. Suppose firm $i$ owns multiple TV stations including TV station $j$, i.e., $\left|J_{i}\right|>1$ and $j \in J_{i}$. Consider a vector of bids $b$ with $0<b_{j}<s_{j}$. If $\pi_{i}\left(b_{j}, b_{-j}\right)>\pi_{i}\left(s_{j}, b_{-j}\right)$, then $\pi_{i}\left(0, b_{-j}\right) \geq \pi_{i}\left(b_{j}, b_{-j}\right)$.

We prove Propositions 1 and 2 in Appendix B.

\subsection{Further analysis: Incomplete information}

It is well known that analyzing auctions involving multiple objects under the assumption of incomplete information is difficult (see Chapters 5 and 6 of Milgrom (2004) and Part II, especially Chapter 18, of Krishna (2010)). To make some headway, we recast Example 1 in Section 3.1 as a game of incomplete information. We assume that the reservation value $v_{j}$ of TV station $j$ is privately known to its owner and specify another firm's belief about the reservation value of TV station $j$ to be $\tilde{v}_{j} \sim N\left(v_{j}, \sigma^{2}\right)$, independent across TV stations.

The game of incomplete information gives rise to bidding functions, rather than bids, that depend on beliefs. As beliefs depend on $\sigma$, note that as $\sigma$ goes to zero, beliefs collapse to the true reservation values. In this way, we are able to ascertain the relationship between bidding functions under the game of incomplete information and bids under the game of complete information. Let $b_{1}\left(v_{1}, v_{3}, \sigma\right) \geq 0$ and $b_{3}\left(v_{1}, v_{3}, \sigma\right) \geq 0$ be the bidding functions of TV stations 1 and 3 that are owned by firm 1 and $b_{2}\left(v_{2}, \sigma\right) \geq 0$ the bidding function of TV station 2 that is owned by firm 2 . In Online Appendix B, we characterize the bidding functions as $\sigma \rightarrow 0^{+}$. In the game of incomplete information, we show that firm 1 always bids $b_{1}<b_{3}$. Its expected profit depends solely on $b_{3}$ and, as $\sigma \rightarrow 0^{+}$, closely resembles its profit under complete information. Moreover, for a wide range of values of $\sigma, b_{3}(100,300, \sigma)$ is arbitrarily close to (but different from) $b_{3}=900$ in the game of complete information. Close to extreme overbidding thus arises in the game of incomplete information. In a variant of Example 1, we also show that close to extreme overbidding arises in the game of incomplete information when $\sigma$ is large. In contrast, extreme overbidding does not arise in the game of complete information. These results suggest that our notion of strategic supply reduction in settings with jointly owned TV stations extends beyond complete information. 
While strategic supply reduction is part and parcel of the reverse auction, even our simple examples point to multiple equilibria and behavior within equilibria that depends critically on reservation values, broadcast volumes, and interference constraints. It is therefore difficult to arrive at general predictions about the outcome of the reverse auction and how that outcome differs between strategic bidding under the actual ownership pattern and truthful bidding under the counterfactual of independent ownership. In the subsequent analysis, we therefore combine estimated reservation values with simulation techniques to assess the impact of ownership concentration on the reverse auction.

\section{Data sources}

We first describe the various data sources we combine to estimate the reservation values of the TV stations participating in the reverse auction and to determine their ownership structure. Then we turn to the interference constraints on the repacking process. Finally, we describe some auxiliary data sources. We provide further details on the data sources in Appendix A.

From hereon, we restrict attention to TV stations located in the U.S. excluding Puerto Rico and the Virgin Islands. Out of the 2,194 TV stations that the FCC has declared as eligible for the reverse auction, 44 are located in Puerto Rico and the Virgin Islands. ${ }^{32}$ This leaves us with 2,150 eligible TV stations.

\subsection{Reservation values and ownership structure}

To infer the reservation value of a TV station in the reverse auction, we use the MEDIA Access Pro Database from 2003 to 2013 and for 2015 from BIA Kelsey (henceforth BIA) and the Television Financial Report from 2003 to 2012 from the National Association of Broadcasters (NAB). We model and estimate the components of the cash flow of a TV station, focusing on advertising and non-broadcast revenue and fixed cost, as detailed in Section 6.1. BIA contains the universe of TV stations. It provides station, owner, and market characteristics, as well as transaction histories covering the eight most recent changes in the ownership of a TV station.

The revenue measure in the BIA data covers revenue related to broadcasting in the form of local, regional, and national advertising revenue, commissions, and network compensation, and we refer to it as advertising revenue in what follows. For commercial stations, advertising revenue is missing for $28.3 \%$ of station-year observations, and we impute it as detailed in Appendix A.3. For non-commercial stations, including dark stations, advertising revenue is missing for $93.5 \%$ of station-year observations, and we do not impute it. We return to the distinction between commercial and non-commercial stations in Section 6.1.

The BIA data excludes non-broadcast revenue, most notably retransmission fees that TV stations charge pay-TV providers to use their content. Retransmission fees are a small but growing

\footnotetext{
${ }^{32}$ Out of the $145 \mathrm{TV}$ stations that went off the air, 7 are located in Puerto Rico. These 7 TV stations together claimed less than $0.5 \%$ of payouts in the reverse auction.
} 
source of revenue. ${ }^{33}$ Outside estimates suggest that in 2016 advertising revenue accounts for $69 \%$ of a typical TV station's revenue, with a further $24 \%$ of revenue coming from retransmission fees and $7 \%$ coming from online activities. ${ }^{34}$ Consequently, the variation in advertising revenue across TV stations is a major, but not the only, driver of the variation in cash flow.

To get at non-broadcast revenue, we use the NAB data. For commercial full-power stations, NAB collects financial information. Revenue is broken down into detailed source categories from which we are able to construct non-broadcast revenue. NAB further covers cash flow. However, for confidentiality reasons, NAB reports only the mean as well as the first, second, and third quartile of these measures at various levels of aggregation, resulting in "tables" of station groupings such as "ABC, CBS and NBC affiliates in markets ranked 51-60 in 2012" or "CBS affiliates in markets ranked 1-50 in 2012". Appendix A.4 lists the set of 66 tables for 2012; other years are very similar. In Section 6.1, we describe a method for combining the station-level data on advertising revenue from BIA with the aggregated data from NAB to estimate the cash flow of a TV station.

\subsection{Interference constraints}

The FCC makes available the feasibility checker $S A T F C$ it uses in the reverse auction along with a domain file and a pairwise interference file. ${ }^{35}$ The domain file lists for each TV station the channels it can be assigned to, accounting for restrictions due to international and military broadcasting. Intersecting the domain file with the channels that a given clearing target leaves available for repacking yields the set of available channels $R$ described in Section $3 .^{36}$

The pairwise interference file lists for each TV station and each channel any other TV stations that cannot be located on that channel or on immediately adjacent channels without causing unacceptable levels of interference; these are the interference constraints described in Section 3 that we suppress in our notation for the indicator function $S(X, R)$ for simplicity. In authorizing the Incentive Auction, Congress instructed the FCC to preserve the TV stations' populations served prior to the auction. After public deliberations on the interpretation of this mandate, ${ }^{37}$ the FCC applied an existing standard that treats interference of more than $0.5 \%$ as unacceptable. Accordingly, a channel assignment for a pair of TV stations $j$ and $j^{\prime}$ is included in the pairwise interference file and thus unavailable in the repacking process if transmission by TV station $j$ would reduce the population served of TV station $j^{\prime}$ by more than $0.5 \% .^{38}$ For most of the subsequent

\footnotetext{
${ }^{33}$ See "SNL Kagan raises retrans fee forecast to $\$ 9.8$ B by 2020; Mediacom's CEO complains to FCC", FierceCable, July $7,2015$.

${ }^{34}$ See "Retrans Revenue Share Expands In Latest U.S. TV Station Industry Forecast", Justin Nielson, S\&P Global Market Intelligence, July 14, 2016.

${ }^{35}$ See http://data.fcc.gov/download/incentive-auctions/Constraint_Files/, accessed on March 7, 2018.

${ }^{36}$ For example, achieving the initial clearing target of $126 \mathrm{MHz}$ requires clearing 21 out of a total of 37 nondedicated UHF channels, leaving 16 UHF channels available for repacking; achieving the final clearing target of 84 $\mathrm{MHz}$ requires clearing 14 UHF channels, leaving 23 UHF channels available for repacking (FCC Public Notice 14-191, p. 7).

${ }^{37}$ See https://apps.fcc.gov/edocs_public/attachmatch/FCC-14-50A1.pdf, paragraphs 176-182, accessed on November 15, 2015.

${ }^{38}$ The FCC developed a piece of software, TV Study, that relies on geographically fine interference data to generate the pairwise interference file for any given interference level. See https://www.fcc.gov/oet/tvstudy, accessed on
} 
Figure 1: Same- and adjacent-channel interference constraints for WCAU

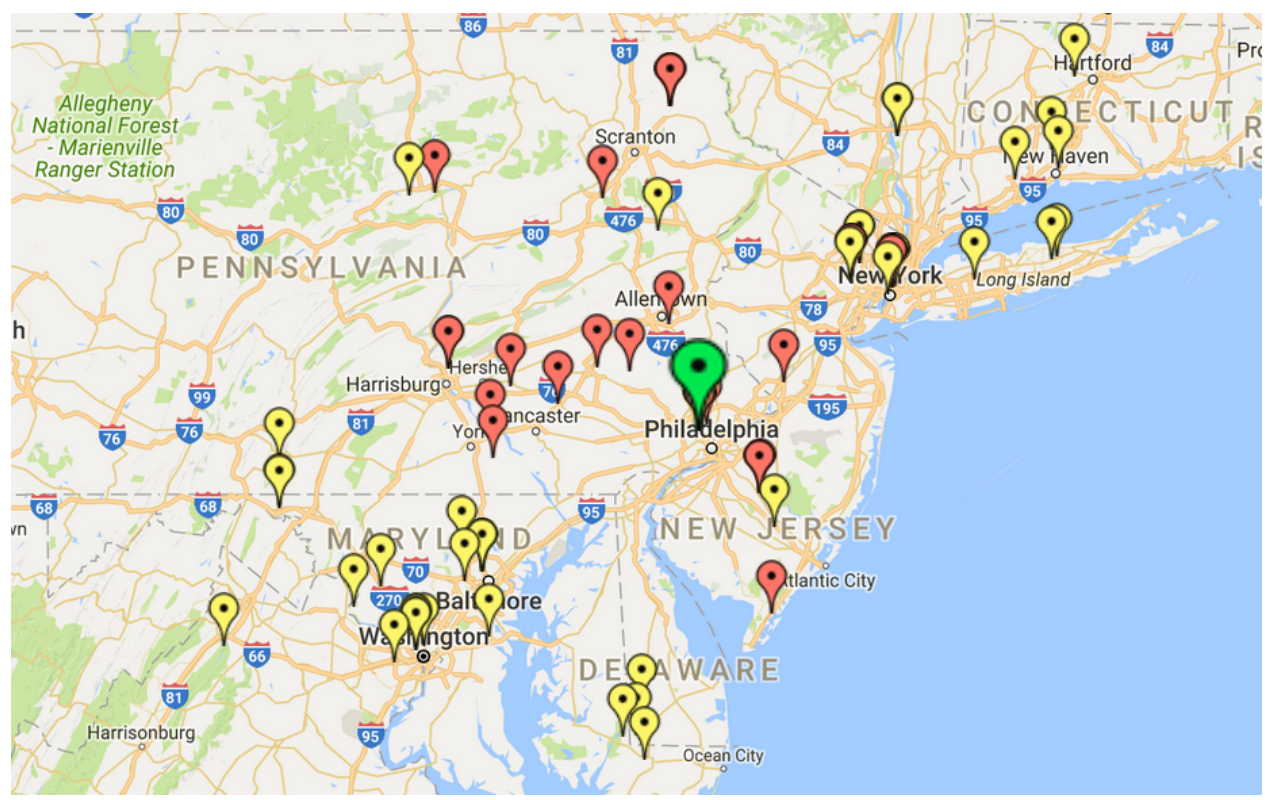

Notes: Each pin represents the facility location of a TV station. WCAU (NBC Philadelphia) is denoted by a green pin. Red pins denote TV stations that have adjacent-channel interference constraints and yellow pins TV stations that have same-channel interference constraints.

analysis, we rely on the pairwise interference file for the chosen $0.5 \%$ standard. We also trace out how the ease of repacking as parameterized by the interference level affects the outcome of the reverse auction. In Section 7.4 we rely on the pairwise interference files for an alternative, looser, standard of $2 \%$ that the FCC considered, and for a very relaxed $10 \%$ standard.

Under a $126 \mathrm{MHz}$ clearing target with UHF channels 14-29 available for repacking, the pairwise interference file imposes 1,729,841 restrictions on the repacking process for an interference level of $0.5 \%$; under an $84 \mathrm{MHz}$ clearing target with UHF channels 14-36 available for repacking, the number of restrictions grows to 2,334,334. To illustrate, Figure 1 shows the 102 TV stations that have interference constraints with WCAU (facility ID 63153), the Philadelphia NBC affiliate, on at least one of the 16 available channels under the $126 \mathrm{MHz}$ clearing target. Of those, $65 \mathrm{TV}$ stations have same-channel constraints and 37 TV stations have adjacent-channel constraints. In Figure 1, the green pin indicates WCAU, a yellow pin a TV station with a same-channel constraint, and a red pin a TV station with an adjacent-channel constraint.

\subsection{Auxiliary data sources}

As described in "Appendix: Analysis of Potential Aggregate Interference" of FCC Public Notice DA 14-677, the FCC conducted its own simulations in June 2014 to assess the likely number of TV stations in each DMA that have to relinquish their licenses for a clearing target of $84 \mathrm{MHz}$ or 120

March 7, 2018. 
$\mathrm{MHz}$ to be met. ${ }^{39}$ The FCC restricts its simulations to UHF stations and to going off the air as the primary relinquishment option. Focusing on the simulations that assume full participation leaves us with 25 simulations for the $84 \mathrm{MHz}$ clearing target and 27 simulations for the $120 \mathrm{MHz}$ clearing target. For our initial descriptive analysis only, we label a DMA as a positive demand DMA if at the median across simulations at least one TV station has to relinquish its license. There are 81 positive demand DMAs for the $84 \mathrm{MHz}$ clearing target and 121 for the $120 \mathrm{MHz}$ clearing target. ${ }^{40}$ Since in many DMAs no TV station has to relinquish its license for the clearing target to be met, we expect payouts from the reverse auction to be concentrated in a relatively small number of DMAs.

\section{Descriptive evidence}

We provide descriptive evidence in support of ownership concentration and strategic supply reduction. From here on, in line with the FCC's own simulations we restrict attention to the 1,670 UHF stations located in the U.S. excluding Puerto Rico and the Virgin Islands that the FCC has declared as eligible for the reverse auction. ${ }^{41}$

\subsection{Ownership concentration}

Our data shows significant ownership concentration, both across and within DMAs, consistent with the notion of "chains" of TV stations. In 2015, the 1,670 TV stations are held by 482 owners. Of these 482 owners, 302 hold one TV station across the U.S., 66 hold two TV stations, 33 hold three TV stations, and the remaining 81 owners hold at least four TV stations. The 1,670 TV stations are assigned to 204 DMAs by the FCC. Turning to ownership concentration within DMAs, 78 DMAs have only single-license owners, meaning that all TV stations within the DMA are independently owned, while the remaining 126 DMAs have at least one multi-license owner, meaning that at least two TV stations within the DMA are jointly owned. Within-DMA multi-license ownership will be the focus of our main analysis in Sections 6 and 7, although we consider ownership across DMAs in Section 8.2.

Table 3 provides further details on ownership concentration, juxtaposing all 204 DMAs with the 121 positive demand DMAs for the $120 \mathrm{MHz}$ clearing target and the 81 positive demand DMAs for the $84 \mathrm{MHz}$ clearing target. As the top panel shows, on average across all DMAs, 6.45 owners hold 8.19 TV stations whereas on average across positive demand DMAs for the $120 \mathrm{MHz}$ (84 $\mathrm{MHz}$ ) clearing target, 7.17 (7.62) owners hold 9.04 (9.62) TV stations. The number of multi-license owners is 1.25 on average for all DMAs compared to 1.40 (1.54) for positive demand DMAs for the $120 \mathrm{MHz}(84 \mathrm{MHz})$ clearing target. The distribution over ownership configurations in the bottom panel of Table 3 reinforces that ownership is more concentrated in positive demand DMAs. In 82

\footnotetext{
${ }^{39}$ See https://apps.fcc.gov/edocs_public/attachmatch/DA-14-677A2.docx, accessed on March $10,2016$.

${ }^{40}$ The FCC excludes 6 DMAs without UHF stations from its simulations. These DMAs are Bangor, ME, Glendive, MT, Juneau, AK, Lafayette, IN, Mankato, MN, and Presque Isle, ME.

${ }^{41}$ We drop 480 VHF stations from the subsequent analysis. These 480 VHF stations together claimed a mere $3.7 \%$ of payouts in the reverse auction in spite of representing a large share of licensed broadcasters.
} 
Table 3: Ownership concentration

\begin{tabular}{lccc}
\hline & $\begin{array}{c}\text { All 204 } \\
\text { DMAs }\end{array}$ & $\begin{array}{c}\text { 121 positive demand } \\
\text { DMAs }(120 \mathrm{MHz})\end{array}$ & $\begin{array}{c}\text { 81 positive demand } \\
\text { DMAs }(84 \mathrm{MHz})\end{array}$ \\
\hline Average across DMAs & & & \\
Number of licenses & 8.19 & 9.04 & 9.62 \\
Number of owners & 6.45 & 7.17 & 7.62 \\
Number of multi-license owners & 1.25 & 1.40 & 1.54 \\
Percentage of DMAs with $j$ multi-license owners & & \\
$j=0$ & 38.2 & 32.2 & 30.9 \\
$j=1$ & 26.0 & 25.6 & 21.0 \\
$j=2$ & 19.6 & 25.6 & 28.4 \\
$j=3$ & 7.35 & 6.61 & 7.41 \\
$j \geq 4$ & 8.82 & 9.92 & 12.4 \\
\hline
\end{tabular}

of 121 , or $68 \%$ (56 of 81 , or $69 \%$ ) of positive demand DMAs for the $120 \mathrm{MHz}(84 \mathrm{MHz}$ ) clearing target, there is at least one multi-license owner as compared to in 126 of 204 , or $62 \%$ of all DMAs. Taken together, this shows that multi-license ownership is prevalent, especially in DMAs that may play a key role in the reverse auction.

Ownership concentration has traditionally been a concern for regulators. The FCC Local TV Ownership Rules permit joint ownership of up to two TV stations in the same DMA if either their service contours do not overlap or at least one of them is not ranked among the top four TV stations in the DMA, based on the most recent audience share, and there are at least eight independently owned commercial or non-commercial full-power stations in the DMA. However, these rules do not apply to non-commercial, low-power, and satellite stations. Moreover, waivers can be - and have been - granted for failing or financially distressed TV stations. ${ }^{42}$ For historical reasons these rules are oriented towards the business of operating TV stations that primarily generate revenues from advertising and therefore prevent broadcasters from gaining excessive market power in the market for advertising. However, as our data and analysis show, these rules do not preclude firms from amassing market power over broadcast spectrum. As a result, some firms may have been able to accumulate market power in the reverse auction through multi-license ownership.

\subsection{Private equity firms}

Some chains of TV stations are recent creations. From 2011 to 2015, three private equity firms LocusPoint Networks, NRJ TV, and OTA Broadcasting (henceforth, LocusPoint, NRJ, and OTA)

\footnotetext{
${ }^{42}$ The rules are set out in paragraph (b) of Title 47 of the Code of Federal Regulations, Chapter I.C, Part 73.H, Section 73.3555, with carve-outs in paragraph (f), note (5), and note (7). See https://www.law.cornell.edu/cfr/ text/47/73.3555, accessed on March 29, 2018. The Low Power Television (LPTV) Service Guide further exempts low-power stations. See https://www.fcc.gov/consumers/guides/low-power-television-lptv-service, accessed on March 29, 2018.
} 
— acquired 48 UHF stations for at least $\$ 380$ million. ${ }^{43,44}$ Of the $48 \mathrm{TV}$ stations, 15 are full-power stations, 33 are low-power class-A stations, 47 are commercial stations, and one is a non-commercial station. Few of the 48 TV stations are affiliated with major networks and many of them are failing or in financial distress. The trade press widely claimed that the private equity firms acquired TV stations with the goal of "flipping" them for profit in the reverse auction. ${ }^{45}$

Most of the acquired TV stations are on the peripheries of major DMAs, ranging from Boston, MA, to Washington, DC, on the Eastern Seaboard and from Seattle, WA, to Los Angeles, CA, along the West Coast. The $48 \mathrm{TV}$ stations are located in 22 DMAs that we refer to as private equity active DMAs. Of the 22 private equity active DMAs, 21 are positive demand DMAs under the $120 \mathrm{MHz}$ clearing target and 18 are positive demand DMAs under the $84 \mathrm{MHz}$ clearing target. In line with a goal of flipping TV stations, the private equity firms appear to have targeted DMAs with robust "demand". At the same time, however, the private equity firms accumulated market power in the reverse auction. For example, NRJ acquired four TV stations in the Los Angeles, CA, DMA and OTA acquired nine TV stations in the Pittsburgh, PA, DMA. The 10 TV stations acquired by LocusPoint are located in 10 different DMAs, the 15 TV stations acquired by NRJ are located in 10 different DMAs, and the 23 TV stations acquired by OTA are located in 11 different DMAs.

Table 4 summarizes attributes of the 48 TV stations acquired by the three private equity firms and contrasts them with the $286 \mathrm{TV}$ stations that were part of other transactions in the four years from 2010 to 2013. While there is considerable overlap in the distributions of transaction price and the other attributes between the two groups, the private equity firms acquired relatively cheaper TV stations. Moreover, these TV stations have higher broadcast volume, both because of higher interference free population and because of higher interference count. The 48 TV stations acquired by the three private equity firms are therefore relatively more difficult to assign to a channel in the repacking process if they opt to remain on the air. At the same time, the base clock price is "magnified" by the relatively high broadcast volume if these TV stations are frozen in the course of the reverse auction.

Perhaps even more telling, the private equity firms relinquished only 19 TV stations, or 40\% of the acquired TV stations, in the reverse auction and sold another $20 \mathrm{TV}$ stations, or $42 \%$ of the acquired TV stations, soon after the reverse auction. This appears difficult to reconcile with the goal of flipping TV stations. Table 5 further fleshes out acquisitions and sales. Separately for

\footnotetext{
${ }^{43}$ According to FCC filings, the Blackstone Group LP owns $99 \%$ of LocusPoint. NRJ is a media holding company funded through loans from Fortress Investment Group LLC according to a recent U.S. Securities and Exchange Commission filing. Lastly, OTA is a division of MSD Capital LP, which was formed to manage the wealth of Dell Computer founder Michael Dell.

${ }^{44}$ LocusPoint acquired another $3 \mathrm{UHF}$ stations for $\$ 4.8$ million that it sold to HME Equity Fund II LLC for $\$ 23.75$ million before the reverse auction. See http://www.tvnewscheck.com/article/92491/ hme-equity-closes-on-purchase-of-3-lptvs, accessed on March 17, 2018. NRJ acquired another VHF station for $\$ 9.9$ million. See http://www.tvnewscheck.com/article/89486/nrj-tv-buys-dallas-vhf-for-99-million, accessed on April 30, 2018.

${ }^{45}$ See, e.g., http://www.tvnewscheck.com/article/65850/tv-spectrum-speculation-nears-345-million and http: //current.org/2013/02/speculators-betting-big-on-fcc-tv-spectrum-auctions/, accessed on November $15,2015$.
} 
Table 4: Comparison of TV stations acquired by private equity firms and other transactions from 2010 to 2013

\begin{tabular}{|c|c|c|c|c|c|c|}
\hline & \multicolumn{3}{|c|}{ Private equity firms } & \multicolumn{3}{|c|}{ Other transactions } \\
\hline & Mean & Std. Dev. & Median & Mean & Std. Dev. & Median \\
\hline Transaction price ( $\$$ million) & 7.91 & 9.74 & 4.55 & 25.20 & 48.90 & 7.73 \\
\hline UHF & 1 & 0 & 1 & 0.80 & 0.40 & 1 \\
\hline Commercial & 0.98 & 0.14 & 1 & 0.98 & 0.13 & 1 \\
\hline Full power & 0.31 & 0.47 & 0 & 0.84 & 0.37 & 1 \\
\hline Major network affiliation & 0.04 & 0.20 & 0 & 0.60 & 0.49 & 1 \\
\hline Broadcast volume (million) & 0.28 & 0.16 & 0.28 & 0.17 & 0.13 & 0.14 \\
\hline Inference free population (million) & 3.61 & 3.47 & 2.53 & 1.69 & 2.04 & 1.01 \\
\hline Interference count & 104.10 & 35.41 & 101.50 & 79.44 & 47.35 & 72.50 \\
\hline Number of licenses & & 48 & & & 286 & \\
\hline
\end{tabular}

Table 5: Private equity firms' acquisitions and sales of TV stations

\begin{tabular}{lccc}
\hline & \multicolumn{3}{c}{ TV stations } \\
\cline { 2 - 4 } & $\begin{array}{c}\text { acquired before } \\
\text { reverse auction }\end{array}$ & $\begin{array}{c}\text { relinquished in } \\
\text { reverse auction }\end{array}$ & $\begin{array}{c}\text { sold after } \\
\text { reverse auction }\end{array}$ \\
\hline LocusPoint & 10 & 2 & 7 \\
Number & 55.85 & 15.20 & 32.70 \\
Amount (\$ million) & & 8.80 & -13.70 \\
Profit/loss (\$ million) & & & \\
NRJ & 15 & 7 & 1 \\
Number & 245.25 & 640.00 & 0.65 \\
Amount (\$ million) & & 526.72 & -42.08 \\
Profit/loss (\$ million) & & & 12 \\
OTA & 23 & 10 & 38.38 \\
Number & 78.75 & 441.00 & -1.64 \\
Amount (\$ million) & & 402.26 & \\
Profit/loss (\$ million) & &
\end{tabular}

LocusPoint, NRJ, and OTA, the table provides the number of TV stations acquired before the reverse auction along with the amount paid, the number of TV stations relinquished in the reverse auction along with the amount received, and the number of TV stations sold soon after the reverse auction along with the amount received. The table finally indicates the profit made or loss incurred on these latter two sets of TV stations. We provide further details and the underlying data in Online Appendix C. While the private equity firms made - typically substantial — profits on the TV stations they relinquished in the reverse auction, they incurred losses on the TV stations they sold soon after.

While the activities of the three private equity firms are very salient, their contribution to ownership concentration is small: the private equity firms are just three of 180 owners, or $2 \%$, that hold more than one TV station across the U.S., and they hold just 48 of 1,368 TV stations, or $4 \%$, that belong to one of these chains. The vast majority of ownership concentration is long 
standing and reflects reasons that are orthogonal to the incentive auction, such as historical accident, advertising market, content provision, etc.

\section{Analysis}

We first describe how we estimate the reservation value of a TV station. With reservation values in hand, we conduct a large-scale simulation exercise to compare the outcome of the reverse auction under the counterfactual of independent ownership and naive bidding with the outcome when we account for the ownership pattern in the data and allow multi-license owners to engage in strategic supply reduction.

\subsection{Reservation values}

In close resemblance to how market participants and industry consultants value a TV station, ${ }^{46}$ we model the reservation value of TV station $j$ in year $t_{0}$ as the greater of its cash flow value $v_{j t_{0}}^{C F}$ and

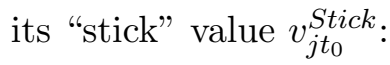

$$
v_{j t_{0}}=\max \left\{v_{j t_{0}}^{C F}, v_{j t_{0}}^{\text {Stick }}\right\} .
$$

The industry standard for valuing a broadcast business as a going concern is to assess its cash flow $C F_{j t_{0}}$ and scale it by a cash flow multiple Multiple ${ }_{j t_{0}}^{C F}$. Hence, the cash flow value of the TV station is

$$
v_{j t_{0}}^{C F}=\text { Multiple } e_{j t_{0}}^{C F} \cdot C F_{j t_{0}} .
$$

This is the price the TV station expects if it sells itself on the private market as a going concern.

The stick value of the TV station, on the other hand, reflects solely the value of its license and broadcast tower, not the ongoing business. It is the default value of a non-commercial station and

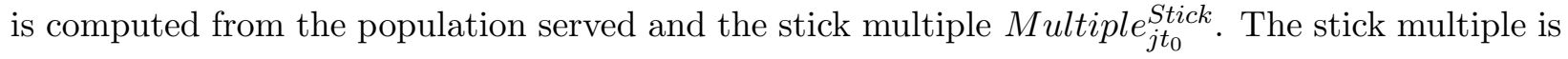
traditionally expressed on a per $\mathrm{MHz}$ per population (henceforth, $\mathrm{MHz}$-pop) basis. For a low-power class-A station, we use interference free population to measure population served. Hence, the stick value of a low-power class-A station is

$$
v_{j t_{0}}^{\text {Stick }}=\text { Multiple }_{j t_{0}}^{\text {Stick }} \cdot 6 \mathrm{MHz} \cdot \text { InterferenceFreePop }{ }_{j t_{0}} .
$$

Because of the must-carry provision of the Cable Television Consumer Protection and Competition Act of 1992, a full-power station must be carried on any cable system operating in the same DMA. ${ }^{47}$ We therefore use DMA population to measure population served. Hence, the stick value of a full-power station is

\footnotetext{
${ }^{46}$ See "Broadcasting M\&A 101: Our View of the Broadcast TV M\&A Surge", Davis Hebert and Eric Fishel, Wells Fargo, June 26, 2013 and "Estimating the Value of TV Broadcast Licenses for the Upcoming FCC Incentive Auction", Mark Mondello and Arya Rahimian, Duff \& Phelps, November 23, 2015.

${ }^{47}$ More specifically, any cable operator offering more than 12 channels must set aside one third of its channels for local commercial broadcasters. Any cable operator offering more than 36 channels must carry all non-commercial and educational broadcasters.
} 


$$
v_{j t_{0}}^{\text {Stick }}=\text { Multiple }_{j t_{0}}^{\text {Stick }} \cdot 6 \mathrm{MHz} \cdot \mathrm{DMAPop} \mathrm{p}_{0} .
$$

While we observe the population served by a TV station, its cash flow is only available at various levels of aggregation in the NAB data. Moreover, we observe neither the cash flow multiple nor the stick multiple. Below we explain how we estimate these objects. We provide further details in Appendix C.

Cash flows. We model the cash flow $C F_{j t}$ of TV station $j$ in year $t$ as

$$
C F_{j t}=\alpha\left(X_{j t} ; \beta\right) A D_{j t}+R T\left(X_{j t} ; \gamma\right)-F\left(X_{j t} ; \delta\right)+\epsilon_{j t}
$$

where $\alpha\left(X_{j t} ; \beta\right) A D_{j t}$ is the contribution of advertising revenue to cash flow, $R T\left(X_{j t} ; \gamma\right)$ is nonbroadcast revenue including retransmission fees, $F\left(X_{j t} ; \delta\right)$ is fixed cost, and $\epsilon_{j t} \sim N\left(0, \sigma^{2}\right)$ is an idiosyncratic, inherently unobservable component of cash flow. Only advertising revenue $A D_{j t}$ and station and market characteristics $X_{j t}$ are directly observable in the BIA data. To estimate the remaining components of cash flow, we specify flexible functional forms of subsets of $X_{j t}$ for $\alpha\left(X_{j t} ; \beta\right), R T\left(X_{j t} ; \gamma\right)$, and $F\left(X_{j t} ; \delta\right)$ and estimate the parameters $\theta=(\beta, \gamma, \delta, \sigma)$ drawing on the aggregated data from NAB.

We proceed using a simulated minimum distance estimator. Our estimation includes all TV stations covered by the aggregated data from NAB. The parameters $\theta=(\beta, \gamma, \delta, \sigma)$, together with our functional form and distributional assumptions in equation (10), imply a distribution of the cash flow $C F_{j t}$ of TV station $j$ in year $t$. We first draw a cash flow error term $\epsilon_{j t}$ for each TV station covered by the aggregated data from NAB. Then we match the moments of the predicted cash flow and non-broadcast revenue distributions to the moments reported by NAB for different sets of TV stations and DMAs. In particular, we match the mean along with the first, second, and third quartile of cash flow and the mean of non-broadcast revenue for each NAB table in each year, yielding a total of 3,313 moments.

The correlation between the moments of the predicted distributions at our estimates and the moments reported by NAB is 0.98 for cash flow and 0.84 for non-broadcast revenue. The estimates indicate that major network affiliates are most profitable; that non-broadcast revenue has grown significantly in recent years; and that there are economies of scale in fixed cost.

Multiples. To estimate the multiples Multiple ${ }_{j t}^{C F}$ and Multiple Stick $_{j t}$, we begin with the 340 transactions for individual TV stations in the 11 years from 2003 to 2013 that BIA records. ${ }^{48}$ We extract 133 transactions based on cash flows and 191 transactions based on stick values. ${ }^{49}$ We infer

\footnotetext{
${ }^{48}$ BIA records 849 transactions with transaction prices, as opposed to station swaps, stock transfers, donations, etc. We focus on the 340 transactions for individual TV stations in order to estimate the multiples as functions of station and market characteristics. We use transactions from 2013 to infer the stick multiple but not to infer the cash flow multiple because 2012 is the last year of availability for the NAB data.

${ }^{49}$ To classify transactions, we proceed as follows: We first define a TV station to be a major network affiliate if it is affiliated with ABC, CBS, Fox, or NBC. We then classify a transaction as based on stick value if it is for a
} 
the cash flow multiple and stick multiple from the transaction price, the population served, and the power output of the TV station using equations (7), (8), and (9), respectively. Because the transacted TV stations may be a selected sample, we incorporate outside estimates of the range of the multiples. Using these estimates as priors, we estimate a Bayesian regression model to project multiples on station and market characteristics $X_{j t}$. We include year fixed effects in $X_{j t}$ to capture the secular decline in the use of broadcast TV. The resulting posteriors are a normal distribution for the cash flow multiple and a log-normal distribution for the stick multiple; see Appendix C.2 for detail. This allows us to predict multiples for any TV station, not just those that were recently transacted.

Reservation values. The aggregated data from NAB that we use to estimate the cash flow model in equation (10) does not cover all 1,670 UHF stations located in the U.S. excluding Puerto Rico and the Virgin Islands that the FCC has declared as eligible for the reverse auction. The omissions are 387 low-power class-A stations, 289 non-commercial stations, and 4 dark stations that we henceforth subsume into non-commercial stations. We therefore extrapolate from our estimates as follows. First, we assume that low-power class-A stations are valued in the same way as full-power stations conditional on station and market characteristics $X_{j t}$. Second, we assume that non-commercial stations are valued by their stick value, consistent with industry practice.

To estimate the reservation value of TV station $j$ going into the reverse auction, we set $t_{0}=2015 .{ }^{50}$ We draw from the estimated distribution of the cash flow error term $\epsilon_{j t_{0}}$ to get $\widehat{C F}_{j t_{0}}$. We draw from the respective posterior distributions of the multiples to get $\widehat{M u l t i p l e} e_{j t_{0}}^{C F}$ and $\widehat{\text { Multipl }} e_{j t_{0}}^{\text {Stick }}$. The reservation value $\widehat{v}_{j t_{0}}$ of a commercial station is then the higher of the realized draws of its cash flow value and its stick value as specified in equations (6)-(9); the reservation value $\widehat{v}_{j t_{0}}$ of a non-commercial station is its stick value.

In the subsequent analysis, we simulate the reverse auction for $N^{s}=100$ draws of reservation values. On average across simulation draws, our estimates imply that the average commercial TV station has a cash flow value of $\$ 45.4$ million and that the average TV station has a stick value of $\$ 4.9$ million. For $34.6 \%$ of TV stations, the reservation value is given by the stick value rather than the cash flow value as the former is higher, and the average TV station has a reservation value of $\$ 40.8$ million.

To illustrate our estimates, Figure 2 shows a sample draw of reservation values for the $23 \mathrm{TV}$ stations in the Philadelphia, PA, DMA. We label the TV stations by their network affiliation, order them by their reservation values (left axis), and overlay their advertising revenues (right

non-major network affiliate with a cash flow of less than $\$ 1$ million. Regardless of network affiliation, we also classify a transaction as based on stick value if the TV station has a negative cash flow. Finally, we classify a transaction that would have implied a stick value greater than $\$ 4$ per $\mathrm{MHz}$-pop to be based on cash flow and a transaction that would have implied a cash flow multiple greater than 30 to be based on stick value. We drop 16 transactions that do not fit these criteria.

${ }^{50}$ Because the NAB data is only available through 2012, we cannot estimate a year fixed effect for 2015 and instead hold it fixed at the year fixed effect for 2012 . 
Figure 2: Sample draw of reservation values for TV stations in Philadelphia, PA, DMA

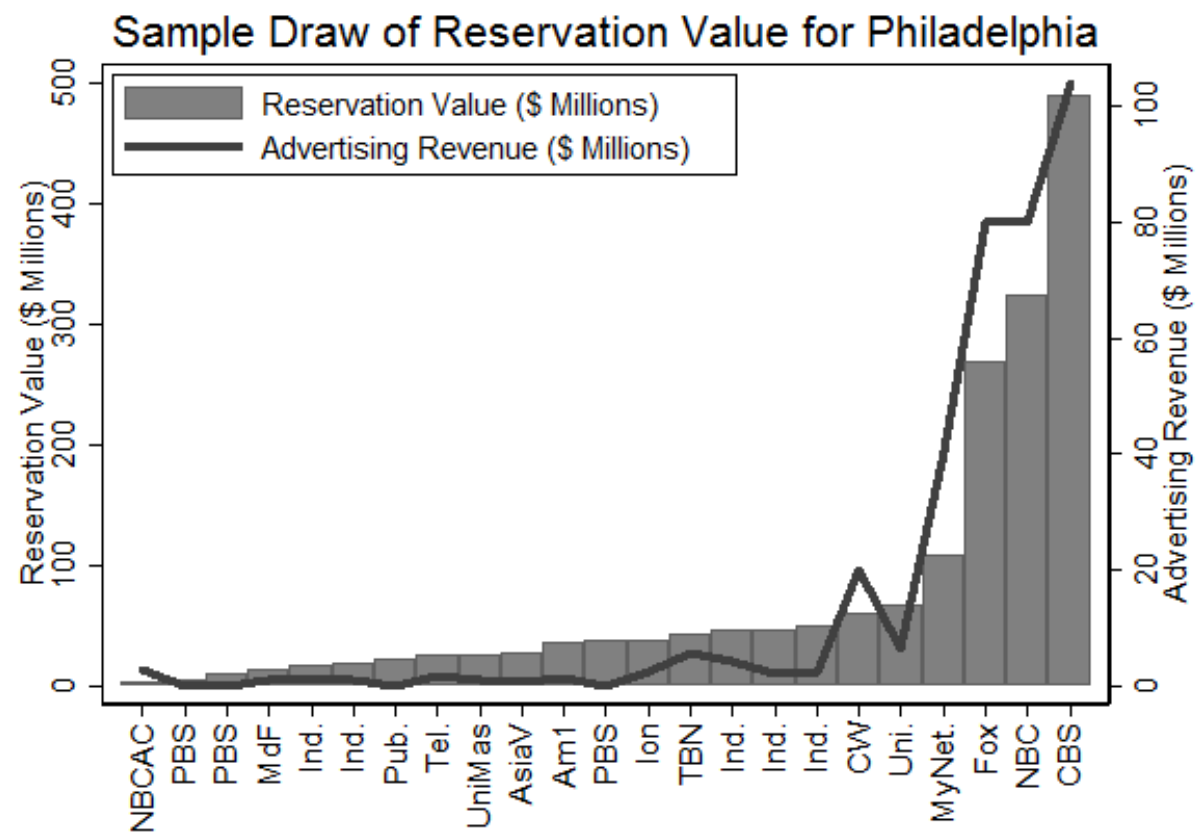

axis) in 2012 from the BIA data. ${ }^{51}$ It is immediately apparent that reservation values correlate with advertising revenues and network affiliation. In addition, it is clear that reservation values can differ greatly across TV stations, even within a DMA.

\subsection{Simulation exercise}

As described in Section 2, the repacking process takes place at the national level. Through a series of domino effects in the interference constraints, it is possible, although perhaps unlikely, that as a TV station in New York, NY, opts to remain on the air, it freezes a TV station in Los Angeles, CA, that can no longer be guaranteed a channel in the next round of the reverse auction. Checking the feasibility of repacking a set $X$ of TV stations into a set $R$ of available channels is a computationally challenging (NP-hard) problem that can easily take hours to run. Indeed, despite its considerable computational resources, on June 14, 2016 the FCC had to delay round 22 of stage 1 of the reverse auction because it failed to solve the problem on time. ${ }^{52}$

Our goal is to enumerate all equilibria of the reverse auction in order to assess the scope for strategic supply reduction and quantify its impact on the outcome of the reverse auction. To do so, we have to simulate the reverse auction under the very large number of strategy profiles that arise because of the large number of jointly owned TV stations, each of which has the strategy space

\footnotetext{
${ }^{51}$ WPVI-TV (facility ID 8616), the Philadelphia ABC affiliate, is a VHF station and therefore not included in Figure 2 .

${ }^{52}$ See https://auctiondata.fcc.gov/public/projects/1000/reports/reverse_announcements, accessed on December 9, 2016.
} 
$b_{j} \in\left\{0, s_{j}, 900\right\}$ (see Section 3). Moreover, we have to repeat these simulations for $N^{s}$ draws of reservation values to account for randomness; below we choose $N^{s}=100$. In contrast, the FCC ran the reverse auction only one time, pausing occasionally to move to the forward auction and assess the final stage rule.

As a step towards making the analysis computationally feasible, we take a regional approach to the repacking problem as follows: given a "focal" DMA, we define its "region" as the set of all DMAs in which at least one TV station has an interference constraint with at least one TV station in the focal DMA. We simulate the reverse auction restricting the repacking problem to TV stations in the region. ${ }^{53}$ This breaks up the national problem into multiple regional problems, one for each focal DMA. Our regional approach is in line with the fact that the FCC's feasibility checker SATFC prioritizes local solutions to the repacking problem, holding fixed the assignments of TV stations with no direct interference constraint with a TV station that is being repacked while looking for a new solution (Frechette, Newman and Leyton-Brown, 2016, Section 4.1). ${ }^{54}$ Throughout, the object of interest is the outcome of the reverse auction in the focal DMA, which we then aggregate to the national level and take statistics across our draws of reservation values.

We base our definition of a region on the interference constraints for the 1,670 UHF stations and UHF channels 14-29 that are available for repacking under the $126 \mathrm{MHz}$ clearing target. This definition is invariant to alternative clearing targets. Figure 3 shows the 127 TV stations located in the Philadelphia, PA, region. Of those, 23 are in the Philadelphia, PA, DMA (denoted by red pins in Figure 3), while 104 are located outside the Philadelphia, PA, DMA (yellow and green pins) in one of the following DMAs: Baltimore, MD, Binghamton, NY, Elmira, NY, Harrisburg-LancasterLebanon-York, PA, Harrisonburg, VA, Hartford-New Haven, CT, Johnstown-Altoona, PA, New York, NY, Providence, RI-New Bedford, MA, Salisbury, MD, Washington, DC, and Wilkes BarreScranton, PA. Moreover, 26 of the TV stations located outside the Philadelphia, PA, DMA do not have an interference constraint with any TV station located inside the Philadelphia, PA, DMA (green pins); they are nevertheless part of the Philadelphia, PA, region and may thus affect the price for a TV station in the Philadelphia, PA, DMA.

Table 6 covers all 204 DMAs and shows that a region is generally much larger than a DMA. We compare a focal DMA to its region in terms of number of TV stations and area in square miles. ${ }^{55}$ On average, a region covers about 10 DMAs and has about 15 as many TV stations and is about 15 times larger in area than the focal DMA. ${ }^{56}$

Beyond repacking regions, a further input into the simulations is the set of participating stations.

\footnotetext{
${ }^{53}$ To speed up the computations and decrease the amount of memory overhead required for large-scale parallel computing, we use Perl scripts to create region-specific domain and pairwise interference files.

${ }^{54}$ See also http://conference.nber.org/confer/2017/AIf17/Milgrom_Tadelis.pdf, accessed on March 18, 2018.

${ }^{55}$ See Sood (2018) for crosswalk between DMAs and zip codes. We obtain zip code area from the Missouri Census Data Center, MABLE/Geocorr14: Geographic Correspondence Engine, at http://mcdc.missouri.edu/websas/ geocorr14.html, accessed on July 22, 2018.

${ }^{56}$ Eleven DMAs coincide with their region. These are El Paso, TX, Medford-Klamath Falls, OR, Missoula, MT, Grand Junction-Montrose, CO, Casper-Roverton, WY, Eureka, CA, Laredo, TX, North Platte, NE, Anchorage, AK, Honolulu, HI, and Fairbanks, AK.
} 


\section{Figure 3: Repacking region for Philadelphia, PA, DMA}

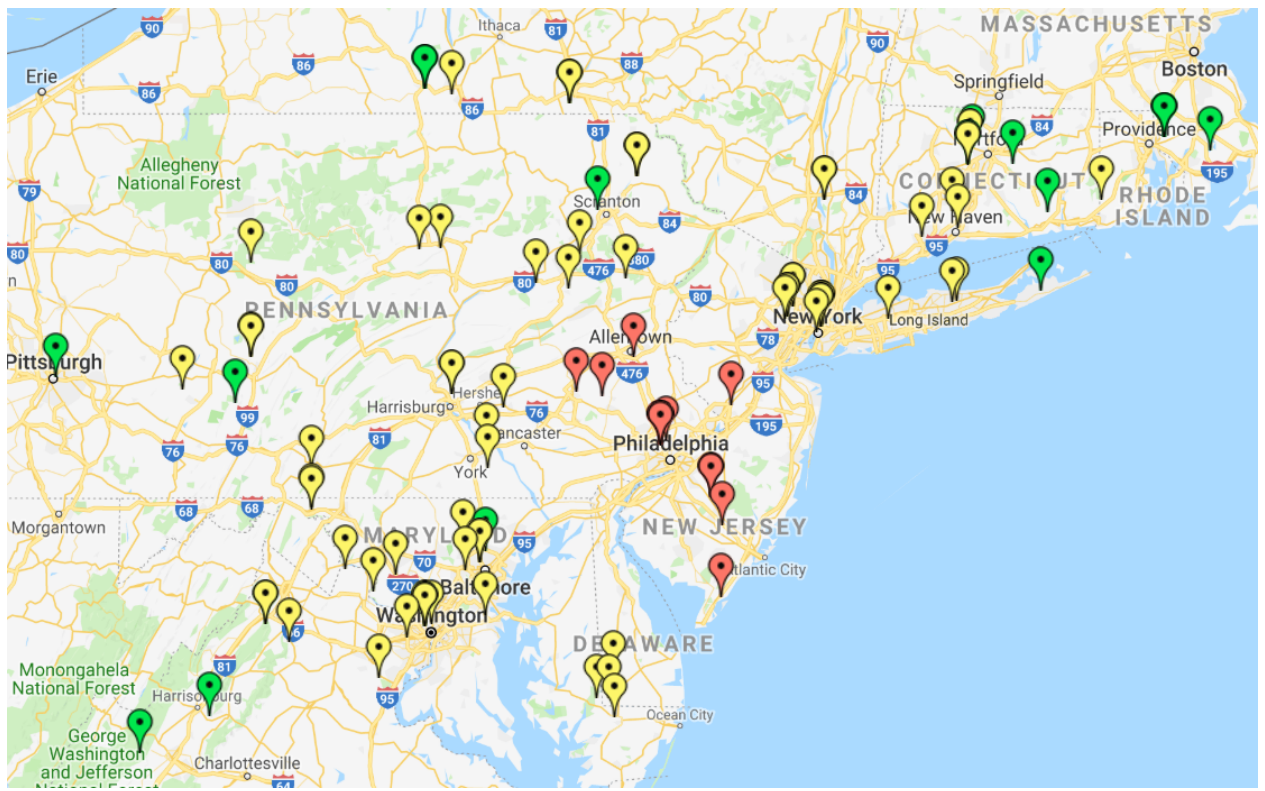

Notes: Each pin represents the facility location of an auction-eligible UHF broadcast TV station in the Philadelphia, PA, repacking region. Red pins denote stations in the Philadelphia, PA, DMA; yellow pins stations in other DMAs that have at least one interference constraint with a Philadelphia station; and green pins stations in the repacking region that do not have any interference constraint with a Philadelphia station.

Table 6: Repacking regions for all 204 DMAs

\begin{tabular}{lcccccc}
\hline & & & \multicolumn{3}{c}{ Quartile } & \\
\cline { 5 - 6 } & Mean & Min & First & Second & Third & Max \\
\hline Number of DMAs per region & 9.8 & 1 & 5 & 10 & 14 & 24 \\
Ratio between region and focal DMA: & & & & & \\
\hline Number of TV stations & 15.7 & 1 & 5.7 & 10.4 & 18.9 & 127 \\
Area (square miles) & 14.9 & 1 & 6.3 & 11.4 & 18.1 & 142.8 \\
\hline
\end{tabular}


We assume that all 1,670 UHF stations participate in the reverse auction. This likely overstates participation. The FCC has long worried that potentially "sentimental" owners, in particular, of religious or college-affiliated stations may be motivated by considerations besides profitability and not participate in the reverse auction. ${ }^{57}$ In the popular press, several chains of commercial TV stations have shown little interest in the reverse auction, with the CEO of Sinclair Broadcasting Group, which operates 98 of the 1,670 UHF stations in 2015, declaring that he "hasn't heard of any broadcaster who has said they have anything for sale." ${ }^{58}$ In Section 8.1 we show that reduced participation can easily double payouts in the reverse auction, even in the absence of strategic supply reduction. The assumption of full participation underlying in our main results is therefore very conservative.

Our baseline is the outcome of the reverse auction under naive bidding, where we ignore the ownership patterns in the data and counterfactually treat all TV stations as independently owned. Hence, TV station $j$ bids $b_{j}=s_{j}=\frac{v_{j}}{\varphi_{j}}$, where $v_{j}$ is its reservation value and $\varphi_{j}$ its broadcast volume. We simulate the reverse auction under naive bidding for $N^{s}=100$ draws of reservation values. In Online Appendix D, we provide pseudo code for our algorithm.

We contrast naive bidding with strategic bidding, where we account for the ownership patterns in the data and allow the owner of a jointly owned TV station $j$ located inside the focal DMA to either bid truthfully $b_{j}=s_{j}$ or overbid $b_{j}=900 .{ }^{59}$ To limit the number of strategy profiles that arise, we assume that a TV station $j$ located outside the focal DMA bids truthfully $b_{j}=s_{j} .{ }^{60}$ This assumption is conservative in that it restricts a multi-license owner's ability to strategically reduce supply to the focal DMA. In Section 8.2 we show that abandoning this assumption and allowing for multi-market strategies can greatly increase the scope for strategic supply reduction and the payouts in the reverse auction.

To simulate the reverse auction under strategic bidding, we modify our algorithm. Recall that, as the reverse auction progresses, each time an active TV station opts to remain on the air, the FCC invokes $S A T F C$ to check if it can still repack any remaining active TV station. We limit this check to any remaining active TV station located in the focal DMA. We further pre-assign to frozen status any TV station located outside the focal DMA that has been frozen at the conclusion of the reverse auction under naive bidding; these TV stations therefore cannot freeze another TV station. In Online Appendix D, we provide pseudo code for the modified algorithm. The primary advantage of this limited repacking is that the computational burden, while still significant as we discuss below, falls by a factor of nearly 10 relative to full repacking. ${ }^{61}$ In Appendix D we show

\footnotetext{
${ }^{57}$ See http://www.tvnewscheck.com/article/73196/wheeler-auction-onceinalifetime-chance, accessed on March 18, 2018.

58 "FCC can auction spectrum, but will broadcasters sell?", Joe Flint, The Los Angeles Times, February 17, 2012.

${ }^{59}$ Example 2 in Section 3.1 shows that underbidding $b_{j}=0$ can also be part of an equilibrium of the reverse auction. In Online Appendix E, we investigate the importance of underbidding for the computationally manageable Washington, DC, DMA. We show that underbidding is not essential for spanning the set of equilibrium payouts and we thus rule it out as a strategy going forward. This restriction greatly reduces the computational burden.

${ }^{60}$ We further assume that a multi-license owner does not overbid $b_{j}=900$ on all its TV stations $j$ that are located inside the focal DMA.

${ }^{61}$ For comparison, the average time for a simulation of the reverse auction under naive bidding and full repacking
} 
Table 7: Top ten computationally most demanding DMAs

\begin{tabular}{ccccc}
\hline DMA & $\begin{array}{c}\text { TV } \\
\text { stations }\end{array}$ & $\begin{array}{c}\text { Multi-license } \\
\text { owners }\end{array}$ & $\begin{array}{c}\text { Jointly owned } \\
\text { TV stations }\end{array}$ & $\begin{array}{c}\text { Strategy } \\
\text { profiles }\end{array}$ \\
\hline Pittsburgh, PA & 20 & 3 & 13 & 4,599 \\
Santa Barbara, CA & 16 & 4 & 12 & 2,205 \\
Yakima, WA & 16 & 4 & 12 & 1,953 \\
San Francisco, CA & 23 & 6 & 13 & 1,701 \\
Los Angeles, CA & 28 & 4 & 11 & 945 \\
Philadelphia, PA & 23 & 6 & 12 & 729 \\
Fort Smith, AR & 14 & 3 & 10 & 567 \\
Austin, TX & 16 & 1 & 9 & 511 \\
Norfolk, VA & 14 & 2 & 9 & 281 \\
Honolulu, HI & 20 & 3 & 9 & 315 \\
\hline
\end{tabular}

that nationwide payouts under limited repacking differ from those under full repacking by $0.2 \%$ under naive bidding and the $126 \mathrm{MHz}$ clearing target and by $3.2 \%$ under naive bidding and the $84 \mathrm{MHz}$ clearing target, reflecting the larger amount of repacking that occurs under the $84 \mathrm{MHz}$ clearing target as more TV stations remain on the air. Simulations for select DMAs under strategic bidding and the $126 \mathrm{MHz}$ clearing target suggest a similar error.

Given a draw of reservation values, we determine that a strategy profile is an equilibrium of the reverse auction if no multi-license owner can unilaterally and profitably deviate to another strategy profile. We use the same $N^{s}=100$ draws of reservation values as above. With no or one multi-license owner in a DMA, there is a unique equilibrium by construction. With more than one multi-license owner, there may be multiple equilibria, and we enumerate all of them. Given the large number of equilibria and the fact that many of them entail identical payouts to all TV stations despite possibly differing bids, we limit attention to "payout-unique equilibria." That is, we collapse multiple equilibria with identical payouts to all TV stations into a single payout-unique equilibrium. We illustrate this concept further in discussing our results in Section 7.

Despite the numerous assumptions and simplifications, our simulation exercise is near the bound of what can be achieved in a reasonable amount of time. The 1,670 TV stations are located in 204 DMAs. Table 7 lists the top ten computationally most demanding DMAs. It provides the number of TV stations, the number of multi-license owners and the number of jointly owned TV stations in the focal DMA and its region, along with the number of strategy profiles to be considered. The Pittsburgh, PA, DMA has 4,599 strategy profiles, each of which requires a run of the "regionalized" reverse auction for each simulation draw. Across all 204 DMAs, the total number of strategy profiles is 17,316 . Scaling this up by $N^{s}=100$ draws of reservation values requires $1,731,600$ runs of the reverse auction. To give a sense of the computational burden of our exercise, we note that simulating the reverse auction under the $84 \mathrm{MHz}$ clearing target for those 1,731,600 runs alone took a total of 6,533 CPU-days.

is 941.80 seconds, but only 131.71 seconds under limited repacking. 


\section{Results}

\subsection{Case study: Philadelphia, PA, DMA}

We use the Philadelphia, PA, DMA as a case study to illustrate how we compare the outcome of the reverse auction under naive bidding with the outcome under strategic bidding and to highlight important features of the subsequent analysis. Figure 4 shows a sample draw of reservation values for the $23 \mathrm{TV}$ stations in the Philadelphia, PA, DMA along with the outcomes of the reverse auction under naive bidding and the $126 \mathrm{MHz}$ clearing target and in two equilibria under strategic bidding. All three panels show reservation values and payouts (in \$ million) in light and dark gray, respectively, on the left axis. As in Figure 2, we label the TV stations by their network affiliation and order them by their reservation values. On the right axis, we account for the broadcast volumes of the TV stations and display their corresponding bids and payouts in terms of the base clock price (in $\$$ ) as rectangles and triangles, respectively. Recall from Section 3 that a bid is the critical value of the base clock price above which a TV station continues in the reverse auction.

Panel (a) of Figure 4 shows the outcome under naive bidding. As can be seen, 15 TV stations relinquish their licenses in exchange for payment. Panels (b) and (c) visualize the two equilibria, where we identify TV stations that are withheld from the reverse auction with bids of $\$ 900$. The first equilibrium highlights that strategic supply reduction by multi-license owners can lead to a larger number of TV stations being sold under strategic bidding than under naive bidding. The second equilibrium highlights that strategic supply reduction can lead to the same TV stations being sold, but at higher prices. In what follows, we provide further details on these equilibria.

Equilibrium 1. In the first equilibrium, displayed in Panel (b) of Figure 4, NRJ withholds AM1 (facility ID 74464, reservation price $\$ 34.80$ million) from the reverse auction and LocusPoint withholds its independent station (facility ID 72278 , reservation price $\$ 49.82$ million). A larger number of TV stations sells than under naive bidding: while AM1 sells under naive bidding but not under strategic bidding, three TV stations-MdF, MyNetwork TV, and UniMas (facility IDs 167540, 73879, and 74216) - sell under strategic bidding but not under naive bidding.

Both NRJ and LocusPoint increase their profits, the total proceeds from the auction less the reservation values of any surrendered stations, through strategic supply reduction. Relative to naive bidding, NRJ foregoes a payout of $\$ 72.3$ million, translating into foregone profit of $\$ 37.5$ million, on AM1. In return, the firm collects an additional payout and thus profit of $\$ 43.5$ million on its independent station (facility ID 55305, reservation price $\$ 46.5$ million), driven by an increase in the freezing base clock price from $\$ 221.79$ to $\$ 298.15$.

LocusPoint, by withholding its independent station, raises the freezing base clock price for its Atlantic City NBC affiliate (facility ID 61111, reservation price $\$ 2.10$ million) from $\$ 72.66$ to $\$ 221.79$, an equivalent payout and profit increase of $\$ 23.8$ million. ${ }^{62}$ This equilibrium exemplifies

\footnotetext{
${ }^{62}$ The forgone profit to NRJ on AM1 is calculated as $(\$ 221.79 \cdot .33-\$ 34.80)$ million $=\$ 37.5$ million, where .33 is AM1's broadcast volume in millions, and the increased profit on its independent station as $(\$ 298.15-\$ 221.79) \cdot .57$ million $=\$ 43.5$ million. The increased profit to LocusPoint on its Atlantic City NBC affiliate is calculated as
} 
two sources of gains from strategic supply reduction: in NRJ's case, strategic supply reduction reduces the number of TV stations that the multi-license owner sells. In LocusPoint's case, in contrast, the multi-license owner withholds a TV station that does not sell regardless, which is nevertheless valuable as it changes the repacking process from the beginning of the reverse auction, relative to naive bidding. Strategic supply reduction also increases payouts to several other TV stations. Payouts in the Philadelphia, PA, DMA go from nearly $\$ 1.7$ billion for 15 TV stations under naive bidding to over $\$ 2.5$ billion for $17 \mathrm{TV}$ stations in this equilibrium under strategic bidding.

Equilibrium 2. In the second equilibrium, displayed in Panel (c) of Figure 4, LocusPoint again withholds its independent station (facility ID 72278) and Univision withholds UniMas (facility ID 74216 , reservation price $\$ 25.7$ million) from the reverse auction. The same TV stations sell as under naive bidding, but at weakly higher prices. LocusPoint experiences an increased payout and profit to its Atlantic City NBC affiliate (facility ID 61111 ) by $\$ 4.4$ million. While Univision does not witness an increased payout, overall, payouts in the Philadelphia, PA, DMA increase from $\$ 1.7$ billion to $\$ 1.8$ billion for the same $15 \mathrm{TV}$ stations as under naive bidding.

Figure 4 illustrates the reverse auction for a sample draw of reservation values and two of the multiple equilibria that arise under strategic bidding. In the Philadelphia, PA, DMA, the average number of payout-unique equilibria across simulation draws is 2.2 , ranging from one to five. In the subsequent analysis, we therefore repeat the above exercise for all 204 DMAs, accounting for randomness in the estimated reservation values via simulation and enumerating all payout-unique equilibria.

\subsection{Naive versus strategic bidding}

In comparing the outcomes of the reverse auction under naive and strategic bidding across all 204 DMAs, we have to account for the fact that there may be multiple payout-unique equilibria in a given DMA under strategic bidding. Under the $84 \mathrm{MHz}$ clearing target, there are 1.09 payoutunique equilibria on average across DMAs and simulation draws, ranging from 1 to 18. For the 125 DMAs with multi-license owners, the average number of payout-unique equilibria is 1.14 . On average, one payout-unique equilibrium summarizes 46.5 underlying equilibrium strategy profiles. ${ }^{63}$

In many of the equilibria under strategic bidding, strategic supply reduction plays no role: on average across DMAs and simulation draws, there are just 0.22 payout-unique equilibria that have payouts that differ from those under naive bidding. At the same time, however, there is significant heterogeneity across DMAs in the prevalence of equilibria that are sustained only by strategic supply reduction, in line with our result below that the impact of strategic supply reduction on payouts is concentrated in a select set of DMAs. Consider, for example, Pittsburgh, PA, the DMA with

$(\$ 221.79-\$ 72.66) \cdot .16$ million $=\$ 23.8$ million.

${ }^{63} \mathrm{In} 0.06 \%$ of runs of the reverse auction, corresponding to up to three out of 100 simulation draws in seven out of 204 DMAs, there is no pure strategy equilibrium under strategic bidding and we thus revert to naive bidding. 
Figure 4: Sample outcomes for Philadelphia, PA, DMA, $126 \mathrm{MHz}$ clearing target (a) Naive Bidding

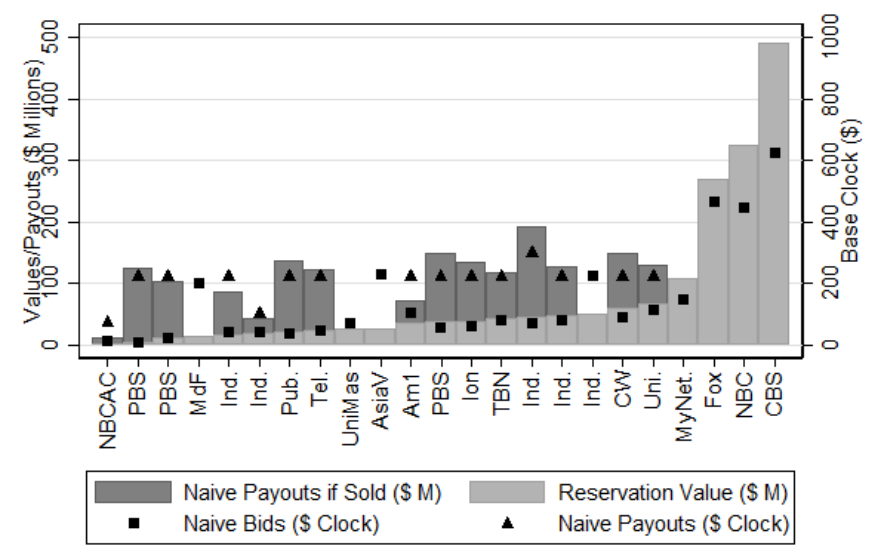

(b) Strategic Bidding, Equilibrium 1

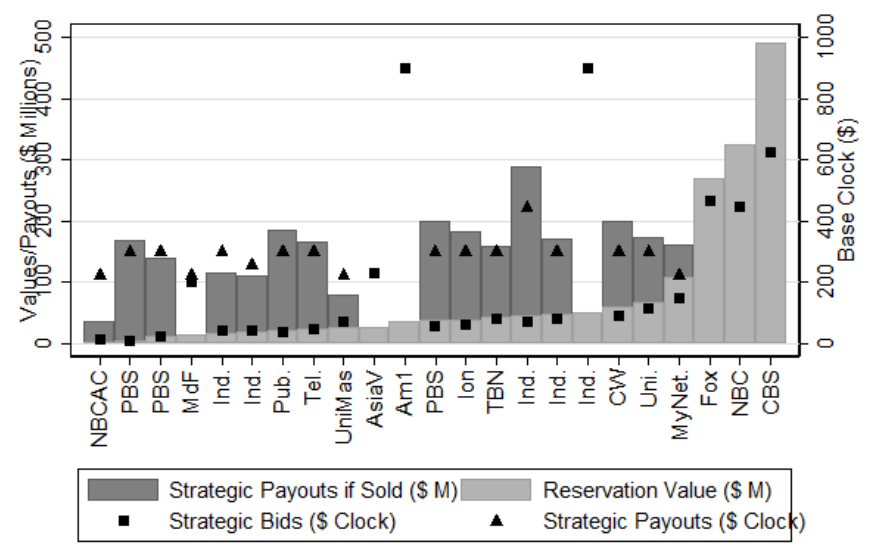

(c) Strategic Bidding, Equilibrium 2

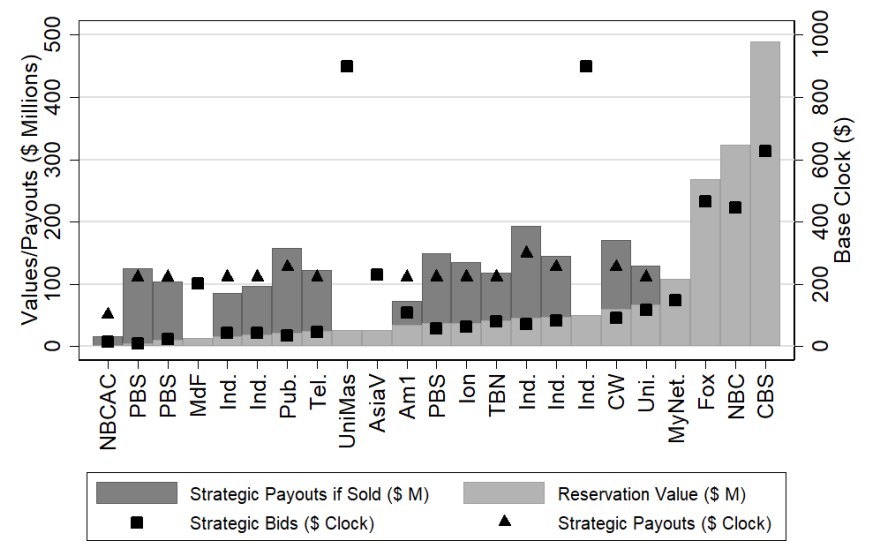


Table 8: Payouts to TV stations nationwide and by owner type

\begin{tabular}{|c|c|c|c|c|c|c|}
\hline \multirow[b]{2}{*}{ Payouts ( $\$$ billion) } & \multirow{2}{*}{$\begin{array}{c}\text { Naive } \\
\text { bidding }\end{array}$} & \multicolumn{4}{|c|}{ Strategic bidding } & \multirow{2}{*}{$\begin{array}{c}\text { Payout } \\
\text { increase at } \\
\text { mean }(\%)\end{array}$} \\
\hline & & Mean & Min & Median & Max & \\
\hline \multicolumn{7}{|c|}{ Panel A: $126 \mathrm{MHz}$ clearing target } \\
\hline \multirow[t]{2}{*}{ Nationwide (204 DMAs) } & 17.008 & 20.530 & 17.678 & 20.447 & 23.300 & 20.7 \\
\hline & $(0.740)$ & $(0.898)$ & $(2.087)$ & $(1.127)$ & $(1.686)$ & \\
\hline \multirow[t]{2}{*}{ Single-license owners } & 12.014 & 14.323 & 12.115 & 14.235 & 16.558 & 19.2 \\
\hline & $(0.498)$ & $(0.693)$ & $(1.564)$ & $(0.751)$ & $(1.487)$ & \\
\hline \multirow[t]{2}{*}{ Multi-license owners } & 4.993 & 6.208 & 5.503 & 6.225 & 6.866 & 24.3 \\
\hline & $(0.358)$ & $(0.379)$ & $(0.583)$ & $(0.458)$ & $(0.436)$ & \\
\hline \multicolumn{7}{|c|}{ Panel B: $84 \mathrm{MHz}$ clearing target } \\
\hline \multirow[t]{2}{*}{ Nationwide (204 DMAs) } & 4.003 & 4.281 & 4.186 & 4.280 & 4.381 & 7.0 \\
\hline & $(0.204)$ & $(0.258)$ & $(0.251)$ & $(0.261)$ & $(0.283)$ & \\
\hline \multirow[t]{2}{*}{ Single-license owners } & 3.005 & 3.197 & 3.133 & 3.195 & 3.265 & 6.4 \\
\hline & $(0.174)$ & $(0.217)$ & $(0.206)$ & $(0.217)$ & $(0.240)$ & \\
\hline \multirow[t]{2}{*}{ Multi-license owners } & 0.998 & 1.084 & 1.048 & 1.084 & 1.121 & 8.6 \\
\hline & $(0.092)$ & $(0.105)$ & $(0.108)$ & $(0.106)$ & $(0.112)$ & \\
\hline
\end{tabular}

Notes: Payouts to single- and multi-license owners add to nationwide payouts for mean (up to rounding error) but not for min, median, and max. Payout increase at mean calculated as percent difference between mean payouts under strategic and naive bidding.

the largest number of strategy profiles. Out of 4,599 strategy profiles, on average across simulation draws, 450.4 are equilibria. These 450.4 equilibria amount to an average of 3.34 payout-unique equilibria, 2.92 of which have payouts that differ from those under naive bidding.

To account for multiple payout-unique equilibria in a given DMA, we report on an aggregate outcome of interest such as nationwide payouts, payouts to different types of owners, or the number of TV stations acquired by the FCC as follows: for a given DMA, we first record the mean, minimum, median, and maximum of the outcome of interest across all payout-unique equilibria for a given draw of reservation values. We then sum these moments across DMAs as needed to get a national level. Finally, we average these sums across simulation draws. We also calculate standard deviations across simulation draws. Comparing the min and the max gives a sense of the importance of multiple equilibria. For the sake of brevity, in what follows we often just report the mean of an outcome of interest.

Payouts. Table 8 shows payouts to TV stations in the reverse auction under naive and strategic bidding and both the $84 \mathrm{MHz}$ and the $126 \mathrm{MHz}$ clearing targets, first nationwide and then broken down for single- and multi-license owners. ${ }^{64}$ Independent of the clearing target, strategic bidding raises nationwide payouts in the reverse auction. At the mean, strategic bidding increases nationwide payouts from $\$ 17.008$ billion to $\$ 20.530$ billion for the $126 \mathrm{MHz}$ clearing target, an increase

\footnotetext{
${ }^{64}$ In contrast to Section 5.1, in what follows we define a multi-license owner as a firm owning more than one TV station within the focal DMA.
} 
of $20.7 \%$, and from $\$ 4.003$ billion to $\$ 4.281$ billion for the $84 \mathrm{MHz}$ clearing target, an increase of $7.0 \%$.

The reduced scope for strategic bidding to raise nationwide payouts under the $84 \mathrm{MHz}$ clearing target reflects the skewed distribution of reservation values we illustrate in Figure 2 for the Philadelphia, PA, DMA. Under the lower clearing target, the number of TV stations acquired falls: we find that under strategic bidding on average across payout-unique equilibria and simulation draws, 378.5 TV stations are acquired to meet the $126 \mathrm{MHz}$ clearing target, but only $186.7 \mathrm{TV}$ stations are acquired to meet the $84 \mathrm{MHz}$ clearing target. Under the lower clearing target, the "marginal" TV station is in a flatter portion of the distribution of reservation values; as a result, withholding a TV station from the reverse auction has a smaller impact on payouts.

The remaining rows in Table 8 break down payouts for single- and multi-license owners. The payout increase from strategic bidding for multi-license owners is $24.3 \%$ and $8.6 \%$ under the 126 $\mathrm{MHz}$ and $84 \mathrm{MHz}$ clearing targets, respectively. This spills over to single-license owners, who do not engage in strategic supply reduction, but see a payout increase of $19.2 \%$ or $6.4 \%$ depending on the clearing target.

Heterogeneity in payouts. There is significant heterogeneity in payouts across DMAs. First of all, in many DMAs the FCC does not acquire any TV stations: there are an average of 90 and 140 DMAs that see payouts of zero across simulation draws under naive bidding and the $126 \mathrm{MHz}$ and $84 \mathrm{MHz}$ clearing targets respectively. Among the remaining DMAs, payouts are highly skewed. To illustrate, the 18 private equity active DMAs contribute $79.4 \%$ of nationwide payouts under naive bidding and the $84 \mathrm{MHz}$ clearing target. The ten DMAs listed in Table 9 similarly account for $\$ 3.3$ billion, or $82.7 \%$ of nationwide payouts.

The payout increases due to strategic bidding are equally concentrated, as Table 9 shows. The table displays the top ten DMAs in terms of gains from strategic bidding under the $84 \mathrm{MHz}$ clearing target. The Philadelphia, PA, DMA accounts for $26.2 \%$ of the average gains from strategic bidding; the next three most significant DMAs contribute $42.7 \%$. In all, the top ten markets generate $95.0 \%$ of the average gains from strategic bidding. Private equity firms are active in seven of these ten DMAs, with the exception of Milwaukee, WI, Washington, DC, and Hartford-New Haven, CT, although these markets are adjacent to other DMAs where they control licenses. While we do not present the breakdown, payouts and gains from strategic bidding under the $126 \mathrm{MHz}$ clearing target are similarly concentrated in a small number of DMAs.

To further investigate the sources of gains from strategic bidding, we decompose the DMA-level and nationwide gains into gains accruing to TV stations that sell under both naive and strategic bidding (labeled "always selling" in Table 10), to TV stations that sell only under strategic bidding ("newly selling"), and to TV stations that sell only under naive bidding ("no longer selling"). Table 10 reports this decomposition for the $84 \mathrm{MHz}$ clearing target along with the number of TV stations in each of the three categories, averaged across payout-unique equilibria and simulation draws. Across the ten DMAs listed, TV stations that sell under both naive and strategic bidding account 
Table 9: Payout gains from strategic bidding in top ten DMAs, $84 \mathrm{MHz}$ clearing target

\begin{tabular}{cccc}
\hline & \multicolumn{2}{c}{ Payouts $(\$$ billion $)$} & Cumulative \\
\cline { 2 - 3 } DMA & $\begin{array}{c}\text { Naive } \\
\text { bidding }\end{array}$ & $\begin{array}{c}\text { Payout } \\
\text { increase }\end{array}$ & $\begin{array}{c}\text { payout } \\
\text { increase }(\%)\end{array}$ \\
\hline Philadelphia, PA & 0.516 & 0.073 & 26.162 \\
Los Angeles, CA & 1.254 & 0.063 & 48.599 \\
San Francisco, CA & 0.383 & 0.040 & 62.892 \\
Milwaukee, WI & 0.107 & 0.017 & 68.862 \\
Washington, DC & 0.066 & 0.016 & 74.658 \\
Chicago, IL & 0.201 & 0.016 & 80.453 \\
Hartford, CT & 0.097 & 0.016 & 86.152 \\
New York, NY & 0.585 & 0.013 & 90.831 \\
Pittsburgh, PA & 0.029 & 0.006 & 92.997 \\
Boston, MA & 0.074 & 0.006 & 95.000 \\
\hline Top ten DMAs & 3.312 & 0.265 & 95.000 \\
Nationwide & 4.003 & 0.279 & \\
\hline
\end{tabular}

Notes: Payout increase due to strategic bidding calculated as difference between mean payouts under strategic and naive bidding. Cumulative payout increase is the cumulative share of nationwide payout increases due to strategic bidding in the DMA under consideration and all DMAs with larger payout increases.

for between $56.96 \%$ and $99.44 \%$ of payout increases, with an average of $79.39 \%$ across DMAs. Similarly, at the national level, always selling TV stations garner $81.67 \%$ of payout increases. The right panel of Table 10 shows that there are very few TV stations that sell only under strategic bidding or only under naive bidding; the vast majority of TV stations (96.49\% of the TV stations that sell under naive bidding at the national level) sell under both forms of bidding.

This suggests that in many equilibria strategic supply reduction does not significantly change the number and identity of the TV stations that sell, but increases the price at which these TV stations sell, similar to the second equilibrium in Section 7.1. Indeed, the average freezing base clock price indicates such price increases: we find that under naive bidding and the $84 \mathrm{MHz}$ clearing target, the average freezing base clock price is $\$ 48.02$, compared to $\$ 51.52$ under strategic bidding. Under the $126 \mathrm{MHz}$ clearing target, the respective prices are $\$ 109.23$ and $\$ 128.80$.

Model fit. We use the available data on the TV stations that relinquished their licenses in the reverse auction to investigate our simulations' ability to predict the auction's outcome. Our model correctly predicts a DMA as either having a positive payout or a zero payout with a probability of 0.84 on average across simulation draws under the $84 \mathrm{MHz}$ clearing target and either naïve or strategic bidding. This "hit rate" can be decomposed into a probability of 0.76 that we predict a DMA to have a positive payout conditional on the DMA actually having a positive payout in the reverse auction and a probability of .88 that we predict a DMA to have a zero payout conditional on the DMA actually having a zero payout. To put these probabilities in perspective, randomly 
Table 10: Decomposition of payout gains from strategic bidding in top ten DMAs by type of TV station, $84 \mathrm{MHz}$ clearing target

\begin{tabular}{|c|c|c|c|c|c|c|c|c|}
\hline \multirow[b]{2}{*}{ DMA } & \multicolumn{4}{|c|}{ Payout change ( $\$$ billion $)$} & \multicolumn{4}{|c|}{ Number of UHF TV stations } \\
\hline & Overall & $\begin{array}{l}\text { Always } \\
\text { selling }\end{array}$ & $\begin{array}{l}\text { Newly } \\
\text { selling }\end{array}$ & $\begin{array}{l}\text { No longer } \\
\text { selling }\end{array}$ & Total & $\begin{array}{l}\text { Always } \\
\text { selling }\end{array}$ & $\begin{array}{l}\text { Newly } \\
\text { selling }\end{array}$ & $\begin{array}{l}\text { No longer } \\
\text { selling }\end{array}$ \\
\hline Philadelphia, PA & 0.073 & 0.042 & 0.049 & -0.018 & 23 & 10.558 & 1.302 & 0.352 \\
\hline Los Angeles, CA & 0.063 & 0.050 & 0.022 & -0.009 & 28 & 11.129 & 0.299 & 0.231 \\
\hline San Francisco, CA & 0.040 & 0.038 & 0.010 & -0.008 & 23 & 10.277 & 0.326 & 0.273 \\
\hline Milwaukee, WI & 0.017 & 0.015 & 0.004 & -0.002 & 13 & 4.910 & 0.155 & 0.160 \\
\hline Washington, DC & 0.016 & 0.012 & 0.008 & -0.004 & 16 & 5.072 & 0.555 & 0.398 \\
\hline Chicago, IL & 0.016 & 0.015 & 0.003 & -0.002 & 21 & 6.225 & 0.105 & 0.075 \\
\hline Hartford, CT & 0.016 & 0.014 & 0.007 & -0.006 & 11 & 4.811 & 0.505 & 0.369 \\
\hline New York, NY & 0.013 & 0.013 & 0.002 & -0.002 & 24 & 8.695 & 0.030 & 0.035 \\
\hline Pittsburgh, PA & 0.006 & 0.005 & 0.004 & -0.003 & 20 & 4.625 & 0.594 & 0.635 \\
\hline Boston, MA & 0.006 & 0.006 & 0.003 & -0.003 & 20 & 6.090 & 0.326 & 0.250 \\
\hline Top ten DMAs & 0.265 & 0.210 & 0.112 & -0.057 & 199 & 72.392 & 4.198 & 2.778 \\
\hline Nationwide & 0.279 & 0.228 & 0.126 & -0.075 & 1671 & 179.378 & 7.340 & 6.522 \\
\hline
\end{tabular}

Notes: Payout change due to strategic bidding calculated as difference between mean payouts under strategic and naive bidding. For a given simulation draw and payout-unique equilibrium, we classify a TV station as always selling if it sells under both naive and strategic bidding, as newly selling if it sells only under strategic bidding, and as no longer selling if it only sells under naive bidding.

drawing 175 TV stations (the actual number that relinquished their licenses, see Section 2) yields a hit rate of 0.56 . Turning from DMAs to the TV stations themselves, we correctly predict a TV station as either selling or not selling with a probability of .89 on average under both naïve and strategic bidding. Taken together, this suggests that our model has some predictive ability.

Efficiency. There are potential efficiency losses from strategic bidding by multi-license owners to the extent that such behavior distorts the set of TV stations that relinquish their licenses in the reverse auction. As we cannot easily ascertain the social value of the re-purposed spectrum, we adopt a notion of constrained efficiency, similar to Milgrom and Segal (2018). In comparing two outcomes of the reverse auction for the same clearing target, we treat as the more efficient one the outcome that has the lower total reservation value of acquired TV stations or, equivalently, the higher total reservation value of TV stations that remain on the air. ${ }^{65}$ Not surprisingly, given the results in Table 10, we find that the total reservation value of acquired TV stations under naive and strategic bidding are very similar under both the $84 \mathrm{MHz}$ and the $126 \mathrm{MHz}$ clearing target. This reflects in part that approximately the same number of TV stations sell in the reverse auction under naive and strategic bidding, averaging across simulation draws to 185.90 under naive bidding and

\footnotetext{
${ }^{65}$ This notion of constrained efficiency suffers of a number of shortcomings. We use the estimated private reservation value of a TV station in lieu of its social value. This in particular neglects consumer surplus, e.g., due to broadcast variety, to the extent that it is not appropriated by the TV station.
} 
Table 11: Number of essential TV stations

\begin{tabular}{lcccc}
\hline & \multicolumn{3}{c}{ Strategic bidding } \\
\cline { 2 - 5 } & Mean & Min & Median & Max \\
\hline Panel A: 126 MHz clearing target & & & & \\
\hline Number of essential TV stations & 30.023 & 16.450 & 29.850 & 44.080 \\
& $(3.828)$ & $(3.264)$ & $(3.791)$ & $(6.093)$ \\
\hline Panel B: 84 MHz clearing target & & & & \\
\hline Number of essential TV stations & 17.324 & 10.130 & 17.265 & 24.640 \\
& $(3.414)$ & $(3.212)$ & $(3.476)$ & $(4.794)$ \\
\hline
\end{tabular}

the $84 \mathrm{MHz}$ clearing target and averaging across payout-unique equilibria and simulation draws to 186.72 under strategic bidding. Under the $126 \mathrm{MHz}$ clearing target, the average number of TV stations that sell is 378.90 under naive bidding and 378.50 under strategic bidding. While we thus do not find a sizable distortion in the set of TV stations that relinquish their licenses in the reverse auction, there is of course a substantial transfer from the government - and ultimately taxpayers - to TV stations. There is furthermore a risk that strategic bidding by multi-license owners causes a stage of the incentive auction to fail, leading to a reduction of the clearing target and thus the amount of spectrum that is re-purposed in the incentive auction. ${ }^{66}$

Bidding behavior. The results so far highlight the payout implications of strategic supply reduction. They do not, however, speak to the changes in behavior that underpin these gains. Investigating how different the behavior under strategic bidding is from that under naive bidding is difficult because many TV stations do not sell, regardless of whether they bid truthfully $b_{j}=s_{j}$ or overbid $b_{j}=900$. Hence, simply counting the number of withheld TV stations in a given equilibrium is not a meaningful measure of differences in behavior. We therefore say that a TV station is essential to a payout-unique equilibrium if and only if that TV station overbids $b_{j}=900$ in all equilibria underlying that payout-unique equilibrium. If a TV station is not essential, then there are some underlying equilibria where the TV station is withheld and some where it is not, and yet the payouts to all TV stations remain the same.

Of the 1,670 UHF stations, 344 belong to a chain within the same DMA and can thus be part of a supply reduction strategy. Table 11 shows that in comparison, the number of essential TV stations is small, even for the payout-unique equilibria with the most essential TV stations. On average across payout-unique equilibria and simulation draws, there are 17.32 and 30.02 essential TV stations under the $84 \mathrm{MHz}$ and $126 \mathrm{MHz}$ clearing targets. Thus, withholding even a few TV stations from the reverse auction suffices to give rise to equilibria that have significantly higher payouts than those under naive bidding. In this sense, the outcome to the reverse auction is sensitive to small changes in bidding behavior.

\footnotetext{
${ }^{66}$ As the forward auction is outside of the scope of this paper, we cannot further quantify this risk.
} 
Private equity firms. The private equity firms acquired TV stations that frequently set the price for other TV stations in the reserve auction. The private equity firms own $2.6 \%$ of the 1,670 UHF stations. Under naive bidding and the $84 \mathrm{MHz}$ clearing target, their TV stations set the price for, on average across simulations, 16.14 other TV stations, or $8.7 \%$ of all frozen TV stations. As we document in Section 5.2, the private equity firms acquired TV stations with relatively high broadcast volumes, interference free populations, and interference counts. The unexpectedly large number of freezes may therefore reflect station characteristics. We investigate this possibility by regressing the average number of freezes at the station-level on flexible polynomial expansions of the TV station's broadcast volume and interference free population, along with an indicator for whether the TV station is owned by a private equity firm. Even after controlling for station characteristics, the private equity firms own TV stations that are responsible for an additional 0.19 freezes over the average TV station, a sizable effect amounting to 0.61 standard deviations in the number of freezes. We find a comparable effect under strategic bidding.

We also find that the private equity firms we study were likely to acquire essential licenses that were pivotal in changing equilibrium payouts. Ranking licenses descendingly by the frequency with which they are essential to a payout-unique equilibrium under the $84 \mathrm{MHz}$ clearing target, we find that the private equity firms, in particular NRJ and OTA, own eight of the top 15 licenses. These amount to 28.6 percent and 20 percent of NRJ and OTA's overall license holdings.

Not surprisingly, the private equity firms benefit significantly from the reverse auction under both forms of bidding. Even under naive bidding, as Table 12 shows, we estimate that NRJ and OTA recover most or all of their acquisition costs with payouts from the reverse auction, while selling about one third of the acquired TV stations. LocusPoint recovers $35.9 \%$ of its acquisition costs from the sale of $19 \%$ of the acquired TV stations. Payouts from the reverse auction plus the value of unsold licenses thus substantially exceed the firms' total acquisition costs. Table 12 also shows that the private equity firms experience sizable payout increases from strategic bidding, ranging from $5.2 \%$ to $47.0 \%$ across firms. Taken together, the private equity firms garner $14.52 \%$ of the gains from strategic bidding, despite the fact that they own $2.6 \%$ of the 1,670 UHF stations.

\subsection{Auction design: Restriction on multi-license owners}

We have so far shown that strategic supply reduction leads to a substantial transfer from the government to TV stations. To highlight how our model can be used in designing future auctions, we consider a simple change in the auction rules that mitigates the payout increase from strategic bidding. In particular, we investigate how a restriction on the bids of multi-license owners affects their ability to exploit the joint ownership of TV stations.

Example 1 in Section 3.1 suggests that strategic supply reduction is more likely to be profitable if the increase in the base clock price from withholding a TV station can be leveraged by selling another TV station with high broadcast volume. To weaken this mechanism, we stipulate that to withhold a TV station with a lower broadcast volume, a multi-license owner must also withhold any other TV station with a higher broadcast volume. This restriction exploits the fact that broadcast 
Table 12: Private equity firms' payouts and sales of TV stations, $84 \mathrm{MHz}$ clearing target

\begin{tabular}{|c|c|c|c|c|c|c|}
\hline & \multirow{2}{*}{$\begin{array}{c}\text { Purchase } \\
\text { price } \\
(\$ \text { million })\end{array}$} & \multicolumn{2}{|c|}{ Naive bidding } & \multicolumn{2}{|c|}{ Strategic bidding } & \multirow{2}{*}{$\begin{array}{c}\text { Payout } \\
\text { increase at } \\
\text { mean }(\%)\end{array}$} \\
\hline & & $\begin{array}{l}\text { Number TV } \\
\text { stations sold }\end{array}$ & $\begin{array}{c}\text { Payout } \\
(\$ \text { million })\end{array}$ & $\begin{array}{l}\text { Number TV } \\
\text { stations sold }\end{array}$ & $\begin{array}{c}\text { Payout } \\
(\$ \text { million })\end{array}$ & \\
\hline NRJ & $\begin{array}{l}235.51 \\
(\mathrm{n}=14)\end{array}$ & $\begin{array}{c}5.40 \\
(1.24)\end{array}$ & $\begin{array}{l}198.711 \\
(41.065)\end{array}$ & $\begin{array}{c}5.40 \\
(1.23)\end{array}$ & $\begin{array}{c}225.878 \\
(51.250)\end{array}$ & 13.672 \\
\hline LocusPoint & $\begin{array}{l}54.75 \\
(\mathrm{n}=9)\end{array}$ & $\begin{array}{c}1.72 \\
(0.95)\end{array}$ & $\begin{array}{c}19.668 \\
(22.682)\end{array}$ & $\begin{array}{c}2.10 \\
(1.08)\end{array}$ & $\begin{array}{c}28.917 \\
(25.940)\end{array}$ & 47.030 \\
\hline OTA & $\begin{array}{l}77.05 \\
(\mathrm{n}=20)\end{array}$ & $\begin{array}{c}6.26 \\
(1.52)\end{array}$ & $\begin{array}{l}110.843 \\
(24.703)\end{array}$ & $\begin{array}{c}5.93 \\
(1.38)\end{array}$ & $\begin{array}{l}116.559 \\
(22.663)\end{array}$ & 5.157 \\
\hline
\end{tabular}

Notes: Payout increase due to strategic bidding calculated as difference between mean payouts under strategic and naive bidding.

volume is observable and contractible, in the spirit of the literature on regulation (Laffont and Tirole, 1986). However, we set aside legal considerations the FCC may face in implementing a similar rule change.

Table 13 shows how the rule change affects our main results in Table 8 . The payout increase from strategic bidding is between $62 \%$ and $80 \%$ less than in Table 8, depending on the clearing target. The rule change mitigates payout increases by requiring that multi-license owners first withdraw TV stations with higher broadcast volumes that likely also have higher reservation values. Our estimates imply that, on average across simulation draws, the correlation between broadcast volume and reservation value is 0.47 for the 1,670 UHF stations. Interestingly, the rule change also renders the two equilibria discussed in Section 7.1 for the Philadelphia, PA, DMA infeasible, since there both multi-license owners withhold the TV station with the lower broadcast volume from the reverse auction.

Table 13: Payouts to TV stations nationwide and by DMA type under restriction on multi-license owners

\begin{tabular}{lcccccc}
\hline & Naive & \multicolumn{3}{c}{ Strategic bidding } & \multirow{2}{*}{$\begin{array}{c}\text { Payout } \\
\text { increase at } \\
\text { mean (\%) }\end{array}$} \\
\cline { 3 - 5 } Payouts $(\$$ billion $)$ & bidding & Mean & Min & Median & Max & \\
\hline Panel A: 126 MHz clearing target & & & & & \\
\hline Nationwide (204 DMAs) & 17.008 & 17.734 & 17.088 & 17.825 & 18.343 & \\
& $(0.740)$ & $(0.753)$ & $(0.738)$ & $(0.840)$ & $(0.833)$ & \\
\hline Panel B: 84 MHz clearing target & & & & & \\
\hline Nationwide (204 DMAs) & 4.003 & 4.118 & 4.093 & 4.116 & 4.145 & \\
& $(0.204)$ & $(0.233)$ & $(0.228)$ & $(0.231)$ & $(0.244)$ & \\
\hline
\end{tabular}

Notes: Payout increase at mean calculated as percent difference between mean payouts under strategic and naive bidding. 
Figure 5: Payouts to TV stations in Philadelphia, PA, DMA under alternative interference levels and clearing targets

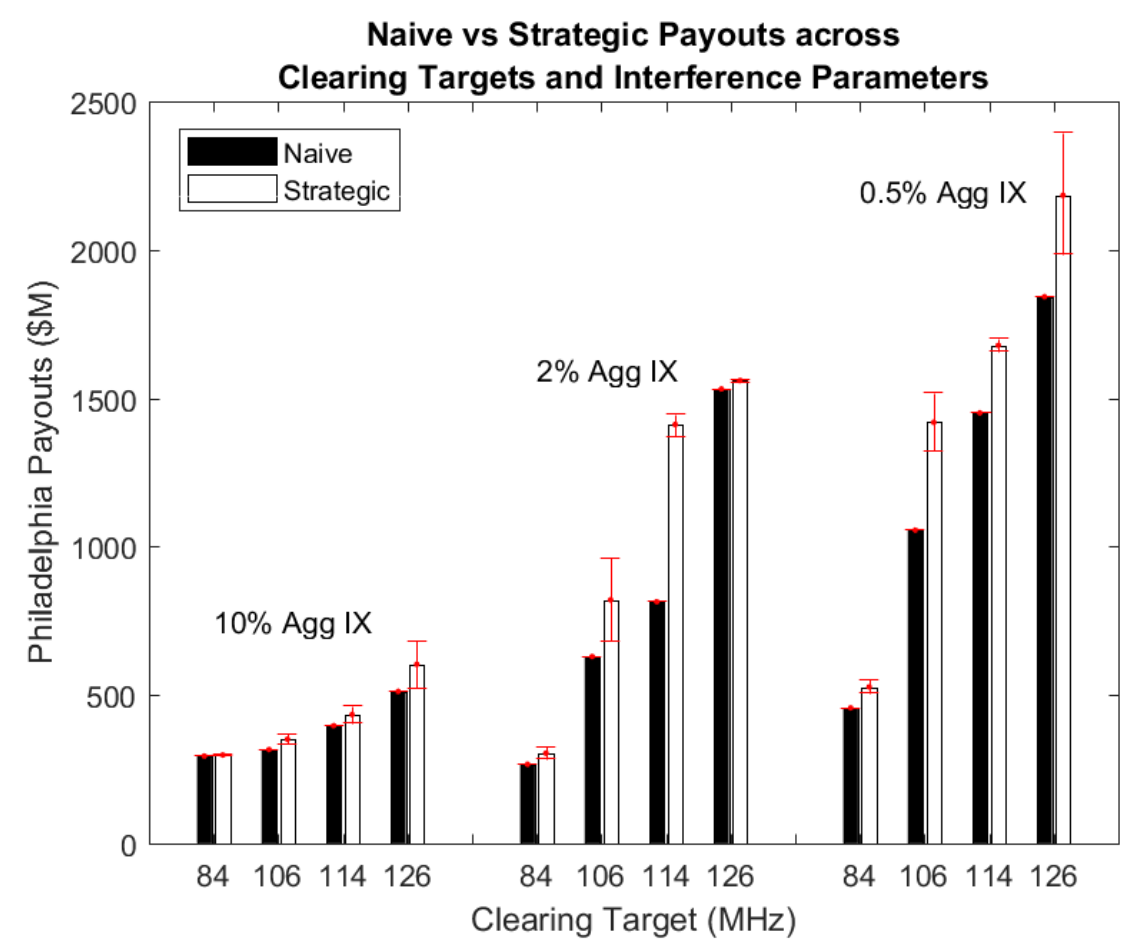

\subsection{Auction design: Relaxing repacking constraints}

In designing the reverse auction, the FCC had to make a number of choices. One such choice was the maximum loss in population served that a TV station may suffer in the repacking process, as discussed in Section 4.2. While the FCC settled on a $0.5 \%$ interference level, the alternative, looser standards of $2 \%$ and $10 \%$ would have eliminated some interference constraints on the repacking process and thus made TV stations more substitutable.

To understand the role of the interference level and the implied degree of substitutability, we simulate the reverse auction for the Philadelphia, PA, DMA under 12 different scenarios, each requiring 72,900 simulations of the reverse auction. Each scenario pairs one of the three interference levels $(0.5 \%, 2 \%$, and $10 \%)$ with one of the four clearing targets $(126 \mathrm{MHz}, 114 \mathrm{MHz}, 106 \mathrm{MHz}$, and $84 \mathrm{MHz}$ ) that the FCC considered. Under these three interference levels, the average number of interference constraints for a TV station in the Philadelphia, PA, DMA drops from 69.60 for the $0.5 \%$ interference level to 52.35 and 30.12 for the $2 \%$ and $10 \%$ interference levels, respectively. The results are shown in Figure 5, where we display payouts (in $\$$ million) under naive bidding as black bars and payouts under strategic bidding as white bars, with $95 \%$ confidence intervals in red.

There are a few conclusions to draw from Figure 5. First, in line with the nationwide results in Table 8, payouts decline in the clearing target, irrespective of the form of bidding and the interference level. Second, payouts tend to decline in the interference level. Third, also as in the nationwide results, the scope for strategic supply reduction, as measured by the payout increase 
from strategic bidding, tends to decline in the clearing target. Finally, the scope for strategic supply reduction is low at the $2 \%$ interference level for all but the $114 \mathrm{MHz}$ clearing target and very low at the $10 \%$ interference level for all clearing targets. As TV stations become more substitutable in the repacking process, in the extreme it is unlikely that withholding a TV station from the reverse auction has a large effect on payouts.

Strategic supply reduction has been explored in previous work on multi-unit auctions in wholesale electricity markets (e.g., Wolfram, 1998, Hortacsu and Puller, 2008). Borenstein, Bushnell and Wolak (2002) note that the effect of such an exercise of market power can be large when demand or supply is inelastic. In contrast to electricity, TV stations are not homogeneous in the repacking process because of interference constraints. We show that product differentiation amplifies the impact of strategic supply reduction, even though the FCC's demand for TV stations is elastic. Our results thus complement the earlier literature by highlighting the interaction of product differentiation and strategic supply reduction.

\section{Extensions}

As discussed in Section 2, payouts in the actual reverse auction amounted to $\$ 10.1$ billion at the 84 $\mathrm{MHz}$ clearing target. Conservatively assuming full participation and a limited geographic extent of strategic bidding, we predict payouts of $\$ 4.28$ billion, on average across payout-unique equilibria and simulation draws. In this section, we investigate the sensitivity of our main results to these two assumptions.

\subsection{Reduced participation}

So far, we have conservatively assumed full participation of the 1,670 UHF stations. The FCC has not committed to release any data on actual participation, despite obvious question around the role of participation in outcomes. We now consider the sensitivity of our main results to reduced participation. In line with the prospective nature of our analysis, we focus on TV stations that were ex-ante expected to be less likely to participate in the reverse auction. We assume that all 108 religious stations and a random subset of $50 \%$ of non-commercial stations do not participate, for a total of 253 non-participating TV stations. ${ }^{67}$

Table 14 compares full and reduced participation under naive bidding for both the $84 \mathrm{MHz}$ and the $126 \mathrm{MHz}$ clearing target. With fewer participating TV stations, the reverse auction is more likely to fail at the outset (see footnote 26). The results for reduced participation in Table 14 condition on the $95.8 \%$ and $99.9 \%$ of the 20,400 runs of the reverse auction for the $126 \mathrm{MHz}$ and $84 \mathrm{MHz}$ clearing targets, that avoid failure at the outset. Because payouts under full participation for these subsets of runs remain within $99.8 \%$ of payouts for all runs, we continue displaying

\footnotetext{
${ }^{67}$ Ultimately, 15 out of 108 religious stations and 34 out of 289 non-commercial stations relinquished their licenses in the reverse auction. As the FCC has not published information on participation, we cannot further assess the participation by these two groups of TV stations.
} 
Table 14: Payouts to TV stations nationwide and in Philadelphia, PA, DMA under reduced participation

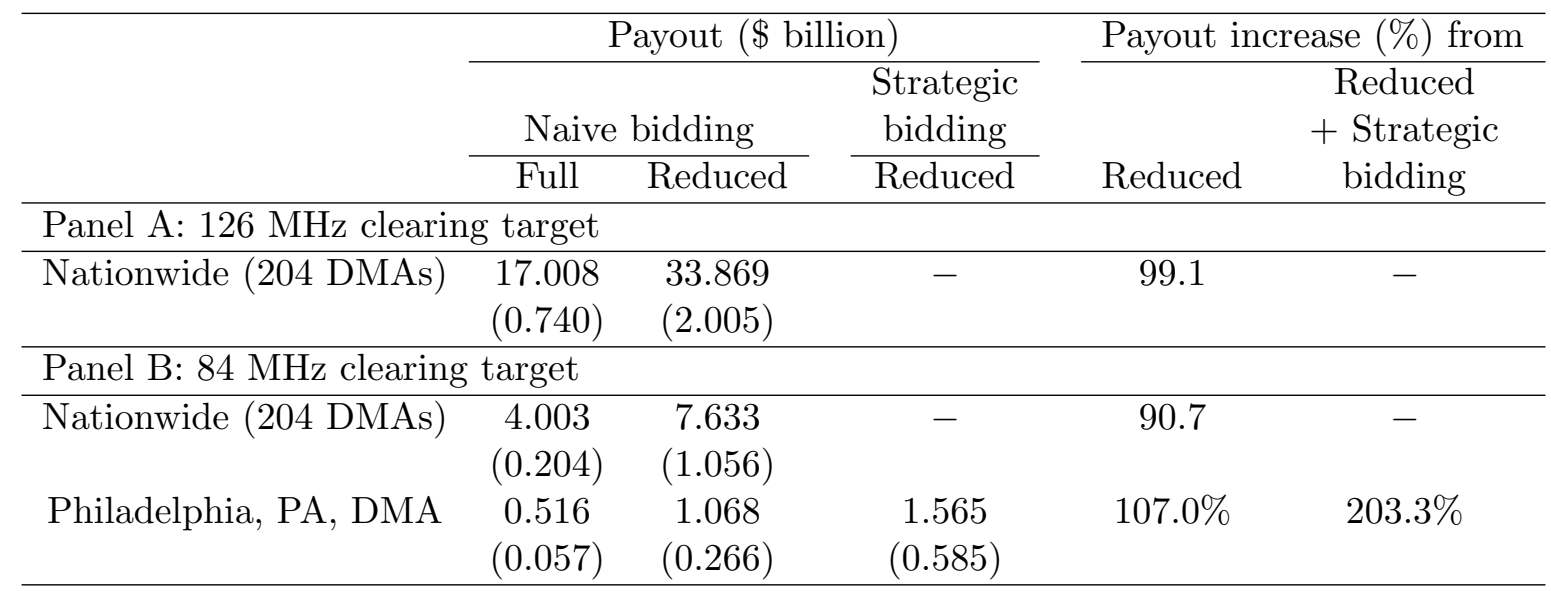

Notes: Payout increase at mean calculated as percent difference between mean payouts under strategic and naive bidding relative to full and reduced participation.

our main results from Table 8 for full participation. Table 14 highlights the importance of full participation for the success of the reverse auction, as previously pointed out by Milgrom and Segal (2018). Under reduced participation, payouts nearly double, irrespective of the clearing target. In particular, payouts amount to $\$ 7.6$ billion under reduced participation and the $84 \mathrm{MHz}$ clearing target, which - while considerably closer — is still less than payouts in the actual reverse auction.

Because analyzing strategic bidding under reduced participation for all 204 DMAs is computationally taxing, we consider the Philadelphia, PA, DMA as a case study. We withhold the same TV stations that we select as non-participating in the above nationwide results. As the bottom row of Table 14 shows, under naive bidding and the $84 \mathrm{MHz}$ clearing target, payouts double in moving from full to reduced participation in line with the above nationwide results. When we further account for strategic bidding, payouts rise to be three times the payouts under naive bidding and full participation. As the Philadelphia, PA, DMA contributes approximately $25 \%$ of the gains from strategic bidding under full participation (see Table 9), a back-of-the-envelope calculation suggests that the combination of strategic bidding and reduced participation would result in payouts similar to the $\$ 10.1$ billion in the actual reverse auction. Since the FCC will not release data on participation, this is our best estimate of the effect of reduced participation.

One likely reason why many small TV stations may choose to remain on the air is the must-carry provision of the Cable Television Consumer Protection and Competition Act of 1992 (see Section 6.1 ), which greatly broadens their reach and potential advertising audience. One simple measure to increase participation, therefore, would be to allow TV stations to relinquish their licenses but retain their must-carry status, so that they can continue to operate as businesses and reach viewers through cable systems. 


\section{Figure 6: Service contours of WGCB-TV and WTVE}

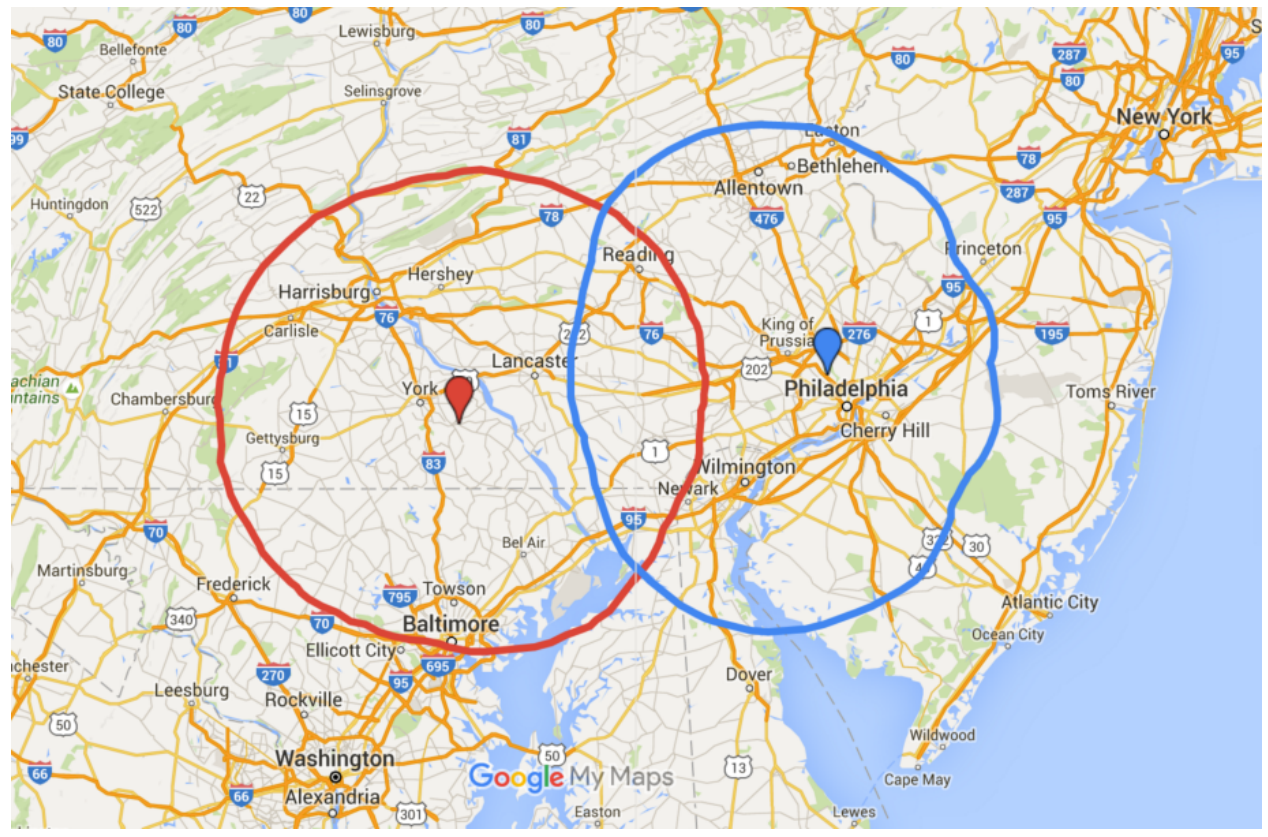

\subsection{Multi-market strategies}

Strategic bidding may extend beyond market boundaries if multi-license owners withhold a TV station in a DMA from the reverse auction to drive up the freezing base clock price for another TV station they own in a neighboring DMA. Regional cross-market multi-license ownership is pronounced. Consider, for example, the private equity firms. LocusPoint holds licenses in eight focal DMAs and additional licenses outside of the focal DMA but in the focal DMA's repacking region in four instances. NRJ and OTA hold licenses in the surrounding repacking region of four and five of the nine focal DMAs in which they are each present. We illustrate how such multimarket strategies may work, continuing with Philadelphia, PA, DMA as a case study in the interest of computational tractability.

In late 2012, NRJ purchased WGCB-TV (facility ID 55350) in the Harrisburg, PA, DMA for $\$ 9$ million. WGCB-TV is located in Red Lion, PA, towards both the Philadelphia, PA, and Baltimore, MD, DMAs. While NRJ owns no other TV station in the Harrisburg, PA, DMA, it had previously purchased WTVE and WPHY-CD (facility IDs 55305 and 74464) in the Philadelphia, PA, DMA in late 2011 and early 2012 for $\$ 30.4$ million and $\$ 3.5$ million, respectively. Figure 6 shows the overlap between the service contours of WGCB-TV (in red) and WTVE (in blue). ${ }^{68}$ WGCB-TV has a very high interference count and may interfere with 161 TV stations in the repacking process. Hence, if NRJ withholds WGCB-TV from the reverse auction, this may affect prices in the Philadelphia, PA, DMA and potentially other DMAs as well; alternatively, withholding a Philadelphia station may increase the payout to WGCB-TV.

\footnotetext{
${ }^{68}$ We obtain service contours from the FCC's TV Query Broadcast Station Search at https://www.fcc.gov/ media/television/tv-query, accessed on March 15, 2018.
} 
Table 15: Payouts to TV stations in Philadelphia, PA, DMA under multi-market strategy

\begin{tabular}{|c|c|c|c|c|c|c|}
\hline \multirow[b]{2}{*}{ Payouts ( $\$$ billion) } & \multirow{2}{*}{$\begin{array}{c}\text { Naive } \\
\text { bidding }\end{array}$} & \multicolumn{4}{|c|}{ Strategic bidding } & \multirow{2}{*}{$\begin{array}{c}\text { Payout } \\
\text { increase at } \\
\text { mean }(\%)\end{array}$} \\
\hline & & Mean & Min & Median & Max & \\
\hline \multicolumn{7}{|c|}{ Panel A: $126 \mathrm{MHz}$ clearing target } \\
\hline \multirow[t]{2}{*}{ Base case } & 2.172 & 2.481 & 2.320 & 2.499 & 2.614 & \multirow[t]{2}{*}{14.2} \\
\hline & $(0.241)$ & $(0.466)$ & $(0.450)$ & $(0.548)$ & $(0.637)$ & \\
\hline Multi-market strategy & $\begin{array}{c}2.172 \\
(0.241)\end{array}$ & $\begin{array}{c}4.065 \\
(0.201)\end{array}$ & $\begin{array}{c}2.141 \\
(0.322)\end{array}$ & $\begin{array}{c}3.995 \\
(0.258)\end{array}$ & $\begin{array}{c}6.190 \\
(0.525)\end{array}$ & 87.2 \\
\hline \multicolumn{7}{|c|}{ Panel B: $84 \mathrm{MHz}$ clearing target } \\
\hline Base case & $\begin{array}{c}0.516 \\
(0.057)\end{array}$ & $\begin{array}{c}0.589 \\
(0.113)\end{array}$ & $\begin{array}{c}0.576 \\
(0.117)\end{array}$ & $\begin{array}{c}0.587 \\
(0.113)\end{array}$ & $\begin{array}{c}0.605 \\
(0.123)\end{array}$ & 14.1 \\
\hline Multi-market strategy & $\begin{array}{c}0.516 \\
(0.057)\end{array}$ & $\begin{array}{c}0.603 \\
(0.106)\end{array}$ & $\begin{array}{c}0.584 \\
(0.112)\end{array}$ & $\begin{array}{c}0.599 \\
(0.107)\end{array}$ & $\begin{array}{c}0.627 \\
(0.123)\end{array}$ & 16.8 \\
\hline
\end{tabular}

Notes: Payouts under multi-market strategy exclude WGCB-TV for comparability to base case. Payout increase at mean calculated as percent difference between mean payouts under strategic and naive bidding.

To investigate, we allow NRJ to bid strategically on WGCB-TV in concert with its TV stations in the Philadelphia, PA, DMA under both the $126 \mathrm{MHz}$ and the $84 \mathrm{MHz}$ clearing target. Allowing for this multi-market strategy increases the number of strategy profiles for the Philadelphia, PA, DMA from 729 in our base case to 1,701. Table 15 compares payouts to TV stations in the Philadelphia, PA, DMA under the multi-market strategy to payouts in our base case. Under the $126 \mathrm{MHz}$ clearing target, payouts can increase dramatically under the multi-market strategy; under the $84 \mathrm{MHz}$ clearing target, the effect is much more muted. Similar to the main results, where small changes in bidding behavior have larger effects for higher clearing targets, NRJ's additional strategic lever appears to be more valuable when there are more constraints on the repacking process.

\section{Conclusions}

In this paper, we explore the implications of ownership concentration for the recently-concluded incentive auction that re-purposed spectrum from broadcast TV to mobile broadband usage. Ownership concentration is a policy concern as the FCC has welcomed the acquisitions of TV stations by private equity firms and other outside investors in the run-up to the incentive auction. The FCC worried about encouraging a healthy supply of TV stations in the reverse auction and viewed outside investors as more likely to part with their TV stations than potentially "sentimental" owners. ${ }^{69}$ At the same time, as our paper shows, ownership concentration is likely to give rise to strategic supply reduction.

Using a large-scale valuation exercise to estimate reservation values for all auction-eligible TV

\footnotetext{
${ }^{69}$ See "FCC Makes Pitch for TV Stations' Spectrum", The Wall Street Journal, October 1, 2014.
} 
stations, we compare the outcome of the reverse auction under strategic bidding when we account for the ownership pattern in the data with the outcome under naive bidding. We show that strategic supply reduction has a large impact on prices and payouts to TV stations. For the $126 \mathrm{MHz}$ clearing target, strategic bidding by multi-license owners increases nationwide payouts by $20.7 \%$ on average; for the $84 \mathrm{MHz}$ clearing target, strategic bidding increases nationwide payouts by $7.0 \%$.

Our simulation exercise affords several additional conclusions. First, while single-license owners do not themselves engage in strategic supply reduction, as a group they witness payout increases that are almost as large as those seen by multi-license owners. Second, there is significant heterogeneity in payouts as well as in payout increases due to strategic bidding across DMAs. Third, strategic supply reduction has limited efficiency implications. Fourth, the outcome of the reverse auction is sensitive to small changes in bidding behavior in that withholding even a few TV stations suffices to give rise to equilibria that have significantly higher payouts than those under naive bidding.

Our main results are likely to understate the impact of strategic supply reduction on prices and payouts to TV stations because we make several conservative assumptions. We show that allowing strategic bidding to extend beyond market boundaries has the potential to further exacerbate payout increases. Perhaps even more important, we show that moving from our baseline assumption of full participation to reduced participation substantially increases both naive payouts and the gains from strategic bidding. Indeed, a back-of-the-envelope calculation suggests that the combination of strategic bidding and reduced participation would result in payouts similar to the $\$ 10.1$ billion in the actual reverse auction.

Our paper differs from most of the empirical literature on auctions and market design by taking an ex ante perspective. We illustrate the usefulness of this approach in two ways. First, we propose a simple change in the auction rules and investigate how placing a restriction on the bids of multi-license owners affects their ability to exploit the joint ownership of TV stations. Second, we trace out the relationship between the interference level that the FCC chooses - and the implied degree of substitutability between TV stations in the repacking process - and payouts in the reverse auction. We hope that the framework we provide proves useful in designing future auctions geared at re-purposing spectrum toward more efficient uses. 


\section{References}

Ausubel, Lawrence M. 2004. "An Efficient Ascending-Bid Auction for Multiple Objects." American Economic Review 94(5):1452-1475.

Ausubel, Lawrence M. 2006. "An Efficient Dynamic Auction for Heterogeneous Commodities." American Economic Review 96(3):602-629.

Ausubel, Lawrence M., Peter Cramton, Marek Pycia, Marzena Rostek and Marek Weretka. 2014. "Demand Reduction and Inefficiency in Multi-Unit Auctions." Review of Economic Studies 81(4):1366-1400.

Back, Kerry and Jaime Zender. 1993. "Auctions of Divisible Goods: On the Rationale for the Treasury Experiment." Review of Financial Studies 6(4):733-764.

Back, Kerry and Jaime Zender. 2001. "Auctions of Divisible Goods with Endogenous Supply." Economics Letters 73(1):29-34.

Bikhchandani, Sushil, Sven de Vries, James Schummer and Rakesh Vohra. 2011. "An Ascending Vickrey Auction for Selling Bases of a Matroid." Operations Research 59(2):400-413.

Borenstein, Severin, James B. Bushnell and Frank A. Wolak. 2002. "Measuring Market Inefficiencies in California's Restructured Wholesale Electricity Market." American Economic Review 92(5):1376-1405.

Brusco, Sandro and Giuseppe Lopomo. 2002. "Collusion via Signalling in Simultaneous Ascending Bid Auctions with Heterogeneous Objects, with and without Complementarities." Review of Economic Studies 69(2):407-436.

Budish, Eric and Estelle Cantillon. 2012. "The Multi-Unit Assignment Problem: Theory and Evidence from Course Allocation at Harvard." American Economic Review 102(5):2237-2271.

Bushnell, James B. and Catherine D. Wolfram. 2012. "Enforcement of Vintage Differentiated Regulations: The Case of New Source Review." Journal of Environmental Economics and Management 64(2):137-152.

Cantillon, Estelle and Martin Pesendorfer. 2007. "Combination Bidding in Multi-Unit Auctions." CEPR Working Paper DP6083.

Cramton, Peter and Jesse A. Schwartz. 2002. "Collusive Bidding in the FCC Spectrum Auctions." Contributions in Economic Analysis $\&$ Policy 1(1):1-20.

Duggan, Mark and Fiona M. Scott Morton. 2006. "The Distortionary Effects of Government Procurement: Evidence from Medicaid Prescription Drug Purchasing." Quarterly Journal of Economics 121(1):1-30. 
Dütting, Paul, Vasilis Gkatzelis and Tim Roughgarden. 2017. "The Performance of DeferredAcceptance Auctions." Mathematics of Operations Research 42(4):897-914.

Engelbrecht-Wiggans, Richard and Charles Kahn. 1998. "Multi-Unit Auctions with Uniform Prices." Economic Theory 12(2):227-258.

Engelbrecht-Wiggans, Richard and Charles Kahn. 2005. "Low-Revenue Equilibria in Simultaneous Ascending-Bid Auctions." Management Science 51(3):508-518.

Engelmann, Dirk and Veronika Grimm. 2009. "Bidding Behaviour in Multi-Unit Auctions - An Experimental Investigation." Economic Journal 119(537):855-882.

Fowlie, Meredith. 2009. "Incomplete Environmental Regulation, Imperfect Competition, and Emissions Leakage." American Economic Journal: Economic Policy 1(2):72-112.

Fox, Jeremy T. and Patrick Bajari. 2013. "Measuring the Efficiency of an FCC Spectrum Auction." American Economic Journal: Microeconomics 5(1):100-146.

Frechette, Alexandre, Neil Newman and Kevin Leyton-Brown. 2016. "Solving the Station Repacking Problem." Thirtieth AAAI Conference on Artificial Intelligence .

Goeree, Jacob K., Theo Offerman and Randolph Sloof. 2013. "Demand Reduction and Preemptive Bidding in Multi-Unit License Auctions." Experimental Economics 16(1):52-87.

Goolsbee, Austan. 2000. "What Happens When You Tax the Rich? Evidence from Executive Compensation." Journal of Political Economy 108(2):352-378.

Grimm, Veronika, Frank Riedel and Elmar Wolfstetter. 2003. "Low Price Equilibrium in MultiUnit Auctions: the GSM Spectrum Auction in Germany." International Journal of Industrial Organization 21(10):1557-1569.

Hitsch, Günter J., Ali Hortacsu and Dan Ariely. 2010. "Matching and Sorting in Online Dating." American Economic Review 100(1):130-163.

Hortacsu, Ali and Steven Puller. 2008. "Understanding Strategic Bidding in Multi-Unit Auctions: A Case Study of the Texas Electricity Spot Market." Rand Journal of Economics 39(1):86-114.

Kagel, John H. and Dan Levin. 2001. "Behavior in Multi-Unit Demand Auctions: Experiments with Uniform Price and Dynamic Vickrey Auctions." Econometrica 69(2):413-454.

Kazumori, Eiichiro. 2016. "Generalized Deferred Acceptance Auctions with Multiple Relinquishment Options for Spectrum Reallocation." Working Paper, State University of New York, Buffalo, NY.

Krishna, Vijay. 2010. Auction Theory. 2nd ed. New York: Academic Press. 
Laffont, Jean-Jacques and Jean Tirole. 1986. "Using Cost Observation to Regulate Firms." Journal of Political Economy 94(3):614-641.

Levin, Jonathan and Andrzej Skrzypacz. 2016. "Properties of the Combinatorial Clock Auction." American Economic Review 106(9):2528-2551.

Li, Shengwu. 2017. "Obviously Strategy-Proof Mechanisms." American Economic Review 107(11):3257-3287.

List, John A. and David Lucking-Reiley. 2000. "Demand Reduction in Multiunit Auctions: Evidence from a Sportscard Field Experiment." American Economic Review 90(4):961-972.

Menezes, Flavio. 1996. "Multiple-Unit English Auctions." European Journal of Political Economy $12(4): 671-684$.

Milgrom, Paul. 2004. Putting Auction Theory to Work. Cambridge: Cambridge University Press.

Milgrom, Paul and Ilya Segal. 2018. "Clock Auctions and Radio Spectrum Reallocation." Journal of Political Economy forthcoming.

Oyer, Paul. 1998. "Fiscal Year Ends and Nonlinear Incentive Contracts: The Effect on Business Seasonality." Quarterly Journal of Economics 113(1):149-185.

Riedel, Frank and Elmar Wolfstetter. 2006. "Immediate Demand Reduction in Simultaneous Ascending-Bid Auctions: A Uniqueness Result." Economic Theory 29(3):721-726.

Sood, Gaurav. 2018. "Geographic Information on Designated Media Markets.". URL: https://doi.org/10.7910/DVN/IVXEHT

Weber, Robert J. 1997. "Making More from Less: Strategic Demand Reduction in the FCC Spectrum Auctions." Journal of Economics and Management Strategy 6(3):529-548.

Wilson, Robert. 1979. "Auctions of Shares." Quarterly Journal of Economics 93(47):675-689.

Wolfram, Catherine D. 1998. "Strategic Bidding in a Multiunit Auction: An Empirical Analysis of Bids to Supply Electricity in England and Wales." Rand Journal of Economics 29(4):703-725. 


\section{Appendix}

\section{A Data sources}

In this appendix, we discuss several details of the data sources we rely on and describe how we construct our sample and primary variables.

\section{A.1 TV stations}

We restrict attention to TV stations located in the U.S. excluding Puerto Rico and the Virgin Islands that the FCC has declared as eligible for the reverse auction. Table A1 breaks down these 2, $150 \mathrm{TV}$ stations by type of service, type of use, and power output.

Table A1: TV station counts by type of service, type of use, and power output

\begin{tabular}{|c|c|c|c|c|c|}
\hline & \multicolumn{2}{|c|}{ Full-power } & Low-power & \multirow[b]{2}{*}{ Total } \\
\hline & & Primary & Satellite & Class-A & \\
\hline \multirow{2}{*}{ UHF } & Commercial & 947 & 56 & 378 & \multirow{2}{*}{1,670} \\
\hline & Non-commercial & 282 & 0 & 7 & \\
\hline \multirow{2}{*}{ VHF } & Commercial & 294 & 56 & 24 & \multirow{2}{*}{480} \\
\hline & Non-commercial & 105 & 0 & 1 & \\
\hline Total & & \multicolumn{2}{|c|}{1,740} & 410 & 2,150 \\
\hline
\end{tabular}

\section{A.2 DMAs}

DMAs are ranked annually according to market size as measured by the number of homes with at least one television (henceforth, TV households, measured in thousand). Table A2 lists the top ten DMAs in 2015 along with some characteristics from the BIA data. DMA population is measured as number of people (in million) as opposed to number of TV households. Income is average per capita disposable personal income (in \$). The number of TV station covers the 2,150 TV stations located in the U.S. excluding Puerto Rico and the Virgin Islands that the FCC has declared as eligible for the reverse auction.

\section{A.3 BIA data}

After restricting to full-power stations (primary and satellite stations) and low-power class-A stations, the BIA data provides us with 25,544 station-year observations from 2003 to 2013 and for 2015. Commercial stations make up 20,574 observations and non-commercial stations, including dark stations, 4,970 observations.

The BIA data provides station, owner and market characteristics, as well as transaction histories covering the eight most recent changes in the ownership of a TV station. Advertising revenue and DMA rank are provided for each year from 2003 to 2013 and for 2015. DMA population is provided 
Table A2: Top ten DMAs in 2015

\begin{tabular}{cccccc}
\hline Rank & DMA & $\begin{array}{c}\text { TV households } \\
\text { (thousand) }\end{array}$ & $\begin{array}{c}\text { DMA population } \\
\text { (million) }\end{array}$ & $\begin{array}{c}\text { Income } \\
(\$)\end{array}$ & $\begin{array}{c}\text { TV } \\
\text { stations }\end{array}$ \\
\hline 1 & New York, NY & 7,368 & 21.4 & 57,769 & 28 \\
2 & Los Angeles, CA & 5,490 & 16.3 & 44,678 & 32 \\
3 & Chicago, IL & 3,475 & 9.8 & 46,976 & 24 \\
4 & Philadelphia, PA & 2,918 & 8.1 & 48,620 & 28 \\
5 & Dallas Fort Worth, TX & 2,646 & 7.7 & 44,590 & 21 \\
6 & San Francisco, CA & 2,485 & 7.3 & 64,442 & 26 \\
7 & Washington, DC & 2,444 & 6.9 & 56,362 & 20 \\
8 & Boston, MA & 2,411 & 6.5 & 56,463 & 23 \\
9 & Atlanta, GA & 2,386 & 6.8 & 38,275 & 19 \\
10 & Houston, TX & 2,374 & 6.9 & 49,255 & 19 \\
\hline
\end{tabular}

for 2007, 2008, 2012, 2013, and 2015. We use the data for 2007 and 2008 to extrapolate DMA population linearly to earlier years and the data for 2008 and 2013 to interpolate linearly to the years in-between. With few exceptions, other characteristics are provided only for 2012 and for $2015 .{ }^{70}$ Transaction histories are provided from 2003 to 2013.

For commercial stations, advertising revenue is missing for 5,814, or $28.3 \%$, station-year observations. Table A3 shows the share of station-year observations with missing advertising revenue for commercial stations. Advertising revenue is missing for almost all satellite stations because BIA subsumes their advertising revenues into those of their parent primary stations. ${ }^{71}$ Missing values are further concentrated among low-power class-A stations, among TV stations affiliated with Spanish-language networks (Azteca America, Independent Spanish, Telemundo, Unimas, and Univision) and other minor networks, and among independent stations. There are no discernible patterns in missing values along other dimensions of the data such as market size.

We impute missing advertising revenue for all commercial stations apart from satellite stations as follows. We regress the $\log$ of advertising revenue (in $\$$ thousand) $\ln A D_{j t}$ on station, owner, and market characteristics $X_{j t}$. We run this regression separately for each year from 2003 to 2013 and for 2015 and use it to predict advertising revenue $A D_{j t}$. We include in $X_{j t}$ the $\log$ of the interference free population coverage (in thousand) of the TV station, an indicator for whether the TV station has multicast sub-channels, an indicator for full-power stations, fixed effects for the eleven network affiliations in Table A3, fixed effects for the interaction of affiliation groups (see Appendix C.1.1) with U.S. states, an indicator for whether the owner owns more than one TV station in the same DMA, ownership category fixed effects (whether the owner owns between two and ten, or more than ten TV stations across DMAs), the number of TV stations in the DMA,

\footnotetext{
${ }^{70} \mathrm{An}$ "on air date" is provided and we drop observations for a TV station before it went on the air. A previous affiliation and the date of the affiliation change are provided. We manually fill in historical affiliations, including the merger of United Paramount and Warner Bros in 2006 to form CW and the creation of MyNetwork TV in 2006.

${ }^{71}$ We enforce this convention for the 54 station-year observations where a satellite station has non-missing advertising revenue. We manually link the 112 satellite stations in Table A1 to 78 primary stations because BIA does not provide this information.
} 
the number of major network affiliates in the DMA, the wealth and competitiveness indices for the DMA (see Appendix C.1.1), and the log of DMA population (in thousand). Finally, we account for the contribution of any satellite stations to advertising revenue by including in $X_{j t}$ the number of satellite stations $N_{j t}^{S A T}$ that belong to the primary station. The adjusted $R^{2}$ is 0.99 in all years in logs and 0.75 on average in levels, suggesting that we capture most of the variation in advertising revenue across stations and years. We report the parameter estimates in Online Appendix F.

With the parameter estimates in hand, we impute advertising revenue $A D_{j t}$, where missing, as $\widehat{A D}_{j t}=e^{\sqrt{\ln \widehat{A D}_{j t}}+\frac{\hat{\sigma}^{2}}{2}}$ to account for the non-zero mean of the log-normally distributed error term with estimated variance $\hat{\sigma}^{2}$. We proceed as follows: First, for a primary station we impute advertising revenue $A D_{j t}$ as $\widehat{A D}_{j t}$. We further net out the contribution of satellite stations, if any, to the advertising revenue of their parent primary station by replacing advertising revenue $A D_{j t}$ with $A D_{j t} / e^{\hat{\beta}_{S A T} N_{j t}^{S A T}}$, where $\hat{\beta}_{S A T}$ is the estimated coefficient on $N_{j t}^{S A T}$. Second, we impute advertising revenue for a satellite station by first computing the contribution of all satellite stations as $A D_{j t}-A D_{j t} / e^{\hat{\beta}_{S A T} N_{j t}^{S A T}}$ and then allocating each satellite station's contribution in proportion to its interference free population.

Table A3: Missing advertising revenue for commercial stations

\begin{tabular}{lccc}
\hline & & \multicolumn{2}{c}{ Missing advertising revenue } \\
\cline { 3 - 4 } & $\begin{array}{c}\text { Station-year } \\
\text { count }\end{array}$ & Station-year count & $\%$ \\
\hline Full-power & & & \\
Primary & 14,672 & 958 & 6.53 \\
Satellite & 1,346 & 1,292 & 96.0 \\
Low-power class-A & 4,556 & 3,564 & 78.2 \\
\hline Major networks & & & \\
ABC & 2,669 & 412 & 15.4 \\
CBS & 2,640 & 339 & 12.8 \\
Fox & 2,443 & 344 & 14.1 \\
NBC & 2,656 & 395 & 14.9 \\
Minor networks & & & \\
CW & 930 & 94 & 10.1 \\
MyNetwork TV & 829 & 143 & 17.3 \\
United Paramount & 266 & 34 & 12.8 \\
Warner Bros & 264 & 21 & 7.95 \\
Spanish-language networks & 1,844 & 553 & 30.0 \\
Other & 3,206 & 1,635 & 51.0 \\
Independent & 2,827 & 1,844 & 65.2 \\
\hline Total & 20,574 & 5,814 & 28.3 \\
\hline
\end{tabular}

\section{A.4 NAB data}

NAB collects financial information on cash flow and revenue broken down into detailed source categories for commercial full-power stations. We define advertising revenue as the sum of local, 
regional, national, and political advertising revenue, commissions, and network compensation. We further define non-broadcast revenue as the sum of total trade-outs and barter, multicast revenue, and other broadcast related revenue.

NAB reports the data at various levels of aggregation. Table A4 shows the resulting 66 tables in 2012. ${ }^{72}$ The number of tables fluctuates slightly year-by-year because NAB imposes a minimum of ten TV stations per aggregation category to ensure confidentiality. ${ }^{73,74}$ Note that a TV station may feature in more than one table. For example, WABC-TV (facility ID 1328), the New York $\mathrm{ABC}$ affiliate, is used in calculating statistics for (1) markets of rank 1 to 10; (2) major network affiliates; (3) all ABC affiliates; and (4) ABC affiliates in markets with rank 1 to 25.

For each aggregation category, NAB reports the mean as well as the first, second, and third quartile for cash flow and detailed revenue source categories. Because we do not observe correlations between the detailed revenue source categories, we can construct the mean of advertising revenue and non-broadcast revenue but not the quartiles. We present a sample of the NAB data for select aggregation categories in Table A5.

To validate the data, we compare the mean of advertising revenue from the NAB data to suitably averaged advertising revenue from the BIA data. The resulting 662 pairs of means from the two data sources exhibit a correlation of 0.980 . To investigate the consequences of imputing advertising revenue, where missing, in the BIA data, we equally split the sample into two groups based on the amount of imputation. For each of the 662 NAB tables, we calculate the share of stations in the BIA data that qualify for the table and have imputed advertising revenue. The 329 pairs of means with below-median amounts of imputation exhibit a correlation of 0.981 and the 333 pairs of means with above-median amounts of imputation exhibit a correlation of 0.972 . This suggests that imputing advertising revenue does not significantly diminish the validity of the BIA data.

\footnotetext{
${ }^{72}$ We exclude 15 aggregation categories that are defined by total revenue because the BIA data is restricted to advertising revenue.

${ }^{73}$ In 2012, NAB received 785 responses to 1,288 questionnaires, a response rate of $60.9 \%$.

${ }^{74}$ Some years, in particular, break out United Paramount and Spanish-language networks but not other minor networks. We conclude that the response rate of other minor networks is very low and thus exclude other minor networks from the cash flow estimation in Section C.1.2.
} 
Table A4: NAB tables in 2012

\begin{tabular}{|c|c|c|c|}
\hline Table & Description & Table & Description \\
\hline 1 & All Stations, All Markets & 34 & $\begin{array}{l}\text { ABC, CBS, FOX, NBC, } \\
\text { Markets } 176+\end{array}$ \\
\hline 2 & All Stations, Markets 1-10 & 35 & ABC, All Markets \\
\hline 3 & All Stations, Markets 11-20 & 36 & ABC, Markets 1-25 \\
\hline 4 & All Stations, Markets 21-30 & 37 & ABC, Markets 26-50 \\
\hline 5 & All Stations, Markets 31-40 & 38 & ABC, Markets 51-75 \\
\hline 6 & All Stations, Markets 41-50 & 39 & ABC, Markets 76-100 \\
\hline 7 & All Stations, Markets 51-60 & 40 & ABC, Markets 101+ \\
\hline 8 & All Stations, Markets 61-70 & 41 & CBS, All Markets \\
\hline 9 & All Stations, Markets 71-80 & 42 & CBS, Markets 1-25 \\
\hline 10 & All Stations, Markets 81-90 & 43 & CBS, Markets 26-50 \\
\hline 11 & All Stations, Markets 91-100 & 44 & CBS, Markets 51-75 \\
\hline 12 & All Stations, Markets 101-110 & 45 & CBS, Markets 76-100 \\
\hline 13 & All Stations, Markets 111-120 & 46 & CBS, Markets 101+ \\
\hline 14 & All Stations, Markets 121-130 & 47 & FOX, All Markets \\
\hline 15 & All Stations, Markets 131-150 & 48 & FOX, Markets 1-50 \\
\hline 16 & All Stations, Markets 151-175 & 49 & FOX, Markets 51-75 \\
\hline 17 & All Stations, Markets 176+ & 50 & FOX, Markets 76-100 \\
\hline 18 & ABC, CBS, FOX, NBC, All Markets & 51 & FOX, Markets 101+ \\
\hline 19 & ABC, CBS, FOX, NBC, Markets 1-10 & 52 & NBC, All Markets \\
\hline 20 & ABC, CBS, FOX, NBC, Markets 11-20 & 53 & NBC, Markets 1-25 \\
\hline 21 & ABC, CBS, FOX, NBC, Markets 21-30 & 54 & NBC, Markets 26-50 \\
\hline 22 & ABC, CBS, FOX, NBC, Markets 31-40 & 55 & NBC, Markets 51-75 \\
\hline 23 & ABC, CBS, FOX, NBC, Markets 41-50 & 56 & NBC, Markets 76-100 \\
\hline 24 & ABC, CBS, FOX, NBC, Markets 51-60 & 57 & NBC, Markets 101+ \\
\hline 25 & ABC, CBS, FOX, NBC, Markets $61-70$ & 58 & CW, All Markets \\
\hline 26 & ABC, CBS, FOX, NBC, Markets 71-80 & 59 & CW, Markets 1-25 \\
\hline 27 & ABC, CBS, FOX, NBC, Markets 81-90 & 60 & CW, Markets 26-50 \\
\hline 28 & ABC, CBS, FOX, NBC, Markets 91-100 & 61 & CW, Markets 51-75 \\
\hline 29 & ABC, CBS, FOX, NBC, Markets 101-110 & 62 & MNTV, All Markets \\
\hline 30 & ABC, CBS, FOX, NBC, Markets 111-120 & 63 & MNTV, Markets 1-50 \\
\hline 31 & ABC, CBS, FOX, NBC, Markets 121-130 & 64 & MNTV, Markets 51+ \\
\hline 32 & ABC, CBS, FOX, NBC, Markets 131-150 & 65 & Independent, All markets \\
\hline 33 & ABC, CBS, FOX, NBC, Markets 151-175 & 66 & Independent, Markets 1-25 \\
\hline
\end{tabular}


Table A5: Sample NAB data for select aggregation categories in 2012

\begin{tabular}{|c|c|c|c|c|c|c|}
\hline & \multirow{3}{*}{$\begin{array}{c}\text { Advertising } \\
\text { revenue } \\
(\$ \text { million }) \\
\text { Mean }\end{array}$} & \multicolumn{4}{|c|}{$\begin{array}{l}\text { Cash flow } \\
(\$ \text { million })\end{array}$} & \multirow{3}{*}{$\begin{array}{c}\text { Non-broad- } \\
\text { cast revenue } \\
(\$ \text { million }) \\
\text { Mean }\end{array}$} \\
\hline & & \multirow[b]{2}{*}{ Mean } & \multicolumn{3}{|c|}{ Quartile } & \\
\hline & & & First & Second & Third & \\
\hline All Stations, All Markets & 16.96 & 7.798 & 1.243 & 3.752 & 9.178 & 2.977 \\
\hline All Stations, Markets 101-110 & 8.267 & 4.120 & 1.704 & 3.619 & 6.444 & 2.102 \\
\hline $\mathrm{ABC}, \mathrm{CBS}, \mathrm{FOX}, \mathrm{NBC}$ & & & & & & \\
\hline All Markets & 19.05 & 9.244 & 1.936 & 4.929 & 10.901 & 3.326 \\
\hline ABC, Markets 1-25 & 67.78 & 32.400 & 15.090 & 27.150 & 42.460 & 7.596 \\
\hline NBC, Markets 101+ & 7.568 & 3.652 & 1.293 & 3.283 & 5.901 & 1.883 \\
\hline CW, All Markets & 13.35 & 3.929 & 0.355 & 1.798 & 3.224 & 2.884 \\
\hline MNTV, Markets 1-50 & 9.495 & 3.124 & 1.270 & 1.799 & 3.215 & 2.507 \\
\hline Independent, All Markets & 13.43 & 2.786 & -0.020 & 1.288 & 4.327 & 2.195 \\
\hline
\end{tabular}

\section{B Proofs}

In this appendix, we prove Propositions 1 and 2. We first state and prove two lemmas characterizing the impact of $b_{j}$ on the payout to TV station $j$ and on the profit of its owner, firm $i$. In a slight abuse of notation, we partition the vector $b=\left(b_{1}, \ldots, b_{N}\right)$ of bids as $\left(b_{i}, b_{-i}\right)$, where $b_{i}$ is the vector of bids of firm $i$ and $b_{-i}$ is the vector of bids of the other firms, and as $\left(b_{j}, b_{-j}\right)$, where $b_{j}$ is the bid of TV station $j$ and $b_{-j}$ is the vector of bids of the other TV stations. Let $\tau(j) \geq 1$ denote the round of the reverse auction where TV station $j$ first opts to remain on the air (unless it has already been frozen), i.e., $P_{\tau(j)-1}>b_{j} \geq P_{\tau(j)}$ (and we set $P_{0}=\infty$ ). Partition the set of frozen TV stations at the conclusion of the reverse auction as $F^{*}(b)=\bigcup_{j \in\{1, \ldots, N\}} F_{j}^{*}(b)$, where $F_{j}^{*}(b) \subseteq\{1, \ldots, N\}$ is the (possibly empty) set of TV stations that are frozen by TV station $j$ given the vector of bids $b{ }^{75}$ Note that TV station $j$ determines the payout $P O_{k}(b)=P_{\tau(j)} \varphi_{k}$ to all TV stations $k \in F_{j}^{*}(b)$. Finally, denote the set of inactive TV stations at the conclusion of the reverse auction as $I^{*}(b)$.

Lemma 3. If $j \in J_{i}$ and $j \in F^{*}(b)$, then $\pi_{i}(b)=\pi_{i}\left(\tilde{b}_{j}, b_{-j}\right)$ for all $\tilde{b}_{j} \leq b_{j}$.

Proof. Because $j \in F^{*}(b)$, it must be that $j \in F_{l}^{*}(b)$ for some TV station $l$ with $b_{l}>b_{j}$, i.e., TV station $l$ freezes TV station $j$ under the vector of bids $b$. Note that $j \in F_{l}^{*}\left(\tilde{b}_{j}, b_{-j}\right)$ for all $\tilde{b}_{j} \leq b_{j}$ and thus $F_{j}^{*}(b)=F_{j}^{*}\left(\tilde{b}_{j}, b_{-j}\right)=\emptyset$, i.e., TV station $l$ continues to freeze TV station $j$ under the vector of bids $\left(\tilde{b}_{j}, b_{-j}\right)$ and TV station $j$ does not freeze another TV station. Hence, we have to show that

$$
\pi_{i}(b)=\sum_{k \neq j} \sum_{m \in J_{i} \cap F_{k}^{*}(b)}\left(P_{\tau(k)} \varphi_{m}-v_{m}\right)=\sum_{k \neq j} \sum_{m \in J_{i} \cap F_{k}^{*}\left(\tilde{b}_{j}, b_{-j}\right)}\left(P_{\tau(k)} \varphi_{m}-v_{m}\right)=\pi_{i}\left(\tilde{b}_{j}, b_{-j}\right)
$$

\footnotetext{
${ }^{75}$ If a TV station $k \in Z_{1}(b)$ is frozen at the outset of the reverse auction, then we assign it to a TV station $l \in Y_{1}(b)$ and say that $k \in F_{l}^{*}(b)$.
} 
Figure A1: Case 1 and subcases in proof of Lemma 4

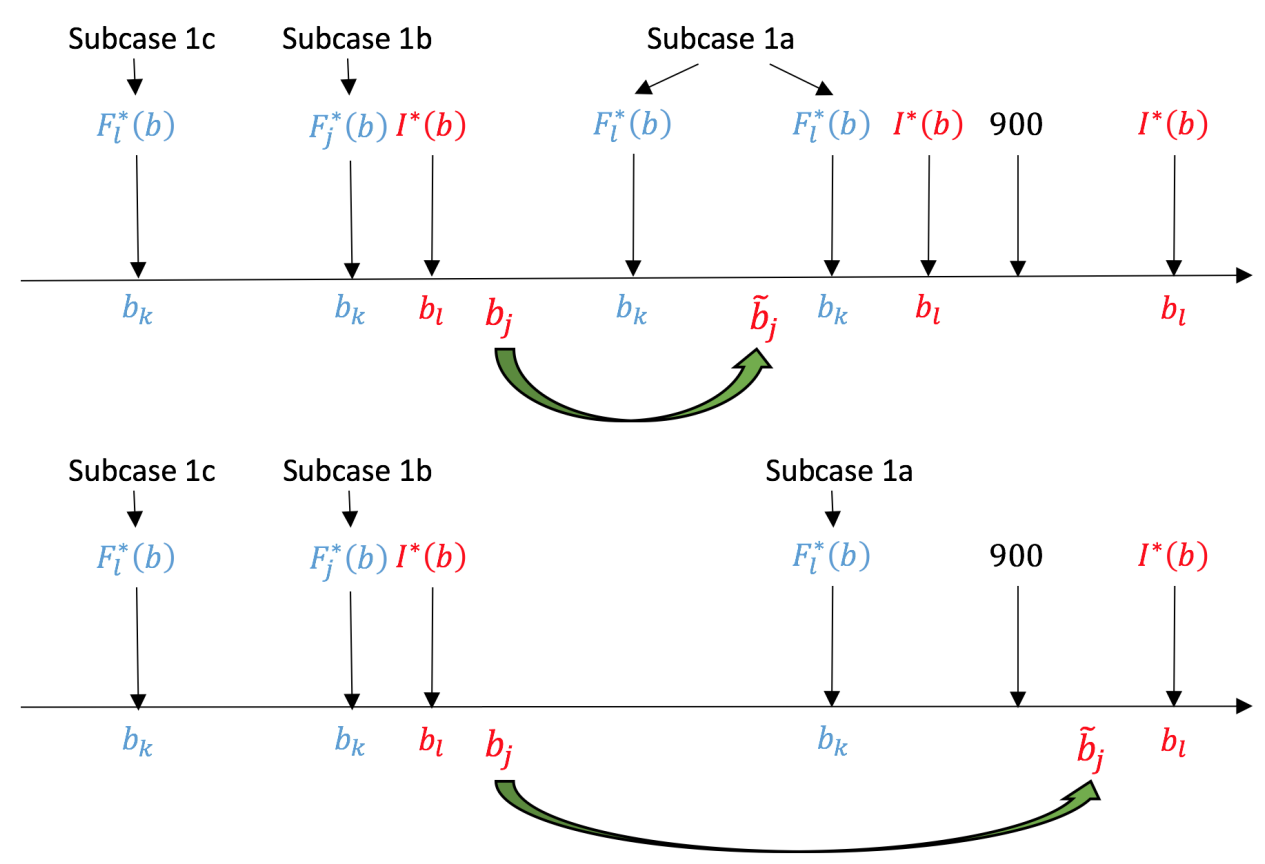

for all $\tilde{b}_{j} \leq b_{j}$. It suffices to show that $F_{k}^{*}(b)=F_{k}^{*}\left(\tilde{b}_{j}, b_{-j}\right)$ for all $\tilde{b}_{j} \leq b_{j}$ and $k \neq j$. First consider any TV station $k$ with $b_{k}>b_{j}$. It is obvious that $F_{k}^{*}(b)=F_{k}^{*}\left(\tilde{b}_{j}, b_{-j}\right)$ for all $\tilde{b}_{j} \leq b_{j}$. Consider next any TV station $k$ with $b_{k}<b_{j}$. Because $F_{\tau(l)+1}(b)=F_{\tau(l)+1}\left(\tilde{b}_{j}, b_{-j}\right)$ and $A_{\tau(l)+1}(b)=$ $A_{\tau(l)+1}\left(\tilde{b}_{j}, b_{-j}\right)$, the reverse auction progresses the same from round $\tau(l)+1$ on under the vector of bids $b$ as under the vector of bids $\left(\tilde{b}_{j}, b_{-j}\right)$. Hence, $F_{k}^{*}(b)=F_{k}^{*}\left(\tilde{b}_{j}, b_{-j}\right)$ for all $\tilde{b}_{j} \leq b_{j}$. This completes the proof.

Lemma 4. If $j \in I^{*}(b)$ and $S\left(Y_{1}(b) \cup\{j\}, R\right)=1$, then $F^{*}(b)=F^{*}\left(\tilde{b}_{j}, b_{-j}\right)$ and $P O_{k}(b) \leq$ $P O_{k}\left(\tilde{b}_{j}, b_{-j}\right)$ for all $\tilde{b}_{j}>b_{j}$ and $k \in\{1, \ldots, N\}$.

Proof. The condition $S\left(Y_{1}(b) \cup\{j\}, R\right)=1$ guarantees that the reverse auction does not fail at the outset for any vector of bids $\left(\tilde{b}_{j}, b_{-j}\right)$. Consider first TV station $j$. Because $j \in I^{*}(b)$, it must be that $j \in I^{*}\left(\tilde{b}_{j}, b_{-j}\right)$ and thus $P O_{j}(b)=0=P O_{j}\left(\tilde{b}_{j}, b_{-j}\right)$ for all $\tilde{b}_{j}>b_{j}$. Next consider any TV station $k \neq j$. If $k \in I^{*}(b)$, then $k \in I^{*}\left(\tilde{b}_{j}, b_{-j}\right)$ for all $\tilde{b}_{j}>b_{j}$ and thus $P O_{k}(b)=0=P O_{k}\left(\tilde{b}_{j}, b_{-j}\right)$. Assuming $k \notin I^{*}(b)$ and therefore $b_{k}<900$, we proceed in two cases, depending on whether or not there exists any inactive TV station with its bid between $b_{j}$ and $\widetilde{b}_{j}$.

Case 1: There does not exist any inactive TV station with its bid between $b_{j}$ and $\widetilde{b}_{j}$, i.e., $\left\{l \mid l \in I^{*}(b), b_{j}<b_{l}<\widetilde{b}_{j}\right\}=\emptyset$. Consider a TV station $k \neq j$. Figure A1 illustrates the possible subcases.

Subcase 1a: If $b_{j}<b_{k}$, then $k \in F_{l}^{*}(b)$ for some TV station $l$ with $b_{l} \geq \widetilde{b}_{j}$. Thus $k \in$ $F_{l}^{*}\left({\widetilde{b_{j}}}_{j} b_{-j}\right) \cup F_{1}\left(\widetilde{b}_{j}, b_{-j}\right)$ and $P O_{k}(b)=P_{\tau(l)} \varphi_{k}=P O_{k}\left(\widetilde{b}_{j}, b_{-j}\right)$.

$\underline{\text { Subcase } 1 \mathrm{~b}:}$ If $b_{k}<b_{j}$ and $k \in F_{j}^{*}(b)$, then $k \in F_{j}^{*}\left(\widetilde{b}_{j}, b_{-j}\right) \cup F_{1}\left(\widetilde{b}_{j}, b_{-j}\right)$ and $P O_{k}(b)=P_{\tau(j)} \varphi_{k}<$ $P O_{k}\left(\widetilde{b}_{j}, b_{-j}\right)$. 
Figure A2: Case 2 and subcases in proof of Lemma 4
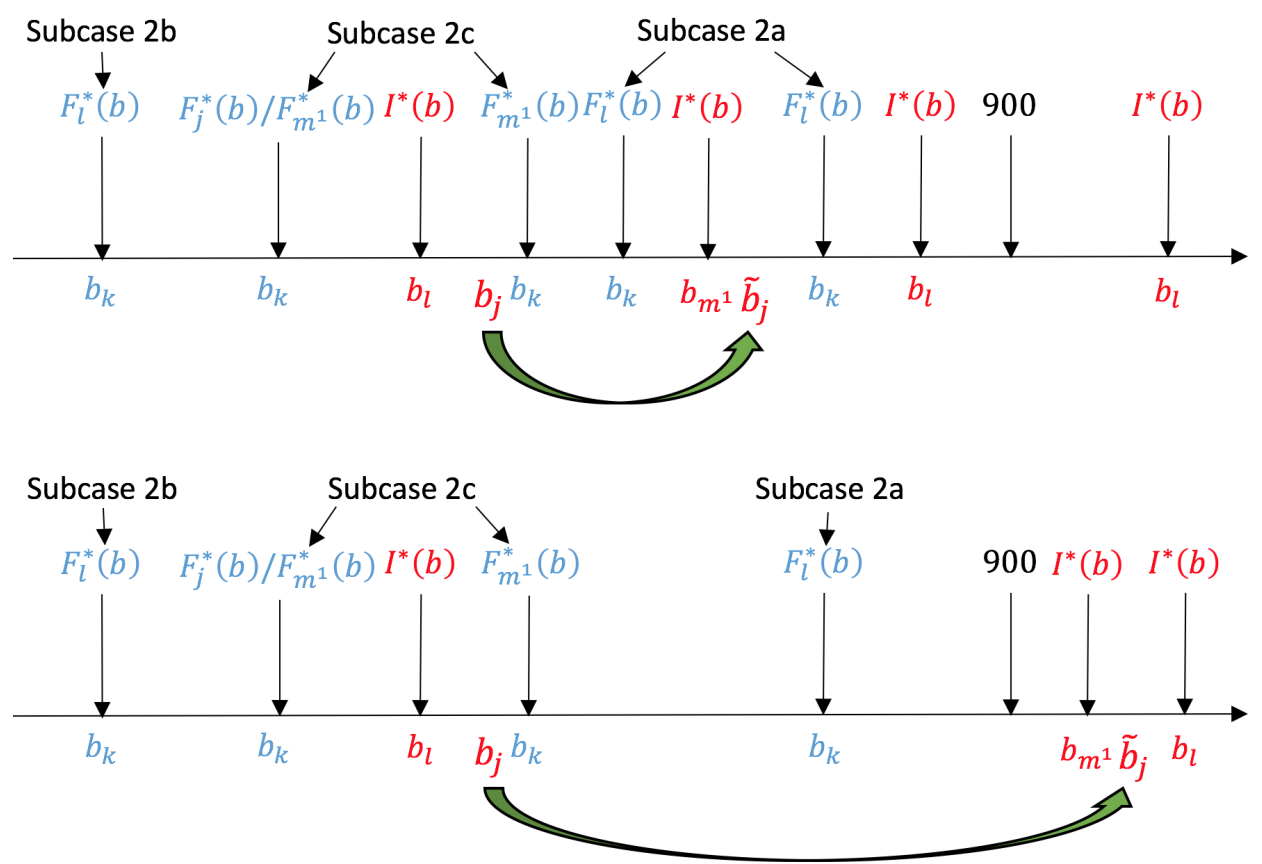

Subcase 1c: If $b_{k}<b_{j}$ and $k \in F_{l}^{*}(b)$ for some TV station $l \in I^{*}(b) \backslash\{j\}$, then $k \in F_{l}^{*}\left(\widetilde{b}_{j}, b_{-j}\right) \cup$

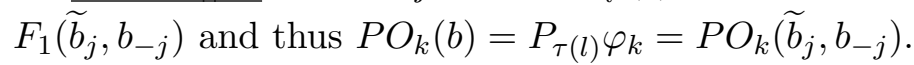

Case 2: There exists at least one inactive TV station with its bid between $b_{j}$ and $\widetilde{b}_{j}$, i.e., $M=\left\{m \mid m \in I^{*}(b), b_{j}<b_{m}<\widetilde{b}_{j}\right\} \neq \emptyset$. Let $M=\left\{m^{1}, \ldots, m^{n}\right\}$ and enumerate its members such that $b_{j}<b_{m^{1}}<b_{m^{2}}<\ldots<b_{m^{n}}<\widetilde{b}_{j}$. It suffices to show that $F^{*}(b)=F^{*}\left(b_{m^{1}}+\epsilon, b_{-j}\right)$ and $P O_{k}(b) \leq P O_{k}\left(b_{m^{1}}+\epsilon, b_{-j}\right)$ for all $k \neq j$ and any sufficiently small $\epsilon>0$; it then follows that $F^{*}(b)=F^{*}\left(b_{m^{1}}+\epsilon, b_{-j}\right)=\ldots=F^{*}\left(b_{m^{n}}+\epsilon, b_{-j}\right)=F^{*}\left(\widetilde{b}_{j}, b_{-j}\right)$, where the last equality follows from Case 1 , and $P O_{k}(b) \leq P O_{k}\left(b_{m^{1}}+\epsilon, b_{-j}\right) \leq \ldots \leq P O_{k}\left(b_{m^{n}}+\epsilon, b_{-j}\right) \leq P O_{k}\left(\widetilde{b}_{j}, b_{-j}\right)$ for all $k \neq j$ for the same reason.

Consider a TV station $k \neq j$. Figure A2 illustrates the possible subcases.

Subcase 2a: If $k \in F_{l}^{*}(b)$ for some TV station $l$ with $b_{m^{1}}<b_{l}$, then $k \in F_{l}^{*}\left(b_{m^{1}}+\epsilon, b_{-j}\right) \cup$ $F_{1}\left(\widetilde{b}_{j}, b_{-j}\right)$ and $P O_{k}(b)=P_{\tau(l)} \varphi_{k}=P O_{k}\left(b_{m^{1}}+\epsilon, b_{-j}\right)$.

Subcase 2b: If $k \in F_{l}^{*}(b)$ for some TV station $l$ with $b_{l}<b_{j}$, then $k \in F_{l}^{*}\left(b_{m^{1}}+\epsilon, b_{-j}\right)$ and $P O_{k}(b)=P_{\tau(l)} \varphi_{k}=P O_{k}\left(b_{m^{1}}+\epsilon, b_{-j}\right)$.

Subcase 2c: If $k \in F_{j}^{*}(b) \cup F_{m^{1}}^{*}(b)$, then $k \in F_{j}^{*}\left(b_{m^{1}}+\epsilon, b_{-j}\right) \cup F_{m^{1}}^{*}\left(b_{m^{1}}+\epsilon, b_{-j}\right) \cup F_{1}\left(\widetilde{b}_{j}, b_{-j}\right)$ and $P O_{k}(b) \leq P_{\tau\left(m^{1}\right)} \varphi_{k}=P O_{k}\left(b_{m^{1}}+\epsilon, b_{-j}\right)$.

This completes the proof.

We are now ready to prove Proposition 1:

Proof of Proposition 1. We first show that $j \in I^{*}(b)$. Suppose to the contrary that $j \notin I^{*}(b)$. Then $j \in F^{*}(b)$ and Lemma 3 implies $\pi_{i}(b)=\pi_{i}\left(s_{j}, b_{-j}\right)$, contradicting $\pi_{i}(b)>\pi_{i}\left(s_{j}, b_{-j}\right)$. Hence, 
$j \in I^{*}(b)$ and it follows from Lemma 4 that

$$
\begin{aligned}
\pi_{i}(b) & =\sum_{l \in J_{i} \cap F^{*}(b)}\left(P O_{l}(b)-v_{l}\right) \\
& \leq \sum_{l \in J_{i} \cap F^{*}\left(900, b_{-j}\right)}\left(P O_{l}\left(900, b_{-j}\right)-v_{l}\right) \\
& =\pi_{i}\left(900, b_{-j}\right) .
\end{aligned}
$$

The proof of Proposition 2 largely parallels that of Proposition 1:

Proof of Proposition 2. Suppose to the contrary that $\pi_{i}\left(0, b_{-j}\right)<\pi_{i}(b)$. Then it must be that $j \in I^{*}(b)$; otherwise, $j \in F^{*}(b)$ and it follows from Lemma 3 that $\pi_{i}\left(0, b_{-j}\right)=\pi_{i}(b)$. Hence, $j \in I^{*}(b)$ and it follows from Lemma 4 that

$$
\begin{aligned}
\pi_{i}(b) & =\sum_{l \in J_{i} \cap F^{*}(b)}\left(P O_{l}(b)-v_{l}\right) \\
& \leq \sum_{l \in J_{i} \cap F^{*}\left(s_{j}, b_{-j}\right)}\left(P O_{l}\left(s_{j}, b_{-j}\right)-v_{l}\right) \\
& =\pi_{i}\left(s_{j}, b_{-j}\right),
\end{aligned}
$$

contradicting $\pi_{i}(b)>\pi_{i}\left(s_{j}, b_{-j}\right)$. 


\section{Reservation values}

In this appendix, we provide details on how we estimate the reservation value of a TV station going into the reverse auction.

\section{C.1 Cash flows}

\section{C.1.1 Functional forms}

In the cash flow model in equation (10), we parameterize $\alpha\left(X_{j t} ; \beta\right), R T\left(X_{j t} ; \gamma\right)$, and $F\left(X_{j t} ; \delta\right)$ as functions of station and market characteristics $X_{j t}$ as

$$
\begin{aligned}
\alpha\left(X_{j t} ; \beta\right) & =\sum_{a=1}^{9} \beta_{0}^{a} 1\left(\text { Affiliation }_{j t}=a\right)+\sum_{s=2003}^{2012} \beta_{0}^{s} 1(t=s)+\beta_{1} \text { Fox }_{j t} \cdot t+\beta_{2} \text { CompIndex }_{j t}, \\
R T\left(X_{j t} ; \gamma\right) & =\exp \left(\gamma_{0}+\gamma_{1} t+\gamma_{2} \ln \left(\text { PopServed }_{j t}\right),\right. \\
F\left(X_{j t} ; \delta\right) & =\delta_{0}+\delta_{1} \text { WealthIndex }_{j t}+\sum_{h=1}^{3} 1\left(\text { Group }_{j t}=h\right)\left(\delta_{2}^{h} \ln \left(\text { PopServed }_{j t}\right)+\delta_{3}^{h} \ln \left(\text { PopServed }_{j t}\right)^{2}\right),
\end{aligned}
$$

where $1(\cdot)$ is the indicator function and we use the shorthand

$$
\begin{aligned}
\text { PopServed }_{j t} & =1\left(\text { PowerOutput }_{j t}=\text { FullPower }\right) \cdot \text { DMAPop }_{j t} \\
& +1(\text { PowerOutput } \\
j t & =\text { LowPowerClassA }) \cdot \text { InterferenceFreePop } \text { L }_{j t} .
\end{aligned}
$$

${\text { Af } \text { filiation }_{j t} \text { refers to nine of the eleven affiliations }}^{76}$ in Table A3 and Group int $_{\text {to }}$ groupings of affiliations (detailed below). WealthIndex $x_{j t}$ and CompIndex $x_{j t}$ are the wealth and competitiveness indices for the DMA. ${ }^{77}$

We allow the share $\alpha\left(X_{j t} ; \beta\right)$ of advertising revenue retained as cash flow to vary flexibly by year and network affiliation. We allow for a separate time trend for Fox affiliates as their profitability grew substantially over time. The competitiveness index CompIndex $x_{j t}$ accounts for differences in the competitive environment across DMAs.

\footnotetext{
${ }^{76}$ We normalize the parameter on the indicator for Spanish-language networks to zero. We exclude any TV station affiliated with other minor networks from the estimation in line with footnote 74 . To predict the cash flow for such a TV station, we use its station and owner characteristics $X_{j t}$ and the estimated parameter on the indicator for Independent.

${ }^{77}$ To parsimoniously capture market characteristics, we conduct a principal component analysis of the log of the market-level variables prime-age (18-54) population, average per capita disposable personal income, retail expenditures, total market advertising revenues, number of primary TV stations, and number of major network affiliates. We define the time-varying number of primary TV stations and major network affiliates based on auction-eligible TV stations contained in the BIA data from 2003 to 2013 and for 2015 but rely on the BIA data for 2015 for the remaining market-level characteristics. The first principal component, denoted as CompIndex ${ }_{j t}$, loads primarily on to prime-age population, advertising revenues, number of primary TV stations, and number of major network affiliates. The second principal component, denoted as WealthIndex $x_{j t}$ loads primarily on to average disposable income and retail expenditures.
} 
We specify $R T\left(X_{j t} ; \gamma\right)$ as an exponential function of DMA population and interference free population for full-power stations and low-power class-A stations, respectively, and a time trend, in light of the rapid growth of retransmission fees. We make no attempt to separately estimate an error term for non-broadcast revenue and assume it is one part of $\epsilon_{j t}$ in equation (10) due to additivity. ${ }^{78}$

Lastly, we let fixed cost $F\left(X_{j t} ; \delta\right)$ vary flexibly with DMA population and interference free population for full-power stations and low-power class-A stations, respectively, as well as the network affiliation. To streamline the specification, we subsume the affiliations in Table A3 into three groups with similar cost structures: (1) ABC, CBS, and NBC; (2) Fox, CW, and Warner Bros; (3) My Network TV, United Paramount, Spanish-language networks, and Independents. We include the wealth index WealthIndex $x_{j t}$ in the fixed cost to reflect the differential cost of operating in different DMAs.

\section{C.1.2 Data and estimation}

We combine the station-level data on advertising revenue, station characteristics, and market characteristics from BIA with the aggregated data from NAB. The NAB data yields 3,313 moments across aggregation categories and the ten years from 2003 to 2012. We drop the years 2013 and 2015 from the BIA data as 2012 is the latest year of availability for the NAB data. There are a total of 11,731 station-year observations from the BIA data that meet NAB's data collection and reporting procedure and therefore map into a table of a NAB report.

We use a simulated minimum distance estimator for the parameters $\theta=(\beta, \gamma, \delta, \sigma)$ of the cash flow model in equation (10). We draw $N^{s}=100$ vectors of cash flow error terms $\epsilon^{s}=\left(\epsilon_{j t}^{s}\right)$, where $\epsilon_{j t}^{s}$ is the cash flow error term of TV station $j$ in year $t$ in draw $s$. Denote by $\overline{C F}_{g t}, C F_{g t}^{1}, C F_{g t}^{2}$, and $C F_{g t}^{3}$ the mean, first, second, and third quartiles of the cash flow distribution reported by NAB in year $t$ for aggregation category $g=1, \ldots, G_{t}$, where $G_{t}$ is the number of aggregation categories in year $t$. Similarly, denote by $\widehat{C F}_{g t}\left(\theta ; \epsilon^{s}\right), \widehat{C F}_{g t}^{1}\left(\theta ; \epsilon^{s}\right), \widehat{C F}_{g t}^{2}\left(\theta ; \epsilon^{s}\right)$, and $\widehat{C F}_{g t}^{3}\left(\theta ; \epsilon^{s}\right)$ the analogous moments of the predicted cash flow distribution for the TV stations that feature in aggregation category $g$ in year $t$. Our notation emphasizes that the latter depend on the parameters $\theta$ and the vector of cash flow error terms $\epsilon^{s}$ in draw $s$; we suppress their dependence on advertising revenue and characteristic data from BIA. We use similar notation, replacing $\overline{C F}$ with $\overline{R T}$, for the mean of the non-broadcast revenue distributions. To estimate $\theta$, we match the moments of the predicted and actual distributions across aggregation categories and years. Formally, we solve

$$
\begin{aligned}
\hat{\theta}=\arg \min _{\theta} \sum_{t=2003}^{2012} \sum_{g=1}^{G_{t}} & \left(\overline{C F}_{g t}-\frac{1}{N^{s}} \sum_{s=1}^{N^{s}} \widehat{\overline{C F}}_{g t}\left(\theta ; \epsilon^{s}\right)\right)^{2}+\sum_{q=1}^{3}\left(C F_{g t}^{q}-\frac{1}{N^{s}} \sum_{s=1}^{N^{s}} \widehat{C F}_{g t}^{q}\left(\theta ; \epsilon^{s}\right)\right)^{2} \\
& +\left(\overline{R T}_{g t}-\widehat{\overline{R T}}_{g t}(\theta)\right)^{2}
\end{aligned}
$$

\footnotetext{
${ }^{78}$ We obtain very similar estimates when we separately estimate such an error term.
} 
We constrain the standard deviation of the error term to be positive. Our interior-point minimization algorithm terminates with a search step less than the specified tolerance of $10^{-12}$. We use multiple starting values to guard against local minima.

\section{C.1.3 Results}

Table A6 reports the parameter estimates for the retained share $\alpha\left(X_{j t} ; \beta\right)$, non-broadcast revenue $R T\left(X_{j t} ; \gamma\right)$, and fixed cost $F\left(X_{j t} ; \delta\right)$. They are in line with our expectations: major network affiliates retain a higher share of advertising revenue than minor networks, with Fox having a positive trend; independent and WB stations retain the highest share of advertising revenues, albeit with the smallest revenue base; the retained share falls over time, bottoming out in 2009 before bouncing back in recent years; the retained share is lower in more competitive markets. Finally, non-broadcast revenue has grown significantly in recent years and there are economies of scale in fixed cost.

Figure A3 plots the distributions of the predicted retained share $\alpha\left(X_{j t} ; \beta\right)$ (left panel), nonbroadcast revenue $R T\left(X_{j t} ; \gamma\right)$ (middle panel), and fixed cost $F\left(X_{j t} ; \delta\right)$ (right panel) for the 1,168 commercial full-power stations surveyed by NAB in 2012. Reassuringly, without imposing restrictions, we predict the retained share to be between 0.2 and 0.7 in 2012 , with an average of 0.53 ; non-broadcast revenue is predicted to be between $\$ 0.22$ million and $\$ 10.9$ million; fixed cost is predicted to be positive for $95 \%$ of TV stations, averaging $\$ 4.4$ million, with the highest predicted fixed cost of $\$ 24.2$ million.

Figure A3: Predicted retained share $\alpha\left(X_{j t} ; \beta\right)$, non-broadcast revenue $R T\left(X_{j t} ; \delta\right)$, and fixed cost $F\left(X_{j t} ; \delta\right)$ in 2012
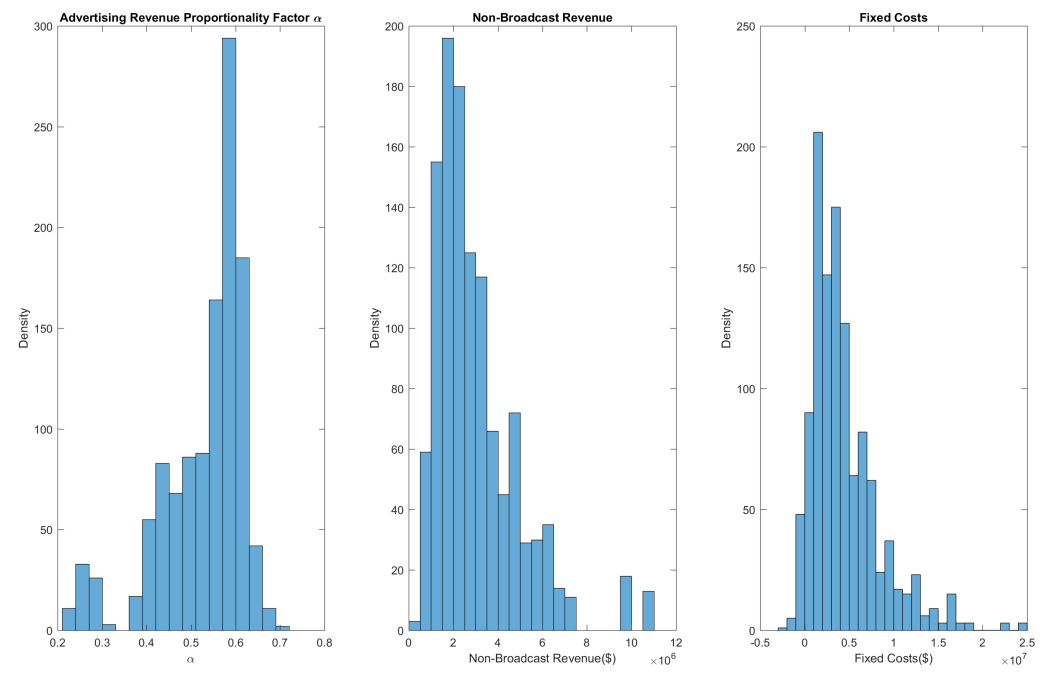

The cash flow model fits the data well. Figure A4 plots the distributions of predicted cash flow for a sample draw of the vector of cash flow error terms $\epsilon^{s}$ (left panel) and non-broadcast revenue 


\section{Table A6: Cash flow parameters estimates}

\begin{tabular}{|c|c|}
\hline & Estimate \\
\hline \multicolumn{2}{|l|}{ Retained share $\alpha\left(X_{j t} ; \beta\right)$} \\
\hline $\mathrm{ABC}$ & -0.032 \\
\hline $\mathrm{CBS}$ & -0.050 \\
\hline Fox & -0.383 \\
\hline $\mathrm{NBC}$ & -0.049 \\
\hline $\mathrm{CW}$ & -0.116 \\
\hline MyNetwork TV & -0.344 \\
\hline United Paramount & -0.352 \\
\hline Warner Bros & 0.010 \\
\hline Independent & -0.103 \\
\hline Fox $\times$ Trend & 0.018 \\
\hline 2003 & 0.693 \\
\hline 2004 & 0.665 \\
\hline 2005 & 0.642 \\
\hline 2006 & 0.629 \\
\hline 2007 & 0.599 \\
\hline 2008 & 0.568 \\
\hline 2009 & 0.534 \\
\hline 2010 & 0.601 \\
\hline 2011 & 0.622 \\
\hline 2012 & 0.638 \\
\hline CompIndex $x_{j t}$ & -0.019 \\
\hline \multicolumn{2}{|c|}{ Non-broadcast revenue $R T\left(X_{j t}, \gamma\right)(\log \$)$} \\
\hline Intercept & 6.248 \\
\hline $\ln \left(\right.$ PopServed $\left._{j t}\right)$ & 0.510 \\
\hline Trend & 0.135 \\
\hline \multicolumn{2}{|l|}{ Fixed cost $F\left(X_{j t} ; \delta\right)(\$$ million $)$} \\
\hline Intercept & 81.747 \\
\hline WealthIndex $x_{j t}$ & 1.133 \\
\hline Group $1 \times \ln \left(\right.$ PopServed $\left._{j t}\right)$ & -15.071 \\
\hline Group $2 \times \ln \left(\right.$ PopServed $\left._{j t}\right)$ & -13.526 \\
\hline Group $3 \times \ln \left(\right.$ PopServed $\left._{j t}\right)$ & -12.229 \\
\hline Group $1 \times \ln \left(\text { PopServed }_{j t}\right)^{2}$ & 0.690 \\
\hline Group $2 \times \ln \left(\text { PopServed }_{j t}\right)^{2}$ & 0.561 \\
\hline Group $3 \times \ln \left(\text { PopServed }_{j t}\right)^{2}$ & 0.468 \\
\hline$\sigma(\$$ million $)$ & 0.854 \\
\hline
\end{tabular}

(right panel) for the 1,168 commercial full-power stations surveyed by NAB in 2012. We predict cash flow of between $\$-8.8$ million and $\$ 126$ million across TV stations, with an average of $\$ 7.2$ million, compared to $\$ 7.8$ million reported by NAB. The first quartile ( $\$ 1.6$ million), second quartile ( $\$ 3.5$ million), and third quartile (\$7.8 million) of the distribution of predicted cash flow are overlaid in red lines (dashed, dotted, and dash-dotted, respectively). The black lines of the same patterns refer to the corresponding moments in the NAB data (table "All Stations, All Markets"). Non-broadcast 


\section{Figure A4: Predicted cash flow and non-broadcast revenue with moments in 2012}
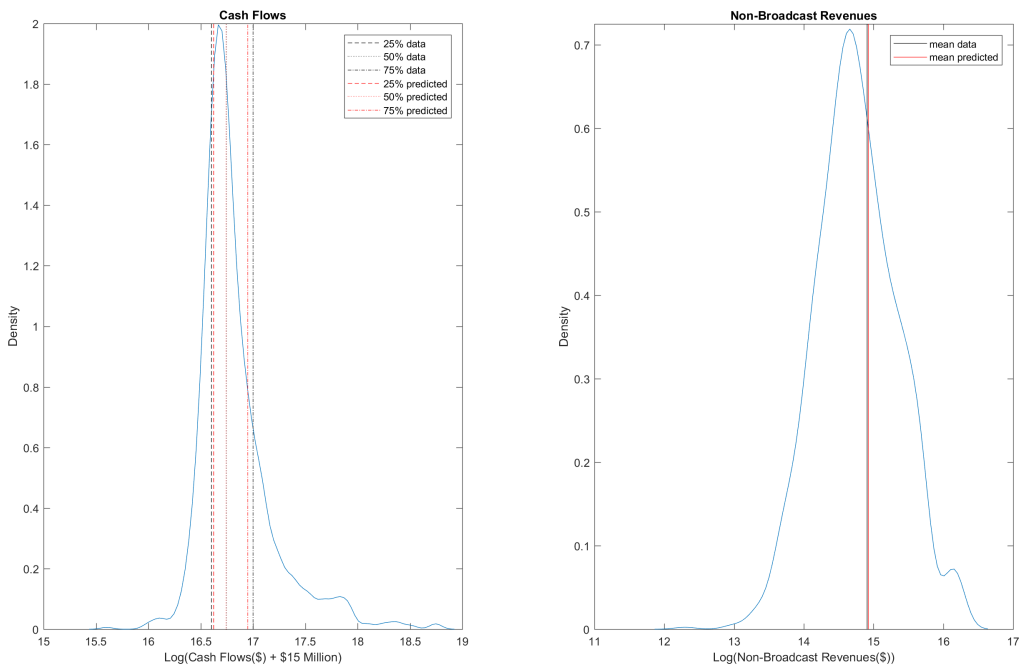

Notes: In logs. Cash flow is shifted by $\$ 15$ million to avoid negative numbers.

revenue is predicted to average $\$ 3.04$ million, compared to $\$ 2.98$ million reported by NAB.

To further assess the fit of the cash flow model, Table A7 compares the cash flow and nonbroadcast revenue moments reported in the NAB data to the corresponding predicted moments, broken down by type of moment, affiliation, year, and market rank. It provides three different measures of fit: the correlation between predicted and data moments and the mean absolute deviation in levels in $\$$ million and as a percent of the data moments. Overall, our cash flow model predicts the 3,313 moments with a 0.98 correlation. The fit between data and predicted moments is better for the 1,995 moments pertaining to major network affiliates than for the 110 moments pertaining to independent stations. Similarly, the fit is better for moments pertaining to larger markets. The 330 predicted moments for 2012 have a 0.98 correlation with the data moments; on average, our predicted moments miss the data moments by $\$ 1.11$ million, or $16.4 \%$. Other years are comparable. 
Table A7: Cash flow and non-broadcast revenue moments and fit measures

\begin{tabular}{lcccc}
\hline & Number of & & \multicolumn{2}{c}{ Mean abs. deviation } \\
\cline { 5 - 5 } & moments & Correlation & $\$$ million & $\%$ \\
\hline All moments & 3313 & 0.98 & 0.90 & 18.04 \\
\hline Moments by type & & & & \\
Cash flow, mean & 663 & 0.99 & 0.89 & 13.17 \\
Cash flow, first quartile & 662 & 0.97 & 0.90 & 35.05 \\
Cash flow, second quartile & 663 & 0.98 & 0.89 & 17.61 \\
Cash flow, third quartile & 663 & 0.98 & 1.35 & 15.02 \\
Non-broadcast revenue, mean & 662 & 0.84 & 0.49 & 29.01 \\
\hline Moments by affiliation & & & & \\
Major network & 1995 & 0.98 & 1.00 & 16.16 \\
Minor network & 350 & 0.93 & 0.97 & 37.60 \\
Independent & 110 & 0.77 & 0.94 & 61.56 \\
\hline Moments by year & & & & \\
2003 & 329 & 0.98 & 1.06 & 19.94 \\
2004 & 325 & 0.99 & 0.88 & 15.23 \\
2005 & 330 & 0.98 & 0.96 & 19.39 \\
2006 & 310 & 0.98 & 0.98 & 16.59 \\
2007 & 344 & 0.98 & 0.88 & 19.30 \\
2008 & 350 & 0.98 & 0.83 & 19.77 \\
2009 & 330 & 0.98 & 0.65 & 22.74 \\
2010 & 330 & 0.98 & 0.83 & 16.10 \\
2011 & 335 & 0.98 & 0.88 & 18.22 \\
2012 & 330 & 0.98 & 1.11 & 16.44 \\
\hline Moments by market rank & & & & \\
$1-25$ & 460 & 0.98 & 2.36 & 14.67 \\
$26-50$ & 385 & 0.95 & 0.96 & 16.36 \\
$51-100$ & 930 & 0.92 & 0.63 & 20.14 \\
$101+$ & 799 & 0.88 & 0.46 & 31.82 \\
\hline
\end{tabular}

\section{C.2 Multiples}

\section{C.2.1 Priors}

Industry analysts give a range of $\$ 0.15$ to $\$ 0.40$ per $\mathrm{MHz}$-pop for the stick multiple and a range of 10 to 12 for the cash flow multiple. ${ }^{79}$ While the stick multiple is believed to be much larger for larger markets, the cash flow multiple is believed to be symmetrically distributed. Therefore, our prior is that the stick multiple is distributed log-normally with mean $\mu_{\text {prior }}^{\text {Stick }}=-1.4$ and standard deviation $\sigma_{\text {prior }}^{\text {Stick }}=0.5$ (corresponding to a mean of $\$ 0.25$ per MHz-pop and a standard deviation of $\$ 1$ per MHz-pop, thereby covering $\$ 0.15$ to $\$ 0.40$ per $\mathrm{MHz}$-pop with probability 0.68 ) and that the cash flow multiple is distributed normally with mean $\mu_{\text {prior }}^{C F}=11$ and standard deviation $\sigma_{\text {prior }}^{C F}=1$.

\footnotetext{
${ }^{79}$ See "Opportunities and Pitfalls on the Road to the Television Spectrum Auction", Bond \& Pecaro, December $12,2013$.
} 


\section{C.2.2 Data and estimation}

Our data consists of 133 transactions between 2003 and 2012 based on cash flow and 191 transactions between 2003 and 2013 based on stick value. For cash flow transactions, we infer the cash flow multiple from the transaction price and the cash flow $\widehat{C F}_{j t}$ predicted using equation (7), setting $\epsilon_{j t}=0$. For stick value transactions, we infer the stick multiple from the transaction price, the population served, and the power output of the TV station using equations (8) and (9).

For cash flow transactions, we estimate the following model for the multiple to construct its conditional likelihood function:

$$
\text { Multiple } e_{j t}^{C F}=\beta^{C F} X_{j t}+\epsilon_{j t}^{C F},
$$

where $X_{j t}$ includes owner, station, and market characteristics. Specifically, we include in $X_{j t}$ an indicator of whether the TV station has multicast sub-channels, DMA population interacted with an indicator for a full-power station, interference free population interacted with an indicator for a low-power class-A station, a low-power class-A fixed effect, ownership category fixed effects (whether the owner owns between two and ten, or more than ten TV stations across DMAs), the wealth and competitiveness indices for the DMA, fixed effects for the ten affiliations in Table A3 except for other minor networks, and a full set of year fixed effects.

For stick value transactions, we estimate the following model:

$$
\ln \text { Multiple } e_{j t}^{\text {Stick }}=\beta^{\text {Stick }} X_{j t}+\epsilon_{j t}^{\text {Stick }}
$$

where we include in $X_{j t}$ the log of the output power of the TV station, the log of DMA population interacted with an indicator for a full-power station, the log of interference free population interacted with an indicator for a low-power class-A station, a low-power class-A fixed effect, ownership category fixed effects, the wealth and competitiveness indices for the DMA, a dark station fixed effect, affiliation fixed effects, and year fixed effects.

\section{C.2.3 Estimates and posteriors}

Table A8 reports parameter estimates for the cash flow and stick value multiples. The model for the cash flow multiple has an adjusted $R^{2}$ of 0.72 , and from the residuals we estimate a standard deviation of $\hat{\sigma}_{\text {likelihood }}^{C F}=4.02$. The model for the stick multiple has an adjusted $R^{2}$ of 0.66 , and we estimate $\hat{\sigma}_{\text {likelihood }}^{\text {Stick }}=1.06$. With the estimates in hand, we can predict multiples for any TV station. To obtain the posterior for the cash flow and stick multiple, we update our prior with the conditional likelihood function using Bayes rule as

$$
\begin{gathered}
\mu_{\text {posterior }}=\frac{\mu_{\text {prior }} \sigma_{\text {likelihood }}^{2}+\mu_{\text {likelihood }} \sigma_{\text {prior }}^{2}}{\sigma_{\text {prior }}^{2}+\sigma_{\text {likelihood }}^{2}}, \\
\sigma_{\text {posterior }}^{2}=\frac{\sigma_{\text {likelihood }}^{2} \sigma_{\text {prior }}^{2}}{\sigma_{\text {prior }}^{2}+\sigma_{\text {likelihood }}^{2}},
\end{gathered}
$$


Table A8: Cash flow and stick value multiples parameter estimates

\begin{tabular}{|c|c|c|c|c|}
\hline & \multicolumn{2}{|c|}{ Cash flow multiple } & \multicolumn{2}{|c|}{ Stick multiple } \\
\hline & Estimate & Std. Err. & Estimate & Std. Err. \\
\hline Multicast & -0.0101 & 1.0044 & & \\
\hline $\ln \left(\right.$ OutputPower $\left.{ }_{j t}\right)$ & & & $0.1745^{* * *}$ & 0.0525 \\
\hline 1 FullPower $\left._{j t}\right) \cdot$ DMAPop $_{j t}$ & $5.405 \cdot 10^{-7 * * *}$ & $1.892 \cdot 10^{-7}$ & & \\
\hline $1\left(\right.$ FullPower $\left._{j t}\right) \cdot \ln \left(\right.$ DMAPop $\left._{j t}\right)$ & & & $-0.4832^{* * *}$ & 0.1774 \\
\hline $1\left(\right.$ LowPowerClass $\left._{j t}\right) \cdot$ IntFreePop $_{j t}$ & $-9.121 \cdot 10^{-8}$ & $3.122 \cdot 10^{-7}$ & & \\
\hline $1\left(\right.$ LowPowerClass $\left._{j t}\right) \cdot \ln \left(\right.$ IntFreePop Pot $\left._{j t}\right)$ & & & $-0.5905^{* * *}$ & 0.1581 \\
\hline $1\left(\right.$ LowPowerClass $\left.A_{j t}\right)$ & -0.2862 & 2.1471 & 0.7136 & 2.5621 \\
\hline Owns 2-10 stations across DMAs & 2.3114 & 1.4404 & 0.3597 & 0.2320 \\
\hline Owns $>10$ stations across DMAs & $3.5031^{* *}$ & 1.3985 & $0.8842^{* * *}$ & 0.2276 \\
\hline WealthIndex $x_{j t}$ & $0.8943^{*}$ & 0.5112 & -0.1319 & 0.1221 \\
\hline CompIndex ${ }_{j t}$ & 0.7099 & 0.5314 & $0.2515^{* *}$ & 0.1246 \\
\hline 2003 & -0.4700 & 2.8612 & $3.9827^{*}$ & 2.3837 \\
\hline 2004 & 1.0119 & 2.4967 & $4.5252^{*}$ & 2.3789 \\
\hline 2005 & $5.2167^{*}$ & 2.8837 & 3.8847 & 2.4077 \\
\hline 2006 & $4.2471^{*}$ & 2.5095 & $4.8581^{* *}$ & 2.4052 \\
\hline 2007 & 3.2069 & 2.4819 & $4.1905^{*}$ & 2.3560 \\
\hline 2008 & 2.1453 & 2.8200 & 3.6902 & 2.4267 \\
\hline 2009 & 3.2956 & 2.7741 & 3.3563 & 2.3545 \\
\hline 2010 & 0.2000 & 2.6595 & 2.5437 & 2.3988 \\
\hline 2011 & -0.7009 & 2.3943 & 3.8630 & 2.4416 \\
\hline 2012 & -2.0504 & 2.2970 & $4.0255^{*}$ & 2.3941 \\
\hline 2013 & & & $4.2716^{*}$ & 2.4125 \\
\hline Dark & & & -0.1393 & 0.4415 \\
\hline $\mathrm{ABC}$ & $4.9792^{* *}$ & 2.2317 & $1.6082^{* * *}$ & 0.4716 \\
\hline CBS & $4.3053^{*}$ & 2.3181 & $1.1402^{* *}$ & 0.5639 \\
\hline Fox & 3.3855 & 2.0626 & $1.5267^{* *}$ & 0.6096 \\
\hline $\mathrm{NBC}$ & 3.3133 & 2.3356 & 0.3905 & 0.4648 \\
\hline Independent & -1.1178 & 1.7898 & 0.1710 & 0.2501 \\
\hline CW & -0.0499 & 1.9789 & 0.1208 & 0.3972 \\
\hline MyNetwork TV & 0.2442 & 2.7894 & -0.5563 & 0.4761 \\
\hline United Paramount & $9.4293^{*}$ & 5.1732 & $0.8315^{*}$ & 0.4334 \\
\hline Warner Bros & 1.6820 & 2.8562 & -1.0249 & 0.7108 \\
\hline Spanish-language networks & -0.7115 & 2.8345 & 0.1728 & 0.3092 \\
\hline Adjusted $R^{2}$ & 0.71 & & 0.6 & \\
\hline$N$ & 13 & & 19 & \\
\hline
\end{tabular}

Notes: To save space, we use the shorthand $1\left(\right.$ FullPower $\left._{j t}\right)$ for $1\left(\right.$ PowerOutput $_{j t}=$ FullPower ,

$1\left(\right.$ LowPowerClass $\left._{j t}\right)$ for 1 (PowerOutput ${ }_{j t}=$ LowPowerClassA), and IntFreePop por $_{j t}$ for InterferenceFreePop jt $_{\text {. }}$. 
where $\mu_{\text {likelihood }}^{C F}=\widehat{\text { Multipl }} e_{j t_{0}}^{C F}$ for cash flow transactions and $\mu_{\text {likelihood }}^{\text {Stick }}=\ln \widehat{\text { Multiple }}$ Stick $_{t_{0}}^{\text {Stick }}$ for stick value transactions, and we set $t_{0}=2015$. The posterior standard deviation of the cash flow multiple is 0.97 and that of the stick multiple is 0.45 . For the 1,670 UHF stations, Figure A5 illustrates a sample draw from the posterior distribution conditional on $X_{j t}$ for the cash flow multiple (left panel) and the stick multiple (right panel). The corresponding unconditional prior distribution is overlaid in red dashed lines.

Figure A5: Prior and posterior distribution of cash flow and stick multiples
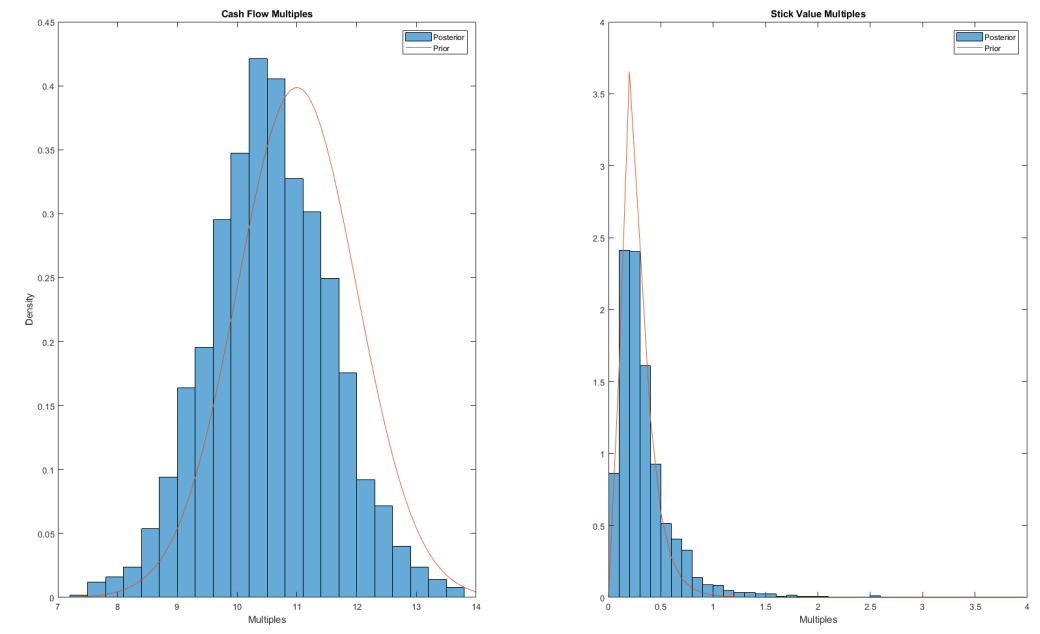

\section{Robustness to full repacking}

We perform two exercises to assess the effect of the limited repacking described in Section 6.2. First, we compare limited to full repacking for all 204 DMAs under naive bidding and both the $84 \mathrm{MHz}$ and the $126 \mathrm{MHz}$ clearing target. The top panel of Table A10 shows that moving to full repacking reduces total payouts by $0.2 \%$ under the $126 \mathrm{MHz}$ clearing target and by $3.2 \%$ under the $84 \mathrm{MHz}$ clearing target. This payout reduction is driven by the smaller number of TV stations that are acquired in the reverse auction under the more flexible full repacking, as the bottom panel of Table A10 shows. A lowering of the clearing target, and the smaller number of TV stations that need to be acquired to meet it, amplifies this effect. Closer inspection shows that the difference in payouts between limited and full repacking are concentrated in minor markets; the largest market with a discrepancy of more than $\$ 1$ million is the Pittsburgh, PA, DMA. At the same time, the correlation between payouts under full and limited repacking is 0.9997 for the $126 \mathrm{MHz}$ clearing target and 0.9866 for the $84 \mathrm{MHz}$ clearing target across all 20,400 runs of the reverse auction, suggesting that limited repacking captures the distribution of payouts well.

Second, we compare limited to full repacking under strategic bidding for two important DMAs, New York, NY, and Washington, DC, as doing so for all 204 DMAs is not computationally feasible. 
Table A10: Nationwide payouts to TV stations and number of TV stations acquired under naive bidding and full repacking

\begin{tabular}{lcc}
\hline & \multicolumn{2}{c}{ Naive bidding } \\
\cline { 2 - 3 } & Payouts $(\$$ billion) & $\begin{array}{c}\text { Number of TV } \\
\text { stations acquired }\end{array}$ \\
\hline Panel A: 126 MHz clearing target & 378.9 \\
\hline Limited repacking & 17.008 & $(6.292)$ \\
& $(0.740)$ & 365.24 \\
Full repacking & 16.966 & $(4.870)$ \\
\hline & $(0.7330)$ & 185.9 \\
\hline Panel B: 84 MHz clearing target & $(7.859)$ \\
Limited repacking & 4.003 & 143.8 \\
& $(0.204)$ & $(4.047)$ \\
\hline
\end{tabular}

The 189 strategy profiles in the New York, NY, DMA, require 18,900 runs of the reverse auction across simulation draws, and the 27 strategy profiles for the Washington, DC, DMA require 2,700 runs. Table A11 shows the results of this exercise, and affirms that the impact of limited repacking on payouts in the New York, NY, and Washington, DC, DMAs is not significant under strategic bidding for the $126 \mathrm{MHz}$ clearing target. We also find that for the Washington, DC, DMA under the $84 \mathrm{MHz}$ clearing target, payouts under full repacking are approximately $1.2 \%$ lower than those under limited repacking in the case of naive bidding and 1.1\% lower than payouts under limited repacking in the case of strategic bidding. In sum, therefore, while limited repacking likely introduces an upward bias in payouts, we do not have any evidence to suggest that it systematically biases the gains to strategic bidding. 
Table A11: Payouts to TV stations in select DMAs under strategic bidding and full repacking

\begin{tabular}{|c|c|c|c|c|c|c|}
\hline & \multirow{2}{*}{$\begin{array}{l}\text { Naive } \\
\text { bidding }\end{array}$} & \multicolumn{4}{|c|}{ Strategic bidding } & \multirow{2}{*}{$\begin{array}{c}\text { Payout } \\
\text { increase at } \\
\text { mean }(\%)\end{array}$} \\
\hline & & Mean & Min & Median & $\operatorname{Max}$ & \\
\hline \multicolumn{7}{|c|}{ Panel A: $126 \mathrm{MHz}$ clearing target, New York, NY, DMA } \\
\hline Limited repacking & $\begin{array}{c}2.363 \\
(0.216)\end{array}$ & $\begin{array}{c}3.086 \\
(0.295)\end{array}$ & $\begin{array}{c}2.363 \\
(0.216)\end{array}$ & $\begin{array}{c}3.096 \\
(0.330)\end{array}$ & $\begin{array}{c}3.893 \\
(1.013)\end{array}$ & 30.6 \\
\hline Full repacking & $\begin{array}{c}2.363 \\
(0.216)\end{array}$ & $\begin{array}{c}3.056 \\
(0.288)\end{array}$ & $\begin{array}{c}2.363 \\
(0.216)\end{array}$ & $\begin{array}{c}3.040 \\
(0.372)\end{array}$ & $\begin{array}{c}3.950 \\
(1.171)\end{array}$ & 29.3 \\
\hline \multicolumn{7}{|c|}{ Panel B: 126 MHz clearing target, Washington, DC, DMA } \\
\hline Limited repacking & $\begin{array}{c}0.290 \\
(0.071)\end{array}$ & $\begin{array}{c}0.327 \\
(0.065)\end{array}$ & $\begin{array}{c}0.317 \\
(0.063\end{array}$ & $\begin{array}{c}0.328 \\
(0.067)\end{array}$ & $\begin{array}{c}0.338 \\
(0.085)\end{array}$ & 12.9 \\
\hline Full repacking & $\begin{array}{c}0.290 \\
(0.071)\end{array}$ & $\begin{array}{c}0.328 \\
(0.066)\end{array}$ & $\begin{array}{c}0.316 \\
(0.063)\end{array}$ & $\begin{array}{c}0.328 \\
(0.067)\end{array}$ & $\begin{array}{c}0.339 \\
(0.087)\end{array}$ & 13.1 \\
\hline \multicolumn{7}{|c|}{ Panel C: 84 MHz clearing target, Washington, DC, DMA } \\
\hline Limited repacking & $\begin{array}{c}0.066 \\
(0.025)\end{array}$ & $\begin{array}{c}0.082 \\
(0.032)\end{array}$ & $\begin{array}{c}0.079 \\
(0.032)\end{array}$ & $\begin{array}{l}0.082 \\
0.032\end{array}$ & $\begin{array}{c}0.085 \\
(0.034)\end{array}$ & 24.5 \\
\hline Full repacking & $\begin{array}{c}0.065 \\
(0.026)\end{array}$ & $\begin{array}{c}0.081 \\
(0.031)\end{array}$ & $\begin{array}{c}0.079 \\
(0.032)\end{array}$ & $\begin{array}{l}0.081 \\
0.031\end{array}$ & $\begin{array}{c}0.084 \\
(0.032)\end{array}$ & 24.8 \\
\hline
\end{tabular}

Notes: Payout increase at mean calculated as percent difference between mean payouts under strategic and naive bidding. 


\section{Online Appendix}

\section{A A model of the reverse auction under complete information}

\section{A.1 Example 1 imposing independently owned TV stations}

We derive the set of equilibria for Example 1 in Section 3.1 whilst imposing that all TV stations are independently owned. Assuming a random tie-breaking rule for bids above 0 and below 900 in line with footnote 25 , the profit of TV station 1 is

$$
\pi_{1}\left(b_{1}, b_{2}, b_{3}\right)=\left\{\begin{array}{ccc}
0 & \text { if } & \min \left\{b_{1}, b_{2}\right\} \geq 900 \vee \min \left\{b_{1}, b_{3}\right\} \geq 900 \\
& & \vee \min \left\{b_{2}, b_{3}\right\} \geq 900, \\
0 & \text { if } & b_{1}>\max \left\{b_{2}, b_{3}\right\}, \\
\min \left\{\max \left\{b_{2}, b_{3}\right\}, 900\right\}-100 & \text { if } & b_{1}<\max \left\{b_{2}, b_{3}\right\}, \\
\frac{1}{2}\left(\max \left\{b_{2}, b_{3}\right\}-100\right) & \text { if } & b_{1}=\max \left\{b_{2}, b_{3}\right\}>\min \left\{b_{2}, b_{3}\right\}, \\
\frac{2}{3}\left(b_{2}-100\right) & \text { if } & b_{1}=b_{2}=b_{3}>0, \\
-100 & \text { if } & b_{1}=b_{2}=b_{3}=0,
\end{array}\right.
$$

where we assume that the relevant case is given by the first applicable if statement. In particular, the first if statement covers the case where the reverse auction fails at the outset because at least two TV stations bid 900 or more. Consequently, in the subsequent if statements at most one TV station bids 900 or more. In the second if statement, TV station 1 is first to opt to remain on the air. In the third if statement, TV station 1 is frozen as either TV station 2 or 3 is first to opt to remain on the air. The remaining if statements cover ties. The profits of the remaining TV stations are analogous.

In Tables S1-S7, we divide the strategy space of TV station 2 into 8 regions, namely $[0,100)$, $100,(100,300), 300,(300,500), 500,(500,900)$, and $[900, \infty)$. We further divide the strategy spaces of TV stations 1 and 3 as needed to either show that there is no profitable deviation for any TV station (indicated by $\checkmark$ in the respective cell) or give an example of a profitable deviation. ${ }^{\mathrm{S} 1}$ Combining the cells marked with $\checkmark$, the set of equilibria is as stated in equation (4).

Table S1: $b_{2} \in[0,100]$

\begin{tabular}{c|cccc}
$b_{1} \backslash b_{3}$ & {$\left[0, b_{2}\right)$} & {$\left[b_{2}, 100\right]$} & $(100,500)$ & {$[500, \infty)$} \\
\hline$\left[0, b_{2}\right)$ & $b_{3}=900$ & $b_{2}=900$ & $b_{2}=900$ & $\checkmark$ \\
{$\left[b_{2}, 300\right]$} & $b_{2}=900$ & $b_{2}=900$ & $b_{2}=900$ & $\checkmark$ \\
$(300,500)$ & $b_{2}=900$ & $b_{2}=900$ & $b_{2}=900$ & $b_{3}=0$ \\
{$[500, \infty)$} & $\checkmark$ & $\checkmark$ & $b_{1}=0$ & $\max \left\{b_{1}, b_{3}\right\}=0$
\end{tabular}

\footnotetext{
${ }^{\mathrm{S} 1}$ The notation $\max \left\{b_{1}, b_{3}\right\}=0$ in Table S1 means that the TV station with the higher bid has a profitable deviation to zero, and similarly for the remaining tables.
} 
Table S2: $b_{2} \in(100,300)$

\begin{tabular}{c|ccc}
$b_{1} \backslash b_{3}$ & {$\left[0, b_{2}\right)$} & {$\left[b_{2}, 500\right)$} & {$[500, \infty)$} \\
\hline$\left[0, b_{2}\right)$ & $b_{3}=900$ & $b_{2}=900$ & $\checkmark$ \\
{$\left[b_{2}, 300\right]$} & $b_{2}=900$ & $b_{2}=900$ & $\checkmark$ \\
$(300,500)$ & $b_{2}=900$ & $b_{2}=900$ & $b_{3}=0$ \\
{$[500, \infty)$} & $b_{1}=0$ & $b_{1}=0$ & $\max \left\{b_{1}, b_{3}\right\}=0$
\end{tabular}

Table S3: $b_{2}=300$

\begin{tabular}{c|ccc}
$b_{1} \backslash b_{3}$ & {$[0,300)$} & {$[300,500)$} & {$[500, \infty)$} \\
\hline$[0,300)$ & $\checkmark$ & $b_{2}=900$ & $\checkmark$ \\
300 & $b_{2}=900$ & $b_{2}=900$ & $\checkmark$ \\
$(300,500)$ & $b_{2}=900$ & $b_{2}=900$ & $b_{3}=0$ \\
{$[500, \infty)$} & $b_{1}=0$ & $b_{1}=0$ & $\max \left\{b_{1}, b_{3}\right\}=0$
\end{tabular}

Table S4: $b_{2} \in(300,500)$

\begin{tabular}{c|ccc}
$b_{1} \backslash b_{3}$ & {$\left[0, b_{2}\right)$} & {$\left[b_{2}, 500\right)$} & {$[500, \infty)$} \\
\hline$\left[0, b_{2}\right)$ & $\checkmark$ & $b_{2}=900$ & $b_{3}=0$ \\
{$\left[b_{2}, 500\right)$} & $b_{2}=900$ & $b_{2}=900$ & $b_{3}=0$ \\
{$[500, \infty)$} & $b_{1}=0$ & $b_{1}=0$ & $\max \left\{b_{1}, b_{3}\right\}=0$
\end{tabular}

Table S5: $b_{2}=500$

\begin{tabular}{c|cc}
$b_{1} \backslash b_{3}$ & {$[0,500)$} & {$[500, \infty)$} \\
\hline$[0,500)$ & $\checkmark$ & $b_{3}=0$ \\
{$[500, \infty)$} & $b_{1}=0$ & $\max \left\{b_{1}, b_{3}\right\}=0$
\end{tabular}

Table S6: $b_{2} \in(500,900)$

\begin{tabular}{c|ccc}
$b_{1} \backslash b_{3}$ & {$[0,500]$} & $\left(500, b_{2}\right]$ & $\left(b_{2}, \infty\right)$ \\
\hline$[0,500]$ & $\checkmark$ & $b_{2}=0$ & $b_{3}=0$ \\
$\left(500, b_{2}\right]$ & $b_{2}=0$ & $b_{2}=0$ & $b_{3}=0$ \\
$\left(b_{2}, \infty\right)$ & $b_{1}=0$ & $b_{1}=0$ & $\max \left\{b_{1}, b_{3}\right\}=0$
\end{tabular}

Table S7: $b_{2} \in[900, \infty)$

\begin{tabular}{c|ccc}
$b_{1} \backslash b_{3}$ & {$[0,500]$} & $(500,900)$ & {$[900, \infty)$} \\
\hline$[0,500]$ & $\checkmark$ & $b_{2}=0$ & $b_{2}=0$ \\
$(500,900)$ & $b_{2}=0$ & $b_{2}=0$ & $b_{2}=0$ \\
{$[900, \infty)$} & $b_{2}=0$ & $b_{2}=0$ & $\checkmark$
\end{tabular}




\section{A.2 Example 1 with joint ownership}

We derive the set of equilibria for Example 1 in Section 3.1. The profit of firm 1 owning TV stations 1 and 3 is

$$
\pi_{1}\left(b_{1}, b_{2}, b_{3}\right)=\left\{\begin{array}{ccc}
0 & \text { if } & \min \left\{b_{1}, b_{2}\right\} \geq 900 \\
& & \vee \min \left\{b_{1}, b_{3}\right\} \geq 900 \\
& & \vee \min \left\{b_{2}, b_{3}\right\} \geq 900, \\
\min \left\{b_{1}, 900\right\}-300 & \text { if } & b_{1}>\max \left\{b_{2}, b_{3}\right\}, \\
2 \min \left\{b_{2}, 900\right\}-400 & \text { if } & b_{2}>\max \left\{b_{1}, b_{3}\right\}, \\
\min \left\{b_{3}, 900\right\}-100 & \text { if } & b_{3}>\max \left\{b_{1}, b_{2}\right\}, \\
\frac{1}{2}\left(2 b_{2}-400\right)+\frac{1}{2}\left(b_{2}-300\right) & \text { if } & b_{1}=b_{2}>b_{3}, \\
\frac{1}{2}\left(b_{1}-100\right)+\frac{1}{2}\left(b_{1}-300\right) & \text { if } & b_{1}=b_{3}>b_{2}, \\
\frac{1}{2}\left(2 b_{2}-400\right)+\frac{1}{2}\left(b_{2}-100\right) & \text { if } & b_{2}=b_{3}>b_{1}, \\
\frac{1}{3}\left(2 b_{2}-400\right)+\frac{1}{3}\left(b_{2}-100\right)+\frac{1}{3}\left(b_{2}-300\right) & \text { if } & b_{1}=b_{2}=b_{3}>0, \\
-400 & \text { if } & b_{1}=b_{2}=b_{3}=0
\end{array}\right.
$$

and the profit of firm 2 owning TV station 2 is

$$
\pi_{2}\left(b_{1}, b_{2}, b_{3}\right)=\left\{\begin{array}{ccc}
0 & \text { if } & \min \left\{b_{1}, b_{2}\right\} \geq 900 \vee \min \left\{b_{1}, b_{3}\right\} \geq 900 \\
& & \vee \min \left\{b_{2}, b_{3}\right\} \geq 900, \\
0 & \text { if } & b_{2}>\max \left\{b_{1}, b_{3}\right\}, \\
\min \left\{\max \left\{b_{1}, b_{3}\right\}, 900\right\}-500 & \text { if } & b_{2}<\max \left\{b_{1}, b_{3}\right\}, \\
\frac{1}{2}\left(\max \left\{b_{1}, b_{3}\right\}-500\right) & \text { if } & b_{2}=\max \left\{b_{1}, b_{3}\right\}>\min \left\{b_{1}, b_{3}\right\}, \\
\frac{2}{3}\left(b_{1}-500\right) & \text { if } & b_{1}=b_{2}=b_{3}>0, \\
-500 & \text { if } & b_{1}=b_{2}=b_{3}=0,
\end{array}\right.
$$

where we again assume that the relevant case is given by the first applicable if statement.

In Tables S8-S10, we again divide the strategy spaces of firms 1 and 2 as needed to either show that there is no profitable deviation for any firm or give an example of a profitable deviation. Combining the cells marked with $\checkmark$, the set of equilibria is as stated in equation (5).

Table S8: $b_{2} \in[0,600)$

\begin{tabular}{c|cccc}
$b_{1} \backslash b_{3}$ & {$\left[0, b_{2}\right)$} & $b_{2}$ & $\left(b_{2}, 900\right)$ & {$[900, \infty)$} \\
\hline$\left[0, b_{2}\right)$ & $\left(b_{1}, b_{3}\right)=(0,900)$ & $\left(b_{1}, b_{3}\right)=(0,900)$ & $\left(b_{1}, b_{3}\right)=(0,900)$ & $\checkmark$ \\
$b_{2}$ & $\left(b_{1}, b_{3}\right)=(0,900)$ & $\left(b_{1}, b_{3}\right)=(0,900)$ & $\left(b_{1}, b_{3}\right)=(0,900)$ & $\checkmark$ \\
$\left(b_{2}, 900\right)$ & $\left(b_{1}, b_{3}\right)=(0,900)$ & $\left(b_{1}, b_{3}\right)=(0,900)$ & $\left(b_{1}, b_{3}\right)=(0,900)$ & $\checkmark$ \\
{$[900, \infty)$} & $\left(b_{1}, b_{3}\right)=(0,900)$ & $\left(b_{1}, b_{3}\right)=(0,900)$ & $\left(b_{1}, b_{3}\right)=(0,900)$ & $\left(b_{1}, b_{3}\right)=(0,900)$
\end{tabular}


Table S9: $b_{2}=600$

\begin{tabular}{c|ccccc}
$b_{1} \backslash b_{3}$ & {$[0,500]$} & $(500,600)$ & 600 & $(600,900)$ & {$[900, \infty)$} \\
\hline$[0,500]$ & $\checkmark$ & $b_{2}=0$ & $b_{2}=0$ & $\left(b_{1}, b_{3}\right)=(0,900)$ & $\checkmark$ \\
$(500,600)$ & $b_{2}=0$ & $b_{2}=0$ & $b_{2}=0$ & $\left(b_{1}, b_{3}\right)=(0,900)$ & $\checkmark$ \\
600 & $b_{2}=0$ & $b_{2}=0$ & $b_{2}=0$ & $\left(b_{1}, b_{3}\right)=(0,900)$ & $\checkmark$ \\
$(600,900)$ & $\left(b_{1}, b_{3}\right)=(0,0)$ & $\left(b_{1}, b_{3}\right)=(0,0)$ & $\left(b_{1}, b_{3}\right)=(0,0)$ & $\left(b_{1}, b_{3}\right)=(0,900)$ & $\checkmark$ \\
{$[900, \infty)$} & $\left(b_{1}, b_{3}\right)=(0,0)$ & $\left(b_{1}, b_{3}\right)=(0,0)$ & $\left(b_{1}, b_{3}\right)=(0,0)$ & $\left(b_{1}, b_{3}\right)=(0,900)$ & $\left(b_{1}, b_{3}\right)=(0,900)$
\end{tabular}

Table S10: $b_{2} \in(600, \infty)$

\begin{tabular}{c|ccccc}
$b_{1} \backslash b_{3}$ & {$[0,500]$} & $\left(500, b_{2}\right)$ & $b_{2}$ & $\left(b_{2}, 900\right)$ & {$[900, \infty)$} \\
\hline$[0,500]$ & $\checkmark$ & $b_{2}=0$ & $b_{2}=0$ & $\left(b_{1}, b_{3}\right)=(0,0)$ & $\left(b_{1}, b_{3}\right)=(0,0)$ \\
$\left(500, b_{2}\right)$ & $b_{2}=0$ & $b_{2}=0$ & $b_{2}=0$ & $\left(b_{1}, b_{3}\right)=(0,0)$ & $\left(b_{1}, b_{3}\right)=(0,0)$ \\
$b_{2}$ & $b_{2}=0$ & $b_{2}=0$ & $b_{2}=0$ & $\left(b_{1}, b_{3}\right)=(0,0)$ & $\left(b_{1}, b_{3}\right)=(0,0)$ \\
$\left(b_{2}, 900\right)$ & $\left(b_{1}, b_{3}\right)=(0,0)$ & $\left(b_{1}, b_{3}\right)=(0,0)$ & $\left(b_{1}, b_{3}\right)=(0,0)$ & $\left(b_{1}, b_{3}\right)=(0,0)$ & $\left(b_{1}, b_{3}\right)=(0,0)$ \\
{$[900, \infty)$} & $\left(b_{1}, b_{3}\right)=(0,0)$ & $\left(b_{1}, b_{3}\right)=(0,0)$ & $\left(b_{1}, b_{3}\right)=(0,0)$ & $\left(b_{1}, b_{3}\right)=(0,0)$ & $\left(b_{1}, b_{3}\right)=(0,0)$
\end{tabular}

\section{A.3 Example 1 with different reservation values}

We derive the set of equilibria for Example 1 in Section 3.1 whilst replacing the reservation value of TV station 2 by $v_{2}=700$. We came back to this variant of Example 1 in Section B. The profit of firm 1 owning TV stations 1 and 3 is

$$
\pi_{1}\left(b_{1}, b_{2}, b_{3}\right)=\left\{\begin{array}{ccc}
0 & \text { if } & \min \left\{b_{1}, b_{2}\right\} \geq 900 \\
& \vee \min \left\{b_{1}, b_{3}\right\} \geq 900 \\
& & \vee \min \left\{b_{2}, b_{3}\right\} \geq 900, \\
\min \left\{b_{1}, 900\right\}-300 & \text { if } & b_{1}>\max \left\{b_{2}, b_{3}\right\}, \\
2 \min \left\{b_{2}, 900\right\}-400 & \text { if } & b_{2}>\max \left\{b_{1}, b_{3}\right\}, \\
\min \left\{b_{3}, 900\right\}-100 & \text { if } & b_{3}>\max \left\{b_{1}, b_{2}\right\}, \\
\frac{1}{2}\left(2 b_{2}-400\right)+\frac{1}{2}\left(b_{2}-300\right) & \text { if } & b_{1}=b_{2}>b_{3}, \\
\frac{1}{2}\left(b_{1}-100\right)+\frac{1}{2}\left(b_{1}-300\right) & \text { if } & b_{1}=b_{3}>b_{2}, \\
\frac{1}{2}\left(2 b_{2}-400\right)+\frac{1}{2}\left(b_{2}-100\right) & \text { if } & b_{2}=b_{3}>b_{1}, \\
\frac{1}{3}\left(2 b_{2}-400\right)+\frac{1}{3}\left(b_{2}-100\right)+\frac{1}{3}\left(b_{2}-300\right) & \text { if } & b_{1}=b_{2}=b_{3}>0, \\
-400 & \text { if } & b_{1}=b_{2}=b_{3}=0
\end{array}\right.
$$


and the profit of firm 2 owning TV station 2 is

$$
\pi_{2}\left(b_{1}, b_{2}, b_{3}\right)=\left\{\begin{array}{ccc}
0 & \text { if } & \min \left\{b_{1}, b_{2}\right\} \geq 900 \vee \min \left\{b_{1}, b_{3}\right\} \geq 900 \\
& & \vee \min \left\{b_{2}, b_{3}\right\} \geq 900, \\
0 & \text { if } & b_{2}>\max \left\{b_{1}, b_{3}\right\}, \\
\min \left\{\max \left\{b_{1}, b_{3}\right\}, 900\right\}-700 & \text { if } & b_{2}<\max \left\{b_{1}, b_{3}\right\}, \\
\frac{1}{2}\left(\max \left\{b_{1}, b_{3}\right\}-700\right) & \text { if } & b_{2}=\max \left\{b_{1}, b_{3}\right\}>\min \left\{b_{1}, b_{3}\right\}, \\
\frac{2}{3}\left(b_{1}-700\right) & \text { if } & b_{1}=b_{2}=b_{3}>0, \\
-700 & \text { if } & b_{1}=b_{2}=b_{3}=0,
\end{array}\right.
$$

where we again assume that the relevant case is given by the first applicable if statement.

In Tables S11-S14, we again divide the strategy spaces of firms 1 and 2 as needed to either show that there is no profitable deviation for any firm or give an example of a profitable deviation. Combining the cells marked with $\checkmark$, the set of equilibria is

$$
\begin{gathered}
\left\{\left(b_{1}, b_{2}, b_{3}\right) \in[0, \infty)^{3} \mid b_{1}<900, b_{2} \leq 600, b_{3} \geq 900\right\} \\
\cup\left\{\left(b_{1}, b_{2}, b_{3}\right) \in[0, \infty)^{3} \mid b_{1} \leq 700, b_{2}>700, b_{3} \leq 700\right\} \\
\cup\left\{\left(b_{1}, b_{2}, b_{3}\right) \in[0, \infty)^{3} \mid \max \left\{b_{1}, b_{3}\right\}<b_{2}, 600 \leq b_{2} \leq 700\right\} .
\end{gathered}
$$

Note that firm 1 never bids $b_{3}=900$ as long as firm 2 truthfully bids $b_{2}=700$.

Table S11: $b_{2} \in[0,600)$

\begin{tabular}{c|cccc}
$b_{1} \backslash b_{3}$ & {$\left[0, b_{2}\right)$} & $b_{2}$ & $\left(b_{2}, 900\right)$ & {$[900, \infty)$} \\
\hline$\left[0, b_{2}\right)$ & $\left(b_{1}, b_{3}\right)=(0,900)$ & $\left(b_{1}, b_{3}\right)=(0,900)$ & $\left(b_{1}, b_{3}\right)=(0,900)$ & $\checkmark$ \\
$b_{2}$ & $\left(b_{1}, b_{3}\right)=(0,900)$ & $\left(b_{1}, b_{3}\right)=(0,900)$ & $\left(b_{1}, b_{3}\right)=(0,900)$ & $\checkmark$ \\
$\left(b_{2}, 900\right)$ & $\left(b_{1}, b_{3}\right)=(0,900)$ & $\left(b_{1}, b_{3}\right)=(0,900)$ & $\left(b_{1}, b_{3}\right)=(0,900)$ & $\checkmark$ \\
{$[900, \infty)$} & $\left(b_{1}, b_{3}\right)=(0,900)$ & $\left(b_{1}, b_{3}\right)=(0,900)$ & $\left(b_{1}, b_{3}\right)=(0,900)$ & $\left(b_{1}, b_{3}\right)=(0,900)$
\end{tabular}

Table S12: $b_{2}=600$

\begin{tabular}{c|ccc}
$b_{1} \backslash b_{3}$ & {$[0,600)$} & {$[600,900)$} & {$[900, \infty)$} \\
\hline$[0,600)$ & $\checkmark$ & $\left(b_{1}, b_{3}\right)=(0,0)$ & $\checkmark$ \\
{$[600,900)$} & $\left(b_{1}, b_{3}\right)=(0,0)$ & $\left(b_{1}, b_{3}\right)=(0,0)$ & $\checkmark$ \\
{$[900, \infty)$} & $\left(b_{1}, b_{3}\right)=(0,0)$ & $\left(b_{1}, b_{3}\right)=(0,0)$ & $\left(b_{1}, b_{3}\right)=(0,0)$
\end{tabular}

Table S13: $b_{2} \in(600,700]$

\begin{tabular}{c|cc}
$b_{1} \backslash b_{3}$ & {$\left[0, b_{2}\right)$} & {$\left[b_{2}, \infty\right)$} \\
\hline$\left[0, b_{2}\right)$ & $\checkmark$ & $\left(b_{1}, b_{3}\right)=(0,0)$ \\
{$\left[b_{2}, \infty\right)$} & $\left(b_{1}, b_{3}\right)=(0,0)$ & $\left(b_{1}, b_{3}\right)=(0,0)$
\end{tabular}


Table S14: $b_{2} \in(700, \infty)$

\begin{tabular}{c|ccc}
$b_{1} \backslash b_{3}$ & {$[0,700]$} & $\left(700, b_{2}\right)$ & {$\left[b_{2}, \infty\right)$} \\
\hline$[0,700]$ & $\checkmark$ & $b_{2}=0$ & $\left(b_{1}, b_{3}\right)=(0,0)$ \\
$\left(700, b_{2}\right)$ & $b_{2}=0$ & $b_{2}=0$ & $\left(b_{1}, b_{3}\right)=(0,0)$ \\
{$\left[b_{2}, \infty\right)$} & $\left(b_{1}, b_{3}\right)=(0,0)$ & $\left(b_{1}, b_{3}\right)=(0,0)$ & $\left(b_{1}, b_{3}\right)=(0,0)$
\end{tabular}

\section{A.4 Example 2 imposing independently owned TV stations}

We derive the set of equilibria for Example 2 in Section 3.1 whilst imposing that all TV stations are independently owned. The profit of TV station 1 is

$$
\pi_{1}\left(b_{1}, b_{2}, b_{3}\right)=\left\{\begin{array}{ccc}
0 & \text { if } & \min \left\{b_{1}, b_{2}\right\} \geq 900 \vee \min \left\{b_{2}, b_{3}\right\} \geq 900, \\
0 & \text { if } & b_{1}>\max \left\{b_{2}, b_{3}\right\}, \\
\min \left\{b_{2}, 900\right\}-100 & \text { if } & b_{2}>\max \left\{b_{1}, b_{3}\right\}, \\
0 & \text { if } & b_{3}>\max \left\{b_{1}, b_{2}\right\} \wedge b_{1}>0, \\
-100 & \text { if } & b_{3}>\max \left\{b_{1}, b_{2}\right\} \wedge b_{1}=0, \\
\frac{1}{2}\left(b_{2}-100\right) & \text { if } & b_{1}=b_{2}>b_{3}, \\
0 & \text { if } & b_{1}=b_{3}>b_{2}, \\
\frac{1}{2}\left(b_{2}-100\right) & \text { if } & b_{2}=b_{3}>b_{1}>0, \\
\frac{1}{2}\left(b_{2}-100\right)+\frac{1}{2}(-100) & \text { if } & b_{2}=b_{3}>b_{1}=0, \\
\frac{1}{3}\left(b_{2}-100\right) & \text { if } & b_{1}=b_{2}=b_{3}>0, \\
-100 & \text { if } & b_{1}=b_{2}=b_{3}=0,
\end{array}\right.
$$

where we assume that the relevant case is given by the first applicable if statement. In particular, the first if statement covers the case where the reverse auction fails at the outset because either TV stations 1 and 2 or TV stations 2 and 3 bid 900 or more. Consequently, in the subsequent if statements at most a single TV station or TV stations 1 and 3 bid 900 or more. In the second if statement, TV station 1 is first to opt to remain on the air. In the third if statement, TV station 1 is frozen as TV station 2 is first to opt to remain on the air. In the fourth and fifth if statement, TV station 2 is frozen as TV station 3 is first to opt to remain on the air; then TV station 1 opts to remain on the air if $b_{1}>0$ or is frozen at the conclusion of the reverse auction if $b_{1}=0$ in line with footnote 27 . The remaining if statements cover ties. The profit of TV station 2 is

$$
\pi_{2}\left(b_{1}, b_{2}, b_{3}\right)=\left\{\begin{array}{ccc}
0 & \text { if } & \min \left\{b_{1}, b_{2}\right\} \geq 900 \vee \min \left\{b_{2}, b_{3}\right\} \geq 900, \\
0 & \text { if } & b_{2}>\max \left\{b_{1}, b_{3}\right\}, \\
5 \min \left\{\max \left\{b_{1}, b_{3}\right\}, 900\right\}-1000 & \text { if } & b_{2}<\max \left\{b_{1}, b_{3}\right\}, \\
\frac{1}{2}\left(5 \max \left\{b_{1}, b_{3}\right\}-1000\right) & \text { if } & b_{2}=\max \left\{b_{1}, b_{3}\right\}>\min \left\{b_{1}, b_{3}\right\}, \\
\frac{2}{3}\left(5 b_{1}-1000\right) & \text { if } & b_{1}=b_{2}=b_{3}>0 \\
-1000 & \text { if } & b_{1}=b_{2}=b_{3}=0
\end{array}\right.
$$


and the profit of TV station 3 is

$$
\pi_{3}\left(b_{1}, b_{2}, b_{3}\right)=\left\{\begin{array}{ccc}
0 & \text { if } & \min \left\{b_{1}, b_{2}\right\} \geq 900 \vee \min \left\{b_{2}, b_{3}\right\} \geq 900, \\
0 & \text { if } & b_{3}>\max \left\{b_{1}, b_{2}\right\}, \\
\frac{1}{3} \min \left\{b_{2}, 900\right\}-100 & \text { if } & b_{2}>\max \left\{b_{1}, b_{3}\right\}, \\
0 & \text { if } & b_{1}>\max \left\{b_{2}, b_{3}\right\} \wedge b_{3}>0, \\
-100 & \text { if } & b_{1}>\max \left\{b_{2}, b_{3}\right\} \wedge b_{3}=0, \\
\frac{1}{2}\left(\frac{1}{3} b_{2}-100\right) & \text { if } & b_{2}=b_{3}>b_{1}, \\
0 & \text { if } & b_{1}=b_{3}>b_{2}, \\
\frac{1}{2}\left(\frac{1}{3} b_{2}-100\right) & \text { if } & b_{1}=b_{2}>b_{3}>0, \\
\frac{1}{2}\left(\frac{1}{3} b_{2}-100\right)+\frac{1}{2}(-100) & \text { if } & b_{1}=b_{2}>b_{3}=0, \\
\frac{1}{3}\left(\frac{1}{3} b_{2}-100\right) & \text { if } & b_{1}=b_{2}=b_{3}>0, \\
-100 & \text { if } & b_{1}=b_{2}=b_{3}=0 .
\end{array}\right.
$$

In Tables S15-S23, we again divide the strategy spaces of the three TV stations as needed to either show that there is no profitable deviation for any firm or give an example of a profitable deviation. A blank cell indicates that the case cannot arise. Combining the cells marked with $\checkmark$, the set of equilibria is

$$
\begin{gathered}
\left\{\left(b_{1}, b_{2}, b_{3}\right) \in[0, \infty)^{3} \mid b_{1} \leq 200, b_{2} \geq 300, b_{3} \leq 200\right\} \\
\cup\left\{\left(b_{1}, b_{2}, b_{3}\right) \in[0, \infty)^{3} \mid b_{1} \geq 200, b_{2} \leq 100,0<b_{3} \leq 100\right\} \\
\cup\left\{\left(b_{1}, b_{2}, b_{3}\right) \in[0, \infty)^{3} \mid b_{1} \geq 200, b_{2}<b_{3}, 100<b_{3}<200\right\} \\
\cup\left\{\left(b_{1}, b_{2}, b_{3}\right) \in[0, \infty)^{3} \mid b_{1}>0, b_{2}<b_{3}, 200 \leq b_{3} \leq 300\right\} \\
\cup\left\{\left(b_{1}, b_{2}, b_{3}\right) \in[0, \infty)^{3} \mid b_{1}>0, b_{2} \leq 300, b_{3}>300\right\} \\
\cup\left\{\left(b_{1}, b_{2}, b_{3}\right) \in[0, \infty)^{3} \mid b_{1}>b_{2}, 300<b_{2}<b_{3}<900\right\} \\
\cup\left\{\left(b_{1}, b_{2}, b_{3}\right) \in[0, \infty)^{3} \mid b_{1}>b_{2}, 300<b_{2}<900, b_{3} \geq 900\right\} .
\end{gathered}
$$

\begin{tabular}{|c|c|c|c|c|c|c|c|c|}
\hline \multirow[t]{2}{*}{$b_{1} \backslash b_{2}$} & \multirow[t]{2}{*}{0} & \multirow[t]{2}{*}{$(0,100)$} & \multirow[t]{2}{*}{100} & \multicolumn{2}{|c|}{$(100,300)$} & \multirow[t]{2}{*}{300} & \multirow[t]{2}{*}{$(300,900)$} & \multirow[t]{2}{*}{$900, \infty$} \\
\hline & & & & $b_{1} \geq b_{2}$ & $b_{1}<b_{2}$ & & & \\
\hline 0 & $b_{2}=900$ & $b_{3}=900$ & $b_{3}=900$ & & $b_{3}=900$ & $\checkmark$ & $\checkmark$ & $\checkmark$ \\
\hline$(0,100)$ & $b_{2}=900$ & $\min \left\{b_{1}, b_{2}\right\}=900$ & $b_{3}=900$ & & $b_{3}=900$ & $\checkmark$ & $\checkmark$ & $\checkmark$ \\
\hline 100 & $b_{2}=900$ & $b_{2}=900$ & $b_{2}=900$ & & $b_{3}=900$ & $\checkmark$ & $\checkmark$ & $\checkmark$ \\
\hline$(100,200)$ & $b_{2}=900$ & $b_{2}=900$ & $b_{2}=900$ & $b_{2}=900$ & $b_{3}=900$ & $\checkmark$ & $\checkmark$ & $\checkmark$ \\
\hline 200 & $b_{3}>0$ & $b_{3}>0$ & $b_{3}>0$ & $b_{1}<100$ & $b_{3}=900$ & $\checkmark$ & $\checkmark$ & $\checkmark$ \\
\hline$(200,300)$ & $b_{3}>0$ & $b_{3}>0$ & $b_{3}>0$ & $b_{1}<100$ & $b_{3}=900$ & $b_{2}<200$ & $b_{2}<200$ & $b_{2}<200$ \\
\hline 300 & $b_{3}>0$ & $b_{3}>0$ & $b_{3}>0$ & $b_{1}<100$ & & $b_{2}<200$ & $b_{2}<200$ & $b_{2}<200$ \\
\hline$(300,900)$ & $b_{3}>0$ & $b_{3}>0$ & $b_{3}>0$ & $b_{1}<100$ & & $b_{1}<300$ & $\max \left\{b_{1}, b_{2}\right\}<300$ & $b_{2}<200$ \\
\hline$[900, \infty)$ & $b_{3}>0$ & $b_{3}>0$ & $b_{3}>0$ & $b_{1}<100$ & & $b_{1}<300$ & $b_{1}<300$ & $b_{2}<200$ \\
\hline
\end{tabular}

Table S15: $b_{3}=0$ 
Table S16: $b_{3} \in(0,100)$

\begin{tabular}{|c|c|c|c|c|c|c|c|c|}
\hline \multirow[t]{2}{*}{$b_{1} \backslash b_{2}$} & \multirow[t]{2}{*}[0,b_{3}]{} & \multirow[t]{2}{*}{$\left(b_{3}, 100\right)$} & \multirow[t]{2}{*}{100} & \multicolumn{2}{|c|}{$(100,300)$} & \multirow[t]{2}{*}{300} & \multirow[t]{2}{*}{$(300,900)$} & \multirow[t]{2}{*}{$900, \infty$} \\
\hline & & & & $b_{1} \geq b_{2}$ & $b_{1}<b_{2}$ & & & \\
\hline$\left[0, b_{3}\right]$ & $b_{2}=900$ & $b_{3}=900$ & $b_{3}=900$ & & $b_{3}=900$ & $\checkmark$ & $\checkmark$ & $\checkmark$ \\
\hline$\left(b_{3}, 100\right)$ & $b_{2}=900$ & $\min \left\{b_{1}, b_{2}\right\}=900$ & $b_{3}=900$ & & $b_{3}=900$ & $\checkmark$ & $\checkmark$ & $\checkmark$ \\
\hline 100 & $b_{2}=900$ & $b_{2}=900$ & $b_{2}=900$ & & $b_{3}=900$ & $\checkmark$ & $\checkmark$ & $\checkmark$ \\
\hline$(100,200)$ & $b_{2}=900$ & $b_{2}=900$ & $b_{2}=900$ & $b_{2}=900$ & $b_{3}=900$ & $\checkmark$ & $\checkmark$ & $\checkmark$ \\
\hline 200 & $\checkmark$ & $\checkmark$ & $\checkmark$ & $b_{1}<100$ & $b_{3}=900$ & $\checkmark$ & $\checkmark$ & $\checkmark$ \\
\hline$(200,300)$ & $\checkmark$ & $\checkmark$ & $\checkmark$ & $b_{1}<100$ & $b_{3}=900$ & $b_{2}<200$ & $b_{2}<200$ & $b_{2}<200$ \\
\hline 300 & $\checkmark$ & $\checkmark$ & $\checkmark$ & $b_{1}<100$ & & $b_{2}<200$ & $b_{2}<200$ & $b_{2}<200$ \\
\hline$(300,900)$ & $\checkmark$ & $\checkmark$ & $\checkmark$ & $b_{1}<100$ & & $b_{1}<300$ & $\max \left\{b_{1}, b_{2}\right\}<300$ & $b_{2}<200$ \\
\hline$[900, \infty)$ & $\checkmark$ & $\checkmark$ & $\checkmark$ & $b_{1}<100$ & & $b_{1}<300$ & $b_{1}<300$ & $b_{2}<200$ \\
\hline
\end{tabular}

Table S17: $b_{3}=100$

\begin{tabular}{c|cccccc}
$b_{1} \backslash b_{2}$ & {$[0,100]$} & \multicolumn{2}{c}{$(100,300)$} & 300 & $(300,900)$ & {$[900, \infty)$} \\
& \multicolumn{5}{c}{$b_{1} \geq b_{2}$} & $b_{1}<b_{2}$ \\
\hline$[0,100]$ & $b_{2}=900$ & & $b_{3}=900$ & $\checkmark$ & $\checkmark$ & $\checkmark$ \\
$(100,200)$ & $b_{2}=900$ & $b_{2}=900$ & $b_{3}=900$ & $\checkmark$ & $\checkmark$ & $\checkmark$ \\
200 & $\checkmark$ & $b_{1}<100$ & $b_{3}=900$ & $\checkmark$ & $\checkmark$ & $\checkmark$ \\
$(200,300)$ & $\checkmark$ & $b_{1}<100$ & $b_{3}=900$ & $b_{2}<200$ & $b_{2}<200$ & $b_{2}<200$ \\
300 & $\checkmark$ & $b_{1}<100$ & & $b_{2}<200$ & $b_{2}<200$ & $b_{2}<200$ \\
$(300,900)$ & $\checkmark$ & $b_{1}<100$ & & $b_{1}<300$ & $\max \left\{b_{1}, b_{2}\right\}<300$ & $b_{2}<200$ \\
{$[900, \infty)$} & $\checkmark$ & $b_{1}<100$ & & $b_{1}<300$ & $b_{1}<300$ & $b_{2}<200$
\end{tabular}

Table S18: $b_{3} \in(100,200)$

\begin{tabular}{|c|c|c|c|c|c|c|c|}
\hline \multirow[t]{2}{*}{$b_{1} \backslash b_{2}$} & \multirow[t]{2}{*}{$0, b_{3}$} & \multirow[t]{2}{*}{$b_{3}$} & \multicolumn{2}{|c|}{$\left(b_{3}, 300\right)$} & \multirow[t]{2}{*}{300} & \multirow[t]{2}{*}{$(300,900)$} & \multirow[t]{2}{*}{$900, \infty$} \\
\hline & & & $b_{1} \geq b_{2}$ & $b_{1}<b_{2}$ & & & \\
\hline$\left[0, b_{3}\right)$ & $b_{2}=900$ & $b_{2}=900$ & & $b_{3}=900$ & $\checkmark$ & $\checkmark$ & $\checkmark$ \\
\hline$b_{3}$ & $b_{2}=900$ & $b_{2}=900$ & & $b_{3}=900$ & $\checkmark$ & $\checkmark$ & $\checkmark$ \\
\hline$\left(b_{3}, 200\right)$ & $b_{2}=900$ & $b_{2}=900$ & $b_{2}=900$ & $b_{3}=900$ & $\checkmark$ & $\checkmark$ & $\checkmark$ \\
\hline 200 & $\checkmark$ & $b_{1}<100$ & $b_{1}<100$ & $b_{3}=900$ & $\checkmark$ & $\checkmark$ & $\checkmark$ \\
\hline$(200,300)$ & $\checkmark$ & $b_{1}<100$ & $b_{1}<100$ & $b_{3}=900$ & $b_{2}<200$ & $b_{2}<200$ & $b_{2}<200$ \\
\hline 300 & $\checkmark$ & $b_{1}<100$ & $b_{1}<100$ & & $b_{2}<200$ & $b_{2}<200$ & $b_{2}<200$ \\
\hline$(300,900)$ & $\checkmark$ & $b_{1}<100$ & $b_{1}<100$ & & $b_{2}<200$ & $\max \left\{b_{1}, b_{2}\right\}<300$ & $b_{2}<200$ \\
\hline$[900, \infty)$ & $\checkmark$ & $b_{1}<100$ & $b_{1}<100$ & & $b_{2}<200$ & $b_{1}<300$ & $b_{2}<200$ \\
\hline
\end{tabular}


Table S19: $b_{3}=200$

\begin{tabular}{c|cccccc}
$b_{1} \backslash b_{2}$ & {$[0,200)$} & 200 & $(200,300)$ & 300 & $(300,900)$ & {$[900, \infty)$} \\
\hline 0 & $b_{1}>0$ & $b_{3}=900$ & $b_{3}=900$ & $\checkmark$ & $\checkmark$ & $\checkmark$ \\
$(0,200)$ & $\checkmark$ & $b_{3}=900$ & $b_{3}=900$ & $\checkmark$ & $\checkmark$ & $\checkmark$ \\
200 & $\checkmark$ & $b_{3}=900$ & $b_{3}=900$ & $\checkmark$ & $\checkmark$ & $\checkmark$ \\
$(200,300)$ & $\checkmark$ & $b_{1}<200$ & $\max \left\{b_{1}, b_{2}\right\}<200$ & $b_{2}<200$ & $b_{2}<200$ & $b_{2}<200$ \\
300 & $\checkmark$ & $b_{1}<200$ & $b_{1}<200$ & $b_{2}<200$ & $b_{2}<200$ & $b_{2}<200$ \\
$(300,900)$ & $\checkmark$ & $b_{1}<200$ & $b_{1}<200$ & $b_{1}<300$ & $\max \left\{b_{1}, b_{2}\right\}<300$ & $b_{2}<200$ \\
{$[900, \infty)$} & $\checkmark$ & $b_{1}<200$ & $b_{1}<200$ & $b_{1}<300$ & $b_{1}<300$ & $b_{2}<200$
\end{tabular}

Table S20: $b_{3} \in(200,300)$

\begin{tabular}{c|cccccc}
$b_{1} \backslash b_{2}$ & {$\left[0, b_{3}\right)$} & $b_{3}$ & $\left(b_{3}, 300\right)$ & 300 & $(300,900)$ & {$[900, \infty)$} \\
\hline 0 & $b_{1}>0$ & $b_{3}=900$ & $b_{3}=900$ & $b_{2}<200$ & $b_{2}<200$ & $b_{2}<200$ \\
$\left(0, b_{3}\right)$ & $\checkmark$ & $b_{3}=900$ & $b_{3}=900$ & $b_{2}<200$ & $b_{2}<200$ & $b_{2}<200$ \\
$b_{3}$ & $\checkmark$ & $b_{3}=900$ & $b_{3}=900$ & $b_{2}<200$ & $b_{2}<200$ & $b_{2}<200$ \\
$\left(b_{3}, 300\right)$ & $\checkmark$ & $b_{1}<200$ & $\max \left\{b_{1}, b_{2}\right\}<200$ & $b_{2}<200$ & $b_{2}<200$ & $b_{2}<200$ \\
300 & $\checkmark$ & $b_{1}<200$ & $b_{1}<200$ & $b_{2}<200$ & $b_{2}<200$ & $b_{2}<200$ \\
$(300,900)$ & $\checkmark$ & $b_{1}<200$ & $b_{1}<200$ & $b_{1}<300$ & $\max \left\{b_{1}, b_{2}\right\}<300$ & $b_{2}<200$ \\
{$[900, \infty)$} & $\checkmark$ & $b_{1}<200$ & $b_{1}<200$ & $b_{1}<300$ & $b_{1}<300$ & $b_{1}<200$
\end{tabular}

Table S21: $b_{3}=300$

\begin{tabular}{c|cccc}
$b_{1} \backslash b_{2}$ & {$[0,300)$} & 300 & $(300,900)$ & {$[900, \infty)$} \\
\hline 0 & $b_{1}>0$ & $b_{2}<300$ & $b_{2}<300$ & $b_{2}<300$ \\
$(0,300)$ & $\checkmark$ & $b_{2}<300$ & $b_{2}<300$ & $b_{2}<300$ \\
300 & $\checkmark$ & $b_{2}<300$ & $b_{2}<300$ & $b_{2}<300$ \\
$(300,900)$ & $\checkmark$ & $b_{1}<300$ & $\max \left\{b_{1}, b_{2}\right\}<300$ & $b_{2}<300$ \\
{$[900, \infty)$} & $\checkmark$ & $b_{1}<300$ & $b_{1}<300$ & $b_{2}<300$
\end{tabular}

Table S22: $b_{3} \in(300,900)$

\begin{tabular}{|c|c|c|c|c|c|c|}
\hline$b_{1} \backslash b_{2}$ & {$[0,300]$} & \multicolumn{2}{|c|}{$\left(300, b_{3}\right)$} & $b_{3}$ & $\left(b_{3}, 900\right)$ & {$[900, \infty)$} \\
\hline 0 & $b_{1}>0$ & & $b_{3}<300$ & $b_{3}<300$ & $b_{2}<300$ & $b_{2}<300$ \\
\hline$(0,300]$ & $\checkmark$ & & $b_{3}<300$ & $b_{3}<300$ & $b_{2}<300$ & $b_{2}<300$ \\
\hline$\left(300, b_{3}\right)$ & $\checkmark$ & $\checkmark$ & $b_{3}<300$ & $b_{3}<300$ & $b_{2}<300$ & $b_{2}<300$ \\
\hline$b_{3}$ & $\checkmark$ & $\checkmark$ & $b_{2}<300$ & $b_{2}<300$ & $b_{2}<300$ & $b_{2}<300$ \\
\hline$\left(b_{3}, 900\right)$ & $\checkmark$ & $\checkmark$ & & $b_{1}<300$ & $\max \left\{b_{1}, b_{2}\right\}<300$ & $b_{2}<300$ \\
\hline$[900, \infty)$ & $\checkmark$ & $\checkmark$ & & $b_{1}<300$ & $b_{1}<300$ & $b_{2}<300$ \\
\hline
\end{tabular}


Table S23: $b_{3} \in[900, \infty)$

\begin{tabular}{|c|c|c|c|c|}
\hline \multirow[t]{2}{*}{$b_{1} \backslash b_{2}$} & {$[0,300]$} & \multicolumn{2}{|c|}{$(300,900)$} & {$[900, \infty)$} \\
\hline & & $b_{1}>b_{2}$ & $b_{1} \leq b_{2}$ & \\
\hline 0 & $b_{1}>0$ & & $b_{3}<300$ & $b_{3}<900$ \\
\hline$(0,300]$ & $\checkmark$ & & $b_{3}<300$ & $b_{3}<900$ \\
\hline$(300,900)$ & $\checkmark$ & $\checkmark$ & $b_{3}<300$ & $b_{3}<900$ \\
\hline$[900, \infty)$ & $\checkmark$ & $\checkmark$ & & $b_{2}<900$ \\
\hline
\end{tabular}

\section{A.5 Example 2 with joint ownership}

We derive the set of equilibria for Example 2 in Section 3.1. The profit of firm 1 owning TV stations 1 and 3 is

$$
\pi_{1}\left(b_{1}, b_{2}, b_{3}\right)=\left\{\begin{array}{ccc}
0 & \text { if } & \min \left\{b_{1}, b_{2}\right\} \geq 900 \vee \min \left\{b_{2}, b_{3}\right\} \geq 900, \\
\frac{4}{3} \min \left\{b_{2}, 900\right\}-200 & \text { if } & b_{2}>\max \left\{b_{1}, b_{3}\right\}, \\
0 & \text { if } & b_{2}<\max \left\{b_{1}, b_{3}\right\} \wedge \min \left\{b_{1}, b_{3}\right\}>0 \\
-100 & \text { if } & b_{2}<\max \left\{b_{1}, b_{3}\right\} \wedge \min \left\{b_{1}, b_{3}\right\}=0, \\
\frac{1}{2}\left(\frac{4}{3} b_{2}-200\right) & \text { if } & b_{2}=\max \left\{b_{1}, b_{3}\right\}>\min \left\{b_{1}, b_{3}\right\}>0, \\
\frac{1}{2}\left(\frac{4}{3} b_{2}-200\right)+\frac{1}{2}(-100) & \text { if } & b_{2}=\max \left\{b_{1}, b_{3}\right\}>\min \left\{b_{1}, b_{3}\right\}=0, \\
\frac{1}{3}\left(\frac{4}{3} b_{2}-200\right) & \text { if } & b_{1}=b_{2}=b_{3}>0, \\
-200 & \text { if } & b_{1}=b_{2}=b_{3}=0,
\end{array}\right.
$$

and the profit of firm 2 owning TV station 2 is

$$
\pi_{2}\left(b_{1}, b_{2}, b_{3}\right)=\left\{\begin{array}{ccc}
0 & \text { if } & \min \left\{b_{1}, b_{2}\right\} \geq 900 \vee \min \left\{b_{2}, b_{3}\right\} \geq 900, \\
0 & \text { if } & b_{2}>\max \left\{b_{1}, b_{3}\right\}, \\
5 \min \left\{\max \left\{b_{1}, b_{3}\right\}, 900\right\}-1000 & \text { if } & b_{2}<\max \left\{b_{1}, b_{3}\right\}, \\
\frac{1}{2}\left(5 \max \left\{b_{1}, b_{3}\right\}-1000\right) & \text { if } & b_{2}=\max \left\{b_{1}, b_{3}\right\}>\min \left\{b_{1}, b_{3}\right\}, \\
\frac{2}{3}\left(5 b_{1}-1000\right) & \text { if } & b_{1}=b_{2}=b_{3}>0, \\
-1000 & \text { if } & b_{1}=b_{2}=b_{3}=0,
\end{array}\right.
$$

where we again assume that the relevant case is given by the first applicable if statement.

In Tables S24-S28, we again divide the strategy spaces of the three TV stations as needed to either show that there is no profitable deviation for any firm or give an example of a profitable deviation. Combining the cells marked with $\checkmark$, the set of equilibria is

$$
\begin{gathered}
\left\{\left(b_{1}, b_{2}, b_{3}\right) \in[0, \infty)^{3} \mid \min \left\{b_{1}, b_{3}\right\}>0, \max \left\{b_{1}, b_{3}\right\} \geq 200, b_{2} \leq 150\right\} \\
\cup\left\{\left(b_{1}, b_{2}, b_{3}\right) \in[0, \infty)^{3} \mid \max \left\{b_{1}, b_{3}\right\}<b_{2}, 150 \leq b_{2} \leq 200\right\} \\
\cup\left\{\left(b_{1}, b_{2}, b_{3}\right) \in[0, \infty)^{3} \mid \max \left\{b_{1}, b_{3}\right\} \leq 200, b_{2}>200\right\}
\end{gathered}
$$


Table S24: $b_{2} \in[0,150)$

\begin{tabular}{c|cccc}
$b_{1} \backslash b_{3}$ & 0 & $\left(0, b_{2}\right]$ & $\left(b_{2}, 200\right)$ & {$[200, \infty)$} \\
\hline 0 & $\left(b_{1}, b_{3}\right)=(900,900)$ & $\left(b_{1}, b_{3}\right)=(900,900)$ & $b_{2}=900$ & $b_{1}=1$ \\
$\left(0, b_{2}\right]$ & $\left(b_{1}, b_{3}\right)=(900,900)$ & $\left(b_{1}, b_{3}\right)=(900,900)$ & $b_{2}=900$ & $\checkmark$ \\
$\left(b_{2}, 200\right)$ & $b_{2}=900$ & $b_{2}=900$ & $b_{2}=900$ & $\checkmark$ \\
{$[200, \infty)$} & $b_{3}=1$ & $\checkmark$ & $\checkmark$ & $\checkmark$
\end{tabular}

Table S25: $b_{2}=150$

\begin{tabular}{c|cccc}
$b_{1} \backslash b_{3}$ & 0 & $(0,150)$ & {$[150,200)$} & {$[200, \infty)$} \\
\hline 0 & $\checkmark$ & $\checkmark$ & $b_{2}=900$ & $b_{1}=1$ \\
$(0,150)$ & $\checkmark$ & $\checkmark$ & $b_{2}=900$ & $\checkmark$ \\
{$[150,200)$} & $b_{2}=900$ & $b_{2}=900$ & $b_{2}=900$ & $\checkmark$ \\
{$[200, \infty)$} & $b_{3}=1$ & $\checkmark$ & $\checkmark$ & $\checkmark$
\end{tabular}

Table S26: $b_{2} \in(150,200]$

\begin{tabular}{c|cc}
$b_{1} \backslash b_{3}$ & {$\left[0, b_{2}\right)$} & {$\left[b_{2}, \infty\right)$} \\
\hline$\left[0, b_{2}\right)$ & $\checkmark$ & $\left(b_{1}, b_{3}\right)=(0,0)$ \\
{$\left[b_{2}, \infty\right)$} & $\left(b_{1}, b_{3}\right)=(0,0)$ & $\left(b_{1}, b_{3}\right)=(0,0)$
\end{tabular}

Table S27: $b_{2} \in(200,900)$

\begin{tabular}{c|ccc}
$b_{1} \backslash b_{3}$ & {$[0,200]$} & $\left(200, b_{2}\right]$ & $\left(b_{2}, \infty\right)$ \\
\hline$[0,200]$ & $\checkmark$ & $b_{2}<200$ & $\left(b_{1}, b_{3}\right)=(0,0)$ \\
$\left(200, b_{2}\right]$ & $b_{2}<200$ & $b_{2}<200$ & $\left(b_{1}, b_{3}\right)=(0,0)$ \\
$\left(b_{2}, \infty\right)$ & $\left(b_{1}, b_{3}\right)=(0,0)$ & $\left(b_{1}, b_{3}\right)=(0,0)$ & $\left(b_{1}, b_{3}\right)=(0,0)$
\end{tabular}

Table S28: $b_{2} \in[900, \infty)$

\begin{tabular}{c|cc}
$b_{1} \backslash b_{3}$ & {$[0,200]$} & $(200, \infty)$ \\
\hline$[0,200]$ & $\checkmark$ & $b_{2}<200$ \\
$(200, \infty)$ & $b_{2}<200$ & $b_{2}<200$
\end{tabular}

\section{B A model of the reverse auction under incomplete information}

As described in Section 3.3, we recast Example 1 in Section 3.1 as a game of incomplete information. Using the notation in Appendix B, the expected profit of firm 1 if it bids $b_{1} \geq 0$ and $b_{3} \geq 0$ is

$$
\begin{aligned}
E \pi_{1}\left(b_{1}, b_{3} ; v_{1}, v_{3}, \sigma\right)= & \int_{\tilde{v}_{2}}\left(P O_{1}\left(b_{1}, b_{2}\left(\tilde{v}_{2}, \sigma\right), b_{3}\right)-v_{1}\right) 1\left(1 \in F^{*}\left(b_{1}, b_{2}\left(\tilde{v}_{2}, \sigma\right), b_{3}\right)\right) \\
& +\left(P O_{3}\left(b_{1}, b_{2}\left(\tilde{v}_{2}, \sigma\right), b_{3}\right)-v_{3}\right) 1\left(3 \in F^{*}\left(b_{1}, b_{2}\left(\tilde{v}_{2}, \sigma\right), b_{3}\right)\right) d \Phi_{2}\left(\tilde{v}_{2}\right),
\end{aligned}
$$


Table S29: Possible bid configurations

\begin{tabular}{ccccccc}
\hline & \multicolumn{2}{c}{ TV station 1} & \multicolumn{2}{c}{ TV station 2} & \multicolumn{2}{c}{ TV station 3} \\
Bid configuration & $\operatorname{Pr}\left(1 \in F^{*}(b)\right)$ & $P O_{1}(b)$ & $\operatorname{Pr}\left(2 \in F^{*}(b)\right)$ & $P O_{2}(b)$ & $\operatorname{Pr}\left(3 \in F^{*}(b)\right)$ & $P O_{3}(b)$ \\
\hline $\min \left\{b_{1}, b_{2}\right\}=900$ & & & & & \\
$\vee \min \left\{b_{1}, b_{3}\right\}=900$ & & & & & & \\
$\vee \min \left\{b_{2}, b_{3}\right\}=900$ & 0 & 0 & 0 & 0 & 0 & 0 \\
$b_{1}>\max \left\{b_{2}, b_{3}\right\}$ & 0 & 0 & 1 & $b_{1}$ & 1 & $b_{1}$ \\
$b_{2}>\max \left\{b_{1}, b_{3}\right\}$ & 1 & $b_{2}$ & 0 & 0 & 1 & $b_{2}$ \\
$b_{3}>\max \left\{b_{1}, b_{2}\right\}$ & 1 & $b_{3}$ & 1 & $b_{3}$ & 0 & 0 \\
$900>b_{1}=b_{2}>b_{3}$ & $\frac{1}{2}$ & $b_{1} \vee 0$ & $\frac{1}{2}$ & $b_{1} \vee 0$ & 1 & $b_{1}$ \\
$900>b_{1}=b_{3}>b_{2}$ & $\frac{1}{2}$ & $b_{1} \vee 0$ & 1 & $b_{1}$ & $\frac{1}{2}$ & $b_{1} \vee 0$ \\
$900>b_{2}=b_{3}>b_{1}$ & 1 & $b_{2}$ & $\frac{1}{2}$ & $b_{2} \vee 0$ & $\frac{1}{2}$ & $b_{2} \vee 0$ \\
$900>b_{1}=b_{2}=b_{3}>0$ & $\frac{2}{3}$ & $b_{1} \vee 0$ & $\frac{2}{3}$ & $b_{1} \vee 0$ & $\frac{2}{3}$ & $b_{1} \vee 0$ \\
$b_{1}=b_{2}=b_{3}=0$ & 1 & 0 & 1 & 0 & 1 & 0 \\
\hline
\end{tabular}

where $1(\cdot)$ is the indicator function and $\tilde{v}_{2}$ is distributed according to the cumulative distribution function $\Phi_{2}\left(\tilde{v}_{2}\right)=\Phi\left(\frac{\tilde{v}_{2}-v_{2}}{\sigma}\right)$ with $\Phi(\cdot)$ being the standard normal cumulative distribution function. As firm 1 bids optimally, the bidding functions are given by $\left(b_{1}\left(v_{1}, v_{3}, \sigma\right), b_{3}\left(v_{1}, v_{3}, \sigma\right)\right)=$ $\arg \max _{b_{1}, b_{3} \geq 0} E \pi_{1}\left(b_{1}, b_{3} ; v_{1}, v_{3}, \sigma\right)$. The expected profit of firm 2 if it bids $b_{2} \geq 0$ is

$$
\begin{aligned}
E \pi_{2}\left(b_{2} ; v_{2}, \sigma\right)= & \int_{\tilde{v}_{1}} \int_{\tilde{v}_{3}}\left(P O_{2}\left(b_{1}\left(\tilde{v}_{1}, \tilde{v}_{3}, \sigma\right), b_{2}, b_{3}\left(\tilde{v}_{1}, \tilde{v}_{3}, \sigma\right)\right)-v_{2}\right) \\
& \cdot 1\left(2 \in F^{*}\left(b_{1}\left(\tilde{v}_{1}, \tilde{v}_{3}, \sigma\right), b_{2}, b_{3}\left(\tilde{v}_{1}, \tilde{v}_{3}, \sigma\right)\right)\right) d \Phi_{3}\left(\tilde{v}_{3}\right) d \Phi_{1}\left(\tilde{v}_{1}\right) .
\end{aligned}
$$

As firm 2 bids optimally, the bidding function is given by $b_{2}\left(v_{2}, \sigma\right)=\arg \max _{b_{2} \geq 0} E \pi_{2}\left(b_{2} ; v_{2}, \sigma\right)$.

In the interest of simplicity, we restrict $b_{j} \leq 900$ and consider the nine possible bid configurations in Table S29. ${ }^{\mathrm{S} 2}$ We determine $F^{*}(b)$ and $P O_{j}(b)$ from the bid configuration along with the specification of $S(X, R)$ in equation (2), assuming a random tie-breaking rule for bids above 0 and below 900 in line with footnote 25 . The expected profit of firm 1 if it bids $b_{1} \in[0,900]$ and $b_{3} \in[0,900]$ is

$$
\begin{aligned}
E \pi_{1}\left(b_{1}, b_{3} ; v_{1}, v_{3}, \sigma\right)= & \int_{\tilde{v}_{2}}\left(b_{1}-v_{3}\right) 1\left(b_{1}>\max \left\{b_{2}\left(\tilde{v}_{2}, \sigma\right), b_{3}\right\}\right) \\
& +\left(2 b_{2}\left(\tilde{v}_{2}, \sigma\right)-v_{1}-v_{3}\right) 1\left(b_{2}\left(\tilde{v}_{2}, \sigma\right)>\max \left\{b_{1}, b_{3}\right\}\right) \\
& +\left(b_{3}-v_{1}\right) 1\left(b_{3}>\max \left\{b_{1}, b_{2}\left(\tilde{v}_{2}, \sigma\right)\right\}\right) \\
& +\left(\frac{1}{2}\left(b_{3}-v_{1}\right)+\frac{1}{2}\left(b_{1}-v_{3}\right)\right) 1\left(900>b_{1}=b_{3}>b_{2}\left(\tilde{v}_{2}, \sigma\right)\right) \\
& -\left(v_{1}+v_{3}\right) 1\left(b_{1}=b_{2}\left(\tilde{v}_{2}, \sigma\right)=b_{3}=0\right) d \Phi_{2}\left(\tilde{v}_{2}\right),
\end{aligned}
$$

where we anticipate that in equilibrium firm 2's bid does not have mass points above 0 and below 900 and therefore, from firm 1's perspective, cannot tie with firm 1's bids in this range.

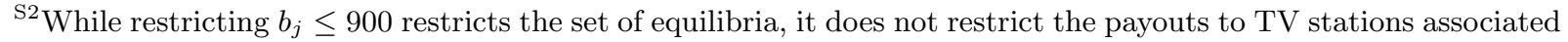
with these equilibria.
} 
The expected profit of firm 2 if it bids $b_{2} \in[0,900]$ is

$$
\begin{aligned}
E \pi_{2}\left(b_{2} ; v_{2}, \sigma\right)= & \int_{\tilde{v}_{1}} \int_{\tilde{v}_{3}}\left(b_{1}\left(\tilde{v}_{1}, \tilde{v}_{3}, \sigma\right)-v_{2}\right) 1\left(b_{1}\left(\tilde{v}_{1}, \tilde{v}_{3}, \sigma\right)>\max \left\{b_{2}, b_{3}\left(\tilde{v}_{1}, \tilde{v}_{3}, \sigma\right)\right\}\right) \\
& +\left(b_{3}\left(\tilde{v}_{1}, \tilde{v}_{3}, \sigma\right)-v_{2}\right) 1\left(b_{3}\left(\tilde{v}_{1}, \tilde{v}_{3}, \sigma\right)>\max \left\{b_{1}\left(\tilde{v}_{1}, \tilde{v}_{3}, \sigma\right), b_{2}\right\}\right) \\
& +\frac{1}{2}\left(b_{1}\left(\tilde{v}_{1}, \tilde{v}_{3}, \sigma\right)-v_{2}\right) 1\left(900>b_{1}\left(\tilde{v}_{1}, \tilde{v}_{3}, \sigma\right)=b_{2}>b_{3}\left(\tilde{v}_{1}, \tilde{v}_{3}, \sigma\right)\right) \\
& +\left(b_{1}\left(\tilde{v}_{1}, \tilde{v}_{3}, \sigma\right)-v_{2}\right) 1\left(900>b_{1}\left(\tilde{v}_{1}, \tilde{v}_{3}, \sigma\right)=b_{3}\left(\tilde{v}_{1}, \tilde{v}_{3}, \sigma\right)>b_{2}\right) \\
& +\frac{1}{2}\left(b_{3}\left(\tilde{v}_{1}, \tilde{v}_{3}, \sigma_{3}\right)-v_{2}\right) 1\left(900>b_{2}=b_{3}\left(\tilde{v}_{1}, \tilde{v}_{3}, \sigma\right)>b_{1}\left(\tilde{v}_{1}, \tilde{v}_{3}, \sigma\right)\right) \\
& +\frac{2}{3}\left(b_{1}\left(\tilde{v}_{1}, \tilde{v}_{3}, \sigma\right)-v_{2}\right) 1\left(900>b_{1}\left(\tilde{v}_{1}, \tilde{v}_{3}, \sigma\right)=b_{2}=b_{3}\left(\tilde{v}_{1}, \tilde{v}_{3}, \sigma\right)>0\right) \\
& -v_{2} 1\left(b_{1}\left(\tilde{v}_{1}, \tilde{v}_{3}, \sigma\right)=b_{2}=b_{3}\left(\tilde{v}_{1}, \tilde{v}_{3}, \sigma\right)=0\right) d \Phi_{3}\left(\tilde{v}_{3}\right) d \Phi_{1}\left(\tilde{v}_{1}\right) .
\end{aligned}
$$

Inspection of the expected profit of firm 2 almost immediately yields

Proposition 5. Truthful bidding $b_{2}\left(v_{2}, \sigma\right)=\max \left\{\min \left\{v_{2}, 900\right\}, 0\right\}$ is a dominant strategy for firm 2.

Proof. We show that for any given values of $b_{1}\left(\tilde{v}_{1}, \tilde{v}_{3}, \sigma\right)$ and $b_{3}\left(\tilde{v}_{1}, \tilde{v}_{3}, \sigma\right)$, firm 2 cannot do better than bid $b_{2}\left(v_{2}, \sigma\right)=\max \left\{\min \left\{v_{2}, 900\right\}, 0\right\}$. We proceed by enumerating the different possible cases for $b_{1}\left(\tilde{v}_{1}, \tilde{v}_{3}, \sigma\right), b_{3}\left(\tilde{v}_{1}, \tilde{v}_{3}, \sigma\right)$, and $v_{2}$. We restrict attention to cases where $b_{1}\left(\tilde{v}_{1}, \tilde{v}_{3}, \sigma\right) \geq b_{3}\left(\tilde{v}_{1}, \tilde{v}_{3}, \sigma\right)$ because cases where $b_{1}\left(\tilde{v}_{1}, \tilde{v}_{3}, \sigma\right) \leq b_{3}\left(\tilde{v}_{1}, \tilde{v}_{3}, \sigma\right)$ are analogous. For each case, Table S30 lists the best response of firm 2. A blank cell indicates that the case cannot arise. As can be seen from Table S30, the best response contains $\max \left\{\min \left\{v_{2}, 900\right\}, 0\right\}$ for each case, thereby establishing the proposition.

\section{Table S30: Best response of firm 2}

\begin{tabular}{c|cccccc} 
& $(1)$ & $(2)$ & $(3)$ & $(4)$ & $(5)$ & $(6)$ \\
& $v_{2}>900$ & $v_{2}=900$ & $900>v_{2}>b_{1}$ & $900>v_{2}=b_{1}>0$ & $v_{2}=b_{1}=0$ & $v_{2}<b_{1}$ \\
\hline $900=b_{1}>b_{3}>0$ & 900 & {$[0,900]$} & & & {$\left[0, b_{1}\right)$} \\
$900>b_{1}>b_{3}>0$ & $\left(b_{1}, 900\right]$ & $\left(b_{1}, 900\right]$ & $\left(b_{1}, 900\right]$ & {$[0,900]$} & {$\left[0, b_{1}\right)$} \\
$900=b_{1}>b_{3}=0$ & 900 & {$[0,900]$} & & & {$\left[0, b_{1}\right)$} \\
$900>b_{1}>b_{3}=0$ & $\left(b_{1}, 900\right]$ & $\left(b_{1}, 900\right]$ & $\left(b_{1}, 900\right]$ & {$[0,900]$} & {$\left[0, b_{1}\right)$} \\
$900=b_{1}=b_{3}$ & 900 & {$[0,900]$} & & & {$\left[0, b_{1}\right)$} \\
$900>b_{1}=b_{3}>0$ & $\left(b_{1}, 900\right]$ & $\left(b_{1}, 900\right]$ & $\left(b_{1}, 900\right]$ & {$[0,900]$} & & {$\left[0, b_{1}\right)$} \\
$b_{1}=b_{3}=0$ & $(0,900]$ & $(0,900]$ & $(0,900]$ & & {$[0,900]$} &
\end{tabular}

In column (1) of Table S30, firm 2 prefers not to sell TV station 2 at the opening price of 900. Firm 2 therefore either causes the reverse auction to fail at the outset if $b_{1}=900$ or withdraws first if $b_{1}<900$. In column (2), firm 2 is indifferent between selling TV station 2 at the opening price of 900 and not selling it. Firm 2 therefore bids anything if $b_{1}=900$ or withdraws first if $b_{1}<900$. In column (3), firm 2 prefers not to sell TV station 2 at a price of $b_{1}$. Firm 2 therefore withdraws first. In column (4) and (5), firm 2 is indifferent between selling TV station 2 at a price of $b_{1}$ and 
not selling it. Firm 2 therefore bids anything. In column (6), firm 2 prefers to sell TV station 2 at a price of $b_{1}$. Firm 2 therefore does not withdraw first.

Using Proposition 5, the expected profit of firm 1 if it bids $b_{1} \in[0,900]$ and $b_{3} \in[0,900]$ can be written as

$$
\begin{aligned}
E \pi_{1}\left(b_{1}, b_{3} ; v_{1}, v_{3}, \sigma\right)= & \int_{900}^{\infty}\left(2 \cdot 900-v_{1}-v_{3}\right) 1\left(900>\max \left\{b_{1}, b_{3}\right\}\right) d \Phi_{2}\left(\tilde{v}_{2}\right) \\
& +\int_{0}^{900}\left(b_{1}-v_{3}\right) 1\left(b_{1}>\max \left\{\tilde{v}_{2}, b_{3}\right\}\right) \\
& +\left(2 \tilde{v}_{2}-v_{1}-v_{3}\right) 1\left(\tilde{v}_{2}>\max \left\{b_{1}, b_{3}\right\}\right) \\
& +\left(b_{3}-v_{1}\right) 1\left(b_{3}>\max \left\{b_{1}, \tilde{v}_{2}\right\}\right) \\
& +\left(\frac{1}{2}\left(b_{3}-v_{1}\right)+\frac{1}{2}\left(b_{1}-v_{3}\right)\right) 1\left(900>b_{1}=b_{3}>\tilde{v}_{2}\right) d \Phi_{2}\left(\tilde{v}_{2}\right) \\
& +\int_{-\infty}^{0}\left(b_{1}-v_{3}\right) 1\left(b_{1}>b_{3}\right) \\
& +\left(b_{3}-v_{1}\right) 1\left(b_{3}>b_{1}\right) \\
& +\left(\frac{1}{2}\left(b_{3}-v_{1}\right)+\frac{1}{2}\left(b_{1}-v_{3}\right)\right) 1\left(900>b_{1}=b_{3}>0\right) \\
& -\left(v_{1}+v_{3}\right) 1\left(b_{1}=b_{3}=0\right) d \Phi_{2}\left(\tilde{v}_{2}\right) .
\end{aligned}
$$

We assume $v_{1}=100$ and $v_{3}=300$ as in Table 1 . Towards determining $b_{1}(100,300, \sigma)$ and $b_{3}(100,300, \sigma)$, the following propositions show that firm 1 always bids $b_{1}<b_{3}$.

Proposition 6. $E \pi_{1}(0,0 ; 100,300, \sigma)<E \pi_{1}(0, \epsilon ; 100,300, \sigma)$ and $E \pi_{1}(b, b ; 100,300, \sigma)<E \pi_{1}(b-$ $\epsilon, b ; 100,300, \sigma)$ for all $b \in(0,900]$ for any sufficiently small $\epsilon>0$.

Hence, firm 1 never bids $b_{1}=b_{3}$.

Proof. First, consider $b=0$. Then plugging into equation (S3) yields

$$
\begin{aligned}
E \pi_{1}(0,0 ; 100,300, \sigma)= & \int_{900}^{\infty}(2 \cdot 900-100-300) d \Phi_{2}\left(\tilde{v}_{2}\right) \\
& +\int_{0}^{900}\left(2 \tilde{v}_{2}-100-300\right) d \Phi_{2}\left(\tilde{v}_{2}\right) \\
& -\int_{-\infty}^{0}(100+300) d \Phi_{2}\left(\tilde{v}_{2}\right) \\
< & \int_{900}^{\infty}(2 \cdot 900-100-300) d \Phi_{2}\left(\tilde{v}_{2}\right) \\
& +\int_{\epsilon}^{900}\left(2 \tilde{v}_{2}-100-300\right) d \Phi_{2}\left(\tilde{v}_{2}\right) \\
& +\int_{-\infty}^{\epsilon}(\epsilon-100) d \Phi_{2}\left(\tilde{v}_{2}\right) \\
= & E \pi_{1}(0, \epsilon ; 100,300, \sigma)
\end{aligned}
$$


for any sufficiently small $\epsilon>0$. Consider next $b \in(0,900)$. Then plugging into equation (S3) yields

$$
\begin{aligned}
E \pi_{1}(b, b ; 100,300, \sigma)= & \int_{900}^{\infty}(2 \cdot 900-100-300) d \Phi_{2}\left(\tilde{v}_{2}\right) \\
& +\int_{b}^{900}\left(2 \tilde{v}_{2}-100-300\right) d \Phi_{2}\left(\tilde{v}_{2}\right) \\
& +\int_{-\infty}^{b}\left(b-\frac{1}{2} 100-\frac{1}{2} 300\right) d \Phi_{2}\left(\tilde{v}_{2}\right) \\
< & \int_{900}^{\infty}(2 \cdot 900-100-300) d \Phi_{2}\left(\tilde{v}_{2}\right) \\
& +\int_{b}^{900}\left(2 \tilde{v}_{2}-100-300\right) d \Phi_{2}\left(\tilde{v}_{2}\right) \\
& +\int_{-\infty}^{b}(b-100) d \Phi_{2}\left(\tilde{v}_{2}\right) \\
= & E \pi_{1}(b-\epsilon, b ; 100,300, \sigma) .
\end{aligned}
$$

Finally, consider $b=900$. Then plugging into equation (S3) yields

$$
\begin{aligned}
E \pi_{1}(900,900 ; 100,300, \sigma) & =0 \\
& <\int_{-\infty}^{900}(900-100) d \Phi_{2}\left(\tilde{v}_{2}\right) \\
& =E \pi_{1}(900-\epsilon, 900 ; 100,300, \sigma) .
\end{aligned}
$$

Proposition 7. $b_{1}>b_{3}$ implies $E \pi_{1}\left(b_{1}, b_{3} ; 100,300, \sigma\right)>E \pi_{1}\left(b_{3}, b_{1} ; 100,300, \sigma\right)$.

Hence, firm 1 never bids $b_{1}>b_{3}$. Taken together, Propositions 6 and 7 imply that firm 1 always bids $b_{1}<b_{3}$.

Proof. Consider first $900>b_{1}>b_{3} \geq 0$. Then plugging into equation (S3) yields 


$$
\begin{aligned}
E \pi_{1}\left(b_{1}, b_{3} ; 100,300, \sigma\right)= & \int_{900}^{\infty}(2 \cdot 900-100-300) d \Phi_{2}\left(\tilde{v}_{2}\right) \\
& +\int_{b_{1}}^{900}\left(2 \tilde{v}_{2}-100-300\right) d \Phi_{2}\left(\tilde{v}_{2}\right) \\
& +\int_{-\infty}^{b_{1}}\left(b_{1}-300\right) d \Phi_{2}\left(\tilde{v}_{2}\right) \\
< & \int_{900}^{\infty}(2 \cdot 900-100-300) d \Phi_{2}\left(\tilde{v}_{2}\right) \\
& +\int_{b_{1}}^{900}\left(2 \tilde{v}_{2}-100-300\right) d \Phi_{2}\left(\tilde{v}_{2}\right) \\
& +\int_{-\infty}^{b_{1}}\left(b_{1}-100\right) d \Phi_{2}\left(\tilde{v}_{2}\right) \\
= & E \pi_{1}\left(b_{3}, b_{1} ; 100,300, \sigma\right) .
\end{aligned}
$$

Next consider $900=b_{1}>b_{3} \geq 0$. Then plugging into equation (S3) yields

$$
\begin{aligned}
E \pi_{1}\left(900, b_{3} ; 100,300, \sigma\right) & =\int_{-\infty}^{900}(900-300) d \Phi_{2}\left(\tilde{v}_{2}\right) \\
& <\int_{-\infty}^{900}(900-100) d \Phi_{2}\left(\tilde{v}_{2}\right) \\
& =E \pi_{1}\left(b_{3}, 900 ; 100,300, \sigma\right) .
\end{aligned}
$$

Using Propositions 6 and 7, the expected profit of 1 firm if $b_{3}<900$ becomes

$$
\begin{aligned}
E \pi_{1}\left(b_{1}, b_{3} ; 100,300, \sigma\right)= & \int_{900}^{\infty}(2 \cdot 900-100-300) d \Phi_{2}\left(\tilde{v}_{2}\right) \\
& +\int_{b_{3}}^{900}\left(2 \tilde{v}_{2}-100-300\right) d \Phi_{2}\left(\tilde{v}_{2}\right) \\
& +\int_{0}^{b_{3}}\left(b_{3}-100\right) d \Phi_{2}\left(\tilde{v}_{2}\right) \\
& +\int_{-\infty}^{0}\left(b_{3}-100\right) d \Phi_{2}\left(\tilde{v}_{2}\right) \\
= & 1400\left(1-\Phi\left(\frac{900-v_{2}}{\sigma}\right)\right) \\
& +\left(2 v_{2}-400\right)\left(\Phi\left(\frac{900-v_{2}}{\sigma}\right)-\Phi\left(\frac{b_{3}-v_{2}}{\sigma}\right)\right) \\
& +2 \sigma\left(\phi\left(\frac{b_{3}-v_{2}}{\sigma}\right)-\phi\left(\frac{900-v_{2}}{\sigma}\right)\right) \\
& +\left(b_{3}-100\right) \Phi\left(\frac{b_{3}-v_{2}}{\sigma}\right)
\end{aligned}
$$


and

$$
\begin{aligned}
E \pi_{1}\left(b_{1}, 900 ; 100,300, \sigma\right) & =\int_{-\infty}^{900}(900-100) d \Phi_{2}\left(\tilde{v}_{2}\right) \\
& =800 \Phi\left(\frac{900-v_{2}}{\sigma}\right)
\end{aligned}
$$

if $b_{3}=900$. Note that the expected profit of firm 1 depends solely on $b_{3}$; hence, $b_{1} \in\left[0, b_{3}\right)$ is indeterminate. Note also that $\lim _{b_{3} \rightarrow 900-} E \pi_{1}\left(b_{1}, b_{3} ; 100,300, \sigma\right)>E \pi_{1}\left(b_{1}, 900 ; 100,300, \sigma\right)$; hence, firm 1 never bids $b_{3}=900$.

To explore the relationship between the game of incomplete information as $\sigma \rightarrow 0^{+}$so that beliefs collapse at the true reservation values and the game of complete information, we first assume $v_{2}=500$ as in Table 1 . The expected profit of firm 1 in the game of incomplete information becomes

$$
\begin{gathered}
E \pi_{1}\left(b_{1}, b_{3} ; 100,300, \sigma\right) \\
=\left\{\begin{array}{cl}
1400-800 \Phi\left(\frac{400}{\sigma}\right)+\left(b_{3}-700\right) \Phi\left(\frac{b_{3}-500}{\sigma}\right)+2 \sigma\left(\phi\left(\frac{b_{3}-500}{\sigma}\right)-\phi\left(\frac{400}{\sigma}\right)\right) & \text { if } \quad b_{3}<900, \\
800 \Phi\left(\frac{400}{\sigma}\right) & \text { if } \quad b_{3}=900 .
\end{array}\right.
\end{gathered}
$$

For comparison, in the game of complete information the profit of firm 1 in equation (S1) in Online Appendix A.2 becomes

$$
\pi_{1}\left(b_{1}, 500, b_{3}\right)=\left\{\begin{array}{clc}
600 & \text { if } & b_{3}<500 \\
b_{3}-100 & \text { if } & b_{3}>500 \\
500 & \text { if } & b_{3}=500
\end{array}\right.
$$

where we assume that firm 2 truthfully bids $b_{2}=500$ and firm 1 bids $b_{1}<b_{3}$ as in the game of incomplete information. Note that in the game of complete information the profit of firm 1 again depends solely on $b_{3}$ and that firm 1 always bids such that $b_{3}=900$.

Figure S1 plots the expected profit of firm 1 in equation (S5) for various values of $\sigma$ and the profit of firm 1 in equation (S6). As $\sigma \rightarrow 0^{+}$, the expected profit of firm 1 under incomplete information closely resembles the profit of firm 1 under complete information. Moreover, for a wide range of values of $\sigma, b_{3}(100,300, \sigma)$ in the game of incomplete information is arbitrarily close to (but different from) $b_{3}=900$ in the game of complete information. Close to extreme overbidding thus arises in the game of incomplete information.

To further explore the relationship between the games of complete and incomplete information, we consider a variant of Example 1 in Section 3.3 in which we replace the reservation value of TV station 2 by $v_{2}=700$. The expected profit of firm 1 in the game of incomplete information becomes 
Figure S1: Expected profit and profit of firm 1 in equations (S5) and (S6) with $v_{2}=500$

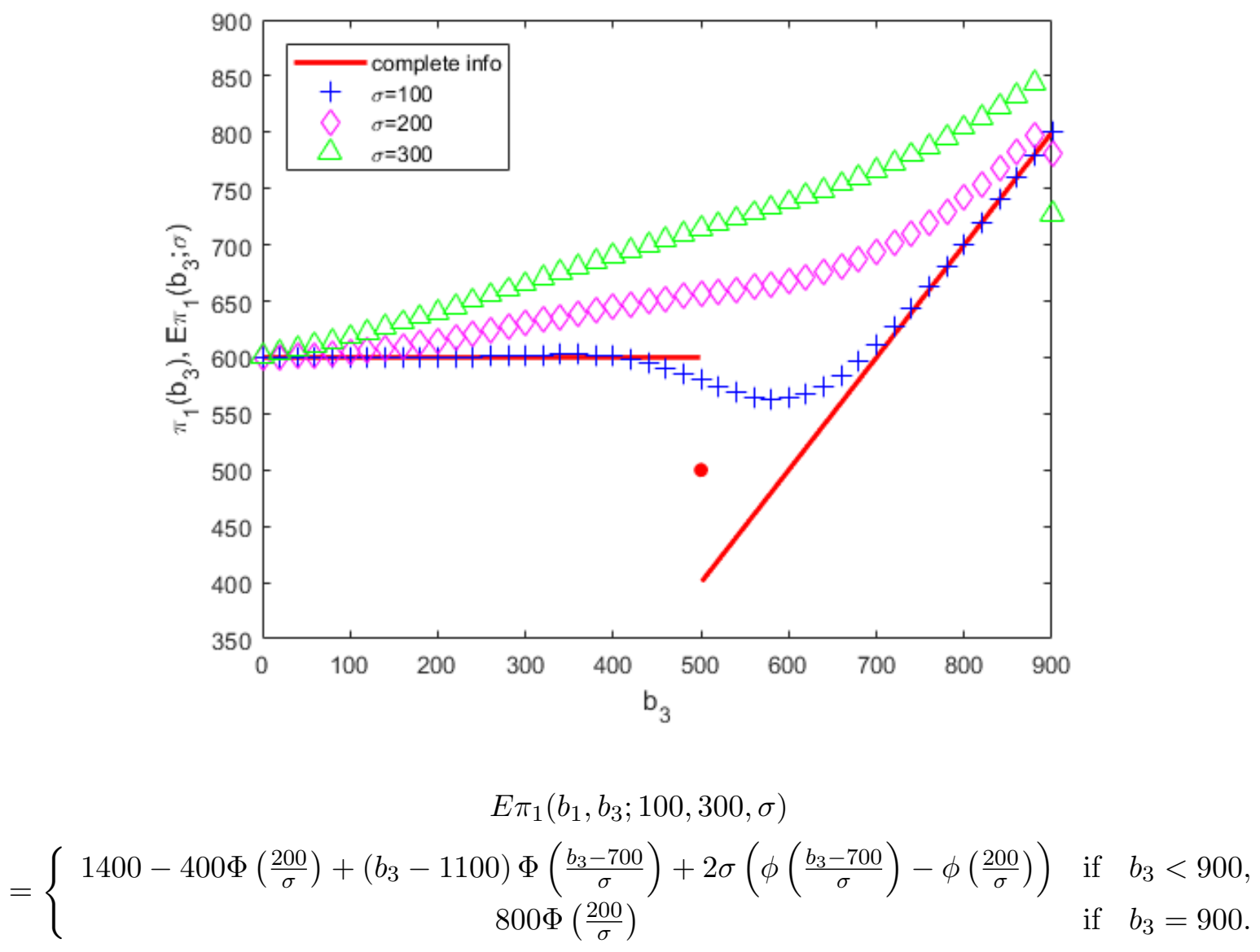

For comparison, in the game of complete information the profit of firm 1 in equation (S2) in Online Appendix A.3 becomes

$$
\pi_{1}\left(b_{1}, 700, b_{3}\right)=\left\{\begin{array}{clc}
1000 & \text { if } & b_{3}<700 \\
b_{3}-100 & \text { if } & b_{3}>700 \\
800 & \text { if } & b_{3}=700
\end{array}\right.
$$

where we assume that firm 2 truthfully bids $b_{2}=700$ and firm 1 bids $b_{1}<b_{3}$ as in the game of incomplete information. Note that in the game of complete information the profit of firm 1 again depends solely on $b_{3}$ and that firm 1 always bids $b_{3} \in[0,700)$.

Figure S2 is analogous to Figure S1. As $\sigma \rightarrow 0^{+}$, the expected profit of firm 1 under incomplete information again closely resembles the profit of firm 1 under complete information. Figure S2 further shows that $b_{3}(100,300, \sigma)$ in the game of incomplete information gets close to the reservation value $v_{3}=300$ of $\mathrm{TV}$ station 3 as $\sigma \rightarrow 0+$. In this example, a small amount of incomplete information thus appears to single out truthful bidding. Finally, Figure S2 shows that $b_{3}(100,300, \sigma)$ gets close to 900 as $\sigma \rightarrow \infty$. A large amount of incomplete information thus appears to support 
Figure S2: Expected profit and profit of firm 1 in equations (S7) and (S8) with $v_{2}=700$

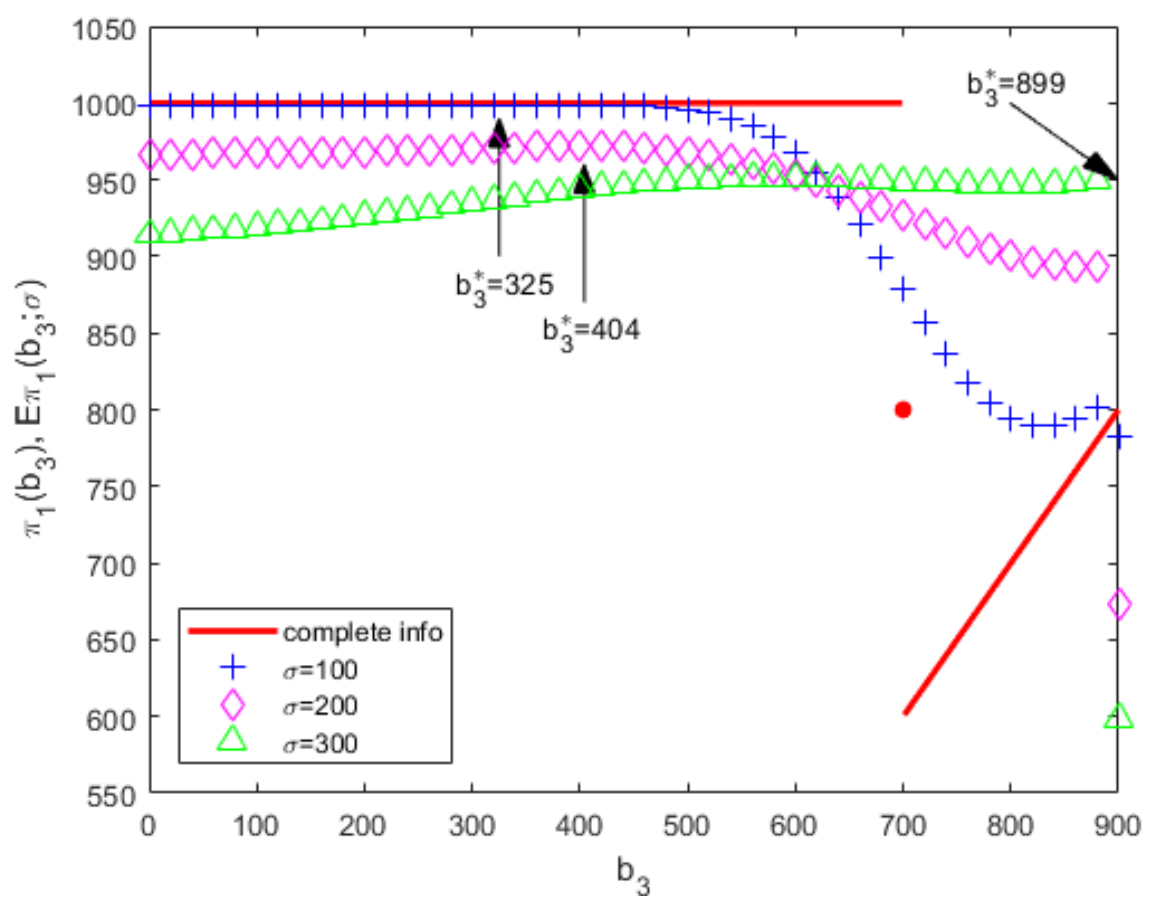

close to extreme overbidding even though firm 1 never bids $b_{3}=900$ in the game of complete information as we show in Online Appendix A.3.

\section{Private equity firms' acquisitions and sales of TV stations}

Figures S3-S5 document the timeline of acquisitions (black) and sales (red) of TV stations by LocusPoint, NRJ, and OTA. As stated in the main text, from 2010 to 2015 these private equity firms acquired 48 UHF stations. In addition, as stated in footnote 44, LocusPoint acquired W33BYD (facility ID 25722), WMJF-CD (facility ID 191262), and WBNF-CD (facility ID 14326) and sold them to HME Equity Fund II LLC before the reverse auction; we exclude these UHF stations from Figure S3. NRJ acquired KFWD (facility ID 29015); we include this VHF station in Figure S4. Finally, LocusPoint acquired WPHA-CD (facility ID 72278) from D.T.V. LLC in a deal that apparently has not been consummated due to a law suit between the two parties; we exclude this UHF station from Figure S3. ${ }^{\text {S3 }}$

We obtain the holdings of LocusPoint, NRJ, and OTA as of 2015 from BIA. We rely on news coverage to confirm these holdings and identify any changes to them. ${ }^{\mathrm{S} 4}$ We have been unable to ascertain the purchase price for W24BB-D (facility ID 68137) and thus set it to zero. If multiple

\footnotetext{
${ }^{\text {S3} S e e ~ h t t p s: / / p u b l i c f i l e s . f c c . g o v / a p i / s e r v i c e / t v / a p p l i c a t i o n / 1709537 . h t m l ~ a n d ~ P a r a g r a p h ~} 81$ of https: //transition.fcc.gov/eb/Orders/2016/FCC-16-41A1.html, accessed on April 1, 2018.

${ }^{\mathrm{S} 4}$ We primarily track TV station trading news through http://www.tvnewscheck.com/ and https://www.rbr. $\mathrm{com} /$.
} 
TV stations were acquired in a single transaction, then we allocate the total purchase price to each acquired TV station in proportion to its interference free population.

The FCC released the identity of the TV stations that relinquished their licenses in the reverse auction along with their payouts. OTA voluntarily surrendered the license of WJPW-CD (facility ID 68407$)$ to the FCC. ${ }^{\text {S5 }}$ We exclude from Table 5 and Figures S3-S5 any sales of non-spectrum assets such as programming contracts, or equipment. For example, OTA and NRJ sold the nonspectrum assets of KTLN-TV (facility ID 49153) and WGCB-TV (facility ID 55350), respectively, after relinquishing their licenses in the reverse auction. ${ }^{\mathrm{S} 6}$

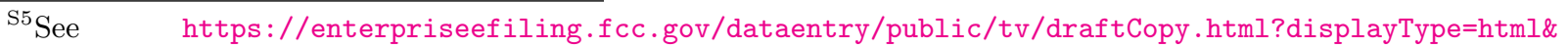

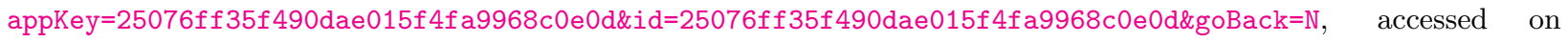
April 30, 2018.

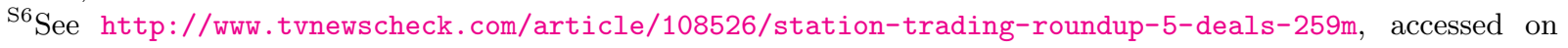
April 1, 2018.
} 

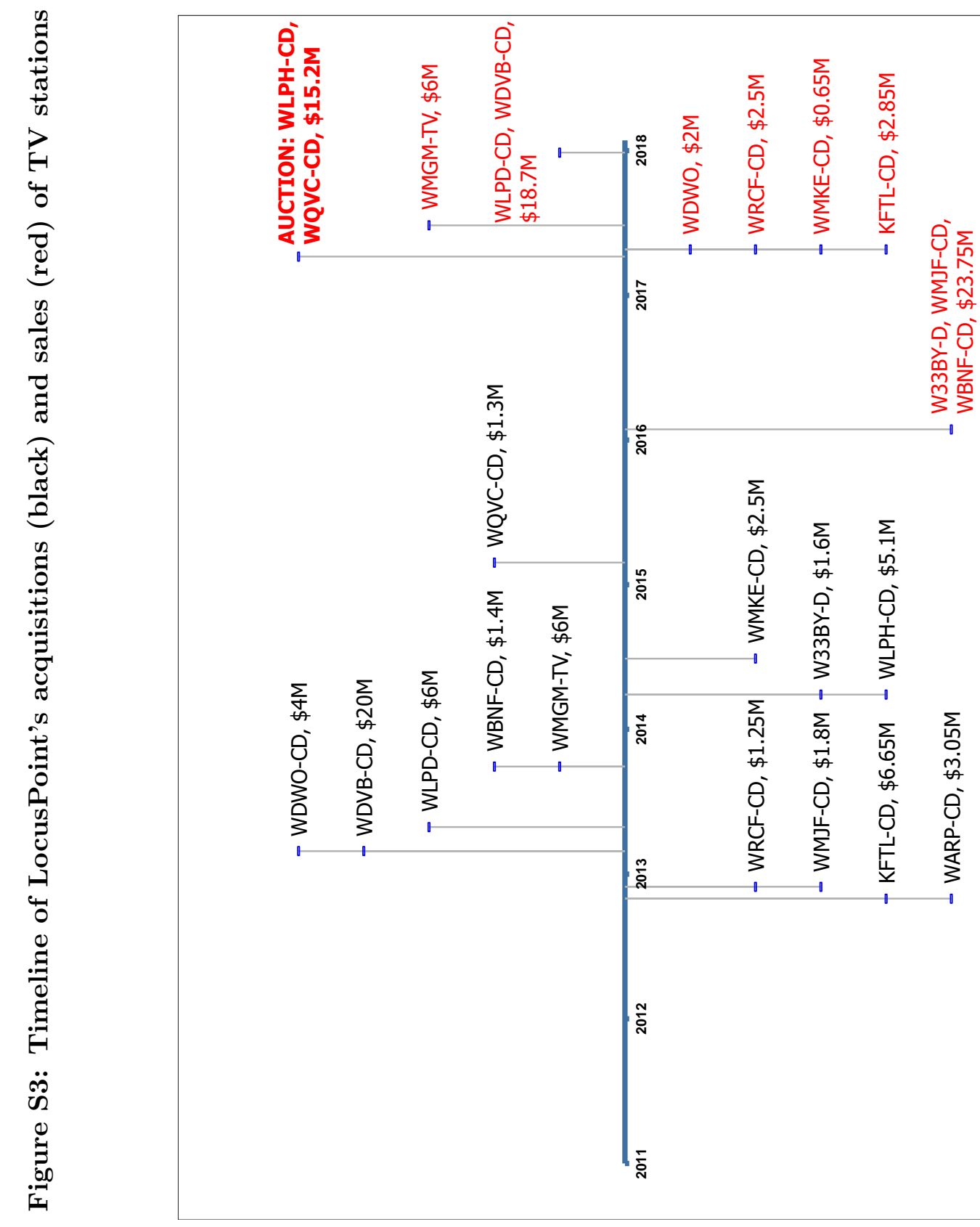

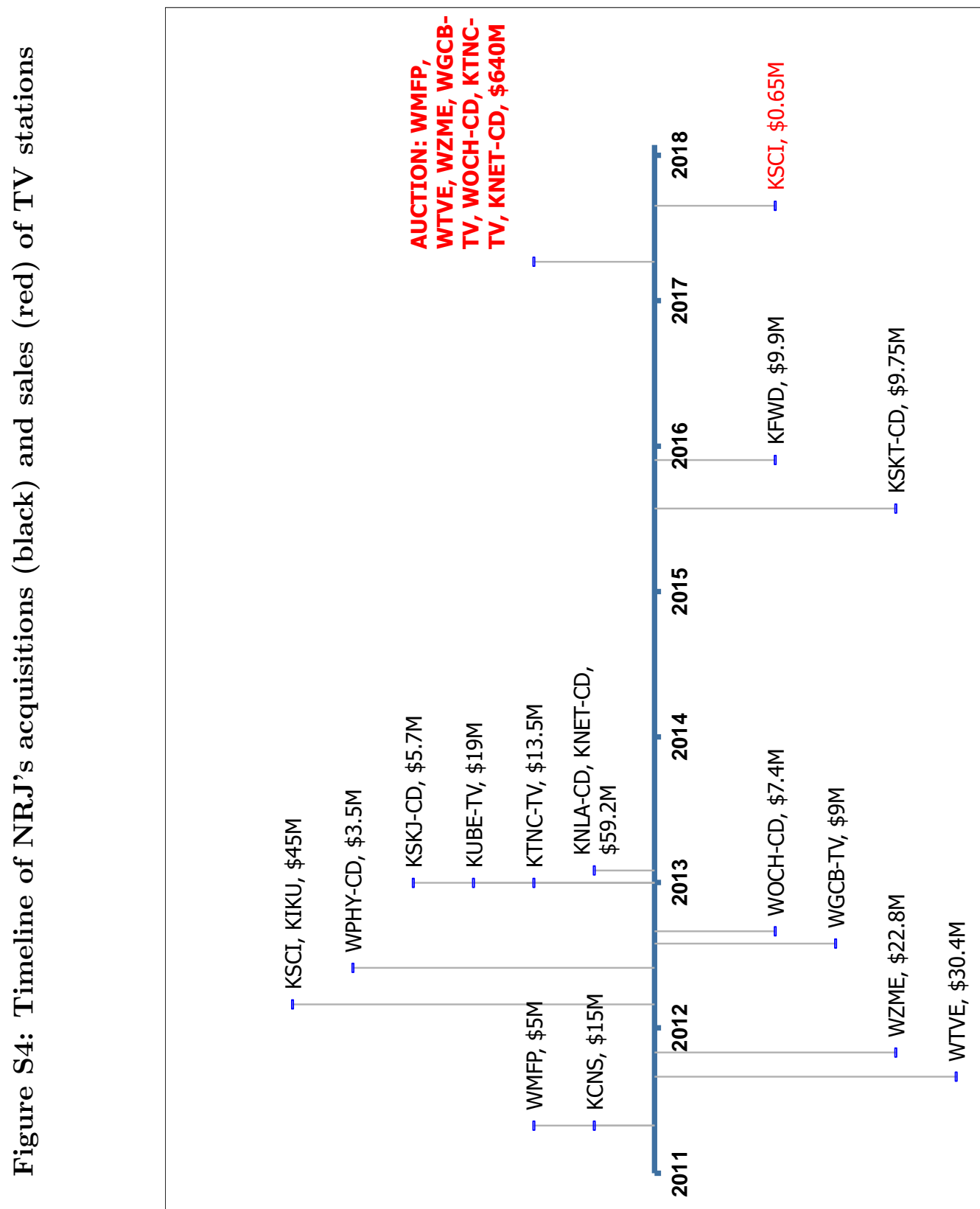

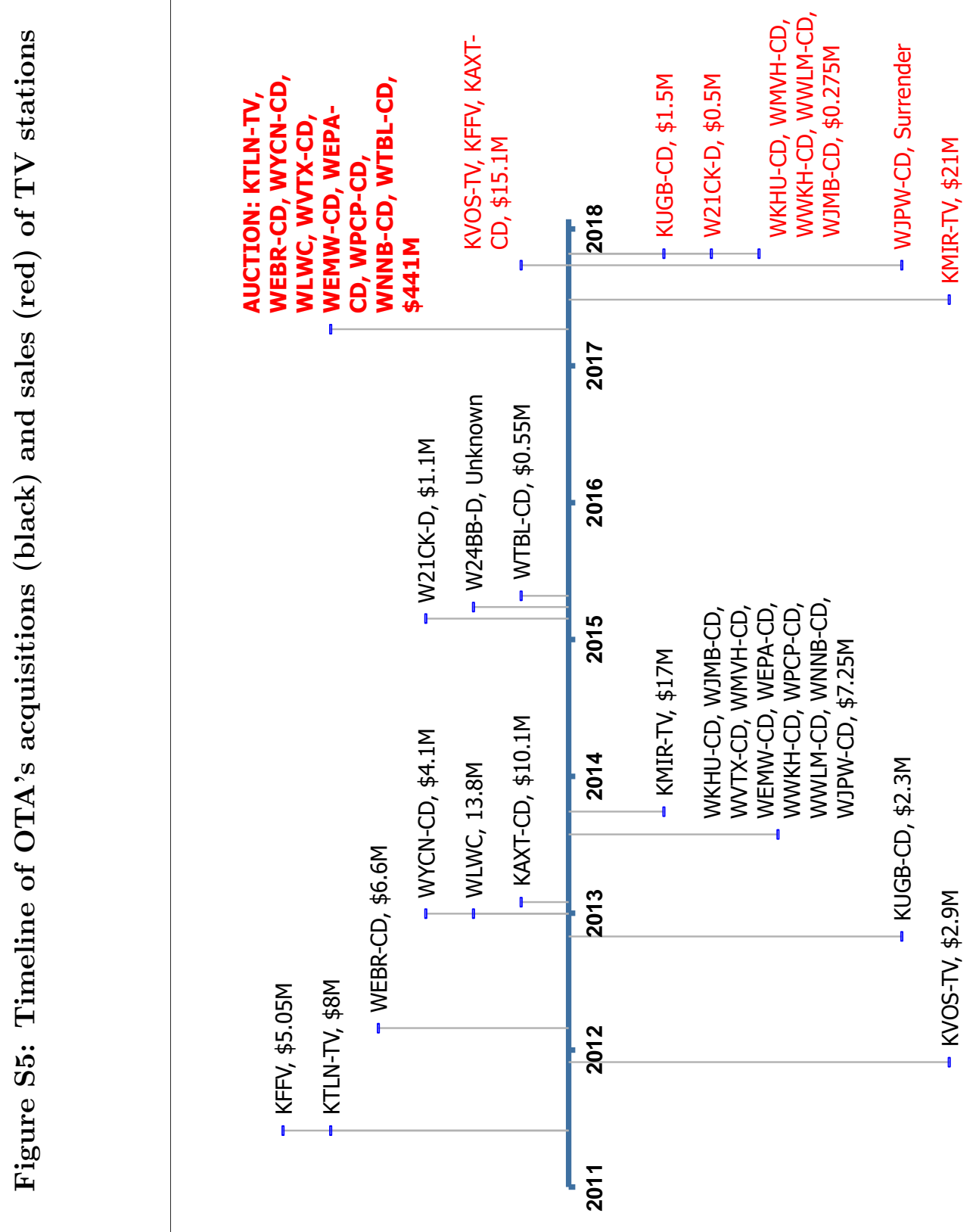


\section{Pseudo code for algorithm}

There are $N$ TV stations in the focal DMA and its neighbors. Throughout we fix the vector $b=\left(b_{1}, \ldots, b_{N}\right)$ of their bids. Using the notation in Section $3, P O_{j}$ is the payout of TV station $j$ from the reverse auction and $\pi_{j}$ its profit. The base clock price is $P$, the set of active TV stations is $A$, the set of inactive TV stations is $I$, and the set of frozen TV stations is $F$, where we omit the dependence of these objects on the round $\tau$ of the reverse auction.

Full repacking. Algorithm 1 describes the algorithm that we use under full repacking as well as under naive bidding with $b=\left(s_{1}, \ldots, s_{N}\right)$. On line $1,|Y| \leq 1$ by assumption, except possibly if $\tau=1$, so that at most one active TV station opts to remain on the air. 
Algorithm 1 Full repacking

Initialization: Set $\tau=1, P=900, A=\{1, \ldots, N\}, I=\emptyset$, and $F=\emptyset$.

Repeat

1. Let $Y=\left\{k \in A \mid b_{k} \geq P\right\}$ be the set of active TV stations that opt to remain on the air at a base clock price of $P$. Set $A \leftarrow A \backslash Y, I \leftarrow I \cup Y$, and $P O_{j}=\pi_{j}=0$ for all $j \in Y$.

2. If $\tau=1$ and $S(Y, R) \neq 1$, then these TV stations cannot be repacked and the reverse auction has failed at the outset (see footnote 26). Set a flag, $P O_{j}=\pi_{j}=0$ for all $j \in A$, and terminate.

3. For all $k \in A$ do

(a) If $S(I \cup\{k\}, R) \neq 1$, then active TV station $k$ cannot additionally be repacked. In this case, set $A \leftarrow A \backslash\{k\}, F \leftarrow F \cup\{k\}, P O_{k}=\varphi_{k} P$, and $\pi_{k}=\varphi_{k} P-v_{k}$.

4. End

5. If $A \neq \emptyset$, then set $P=\max _{j \in A} b_{j}, \tau \leftarrow \tau+1$, and continue with the decreased based clock price.

6. If $P=0$, then the reverse auction concludes with a base clock price of 0 (see footnote 27 ). Set a flag, $F \leftarrow F \cup A, P O_{j}=0$ and $\pi_{j}=-v_{j}$ for all $j \in A$, and $A=\emptyset$ (in this order).

Until $A=\emptyset$.

Limited repacking. Algorithm 2 describes the algorithm that we use under limited repacking. It takes the output of the algorithm under full repacking and naive bidding as an input.

We relabel TV stations such that TV stations $\{1, \ldots, K\}$ are in the focal DMA and TV stations $\{K+1, \ldots, N\}$ are in the neighboring DMAs. We denote by $F^{*, f u l l, \text { naive }}$ the (appropriately relabeled) set of frozen TV stations at the conclusion of the reverse auction from the algorithm under full repacking and naive bidding. In the initialization, $F^{*, f u l l, n a i v e} \cap\{K+1, \ldots, N\}$ is the set of TV stations in neighboring DMAs that have been frozen under full repacking and naive bidding; these TV stations cannot freeze another TV stations under limited repacking. On line $3, A \cap\{1, \ldots, K\}$ is the set of active TV stations in the focal DMA; these are the only TV stations that can be frozen under limited repacking. 


\footnotetext{
Algorithm 2 Limited repacking

Initialization: Set $\tau=1, P=900, A=\{1, \ldots, N\} \backslash\left(F^{*, \text { full, naive }} \cap\{K+1, \ldots, N\}\right), I=\emptyset$, and $F=F^{*, \text { full,naive }} \cap\{K+1, \ldots, N\}$.

Repeat

1. Le $Y=\left\{k \in A \mid b_{k} \geq P\right\}$ be the set of active TV stations that opt to remain on the air at a base clock price of $P$. Set $A \leftarrow A \backslash Y, I \leftarrow I \cup Y$, and $P O_{j}=\pi_{j}=0$ for all $j \in Y$.

2. If $\tau=1$ and $S(Y, R) \neq 1$, then these TV stations cannot be repacked and the reverse auction has failed at the outset (see footnote 26). Set a flag, $P O_{j}=\pi_{j}=0$ for all $j \in A$, and terminate.

3. For all $k \in A \cap\{1, \ldots, K\}$ do

(a) If $S(I \cup\{k\}, R) \neq 1$, then active TV station $k$ cannot additionally be repacked. In this case, set $A \leftarrow A \backslash\{k\}, F \leftarrow F \cup\{k\}, P O_{k}=\varphi_{k} P$, and $\pi_{k}=\varphi_{k} P-v_{k}$.

4. End

5. If $A \neq \emptyset$, then set $P=\max _{j \in A} b_{j}, \tau \leftarrow \tau+1$, and continue with the lower based clock price.

6. If $P=0$, then the reverse auction concludes with a base clock price of 0 (see footnote 27). Set a flag, $F \leftarrow F \cup A, P O_{j}=0$ and $\pi_{j}=-v_{j}$ for all $j \in A$, and $A=\emptyset$ (in this order).

Until $A=\emptyset$.
} 


\section{E Robustness to underbidding}

We investigate the importance of underbidding for the computationally manageable Washington, DC, DMA. Allowing the owner of a jointly owned TV station $j$ located inside the focal DMA to underbid $b_{j}=0$ in addition to bid truthfully $b_{j}=s_{j}$ and overbid $b_{j}=900$ increases the number strategy profiles from 189 to 343. Consequently, ruling out underbidding as a strategy, as we do in the main text, greatly reduces the computational burden.

On average across simulation draws, we find 23.89 (24.62) equilibria under the $126 \mathrm{MHz}(84$ $\mathrm{MHz}$ ) clearing target that map into 1.11 (2.62) payout-unique equilibria. While $87.9 \%$ (83.0\%) of the underlying equilibria involve underbidding by at least one TV station, all payout-unique equilibria can be sustained by an equilibrium that involves no underbidding. That is, for any underlying equilibrium with underbidding, there is another equilibrium without underbidding that

results in identical payouts to all TV stations. Underbidding is therefore not essential for spanning the set of equilibrium payouts.

\section{F Advertising revenue imputation}

Table S31 reports parameter estimates for imputing missing advertising revenue, as described in Appendix A.4. 


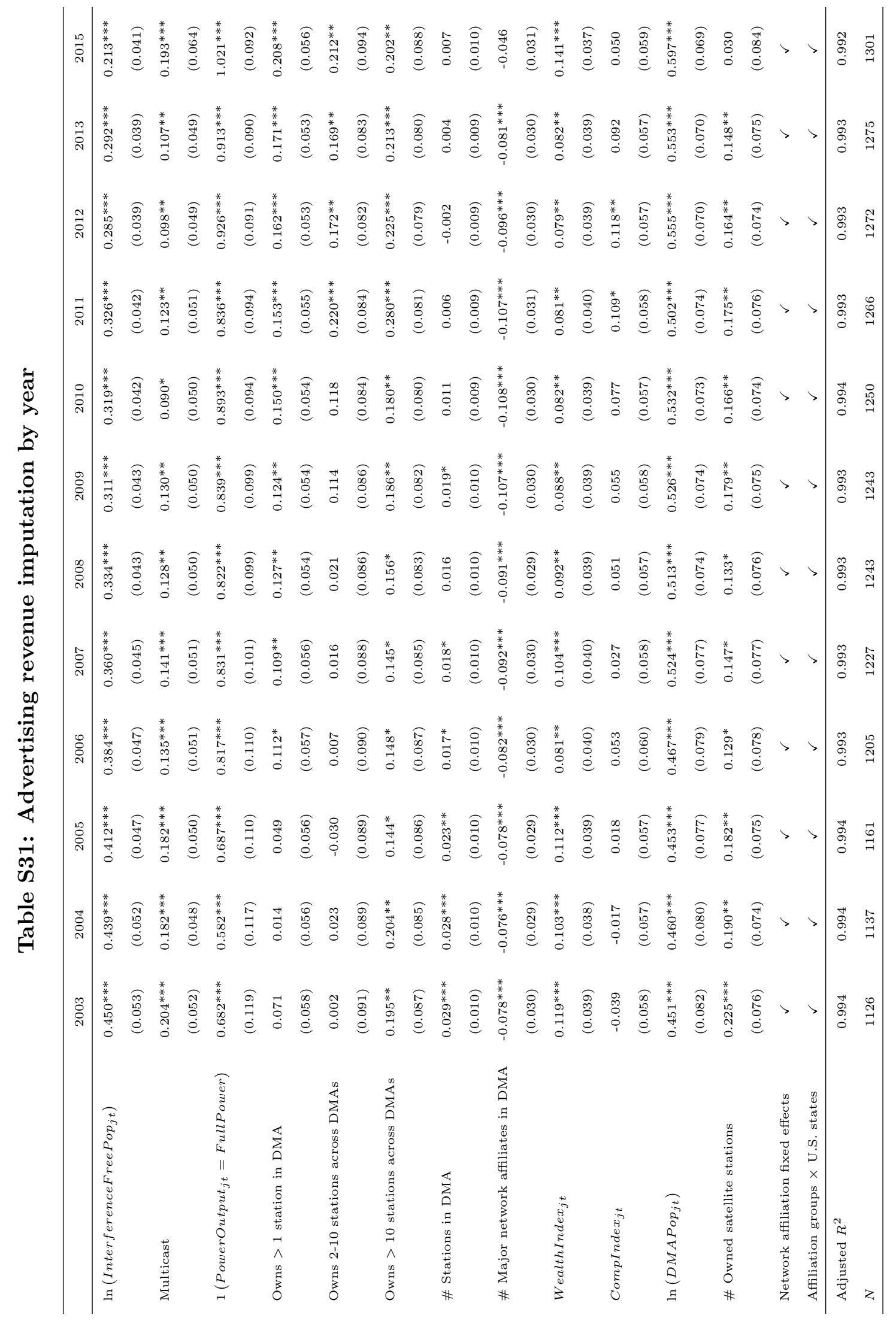

